\title{
DOE/OR/22041--T2
}

\section{LOW TEMPERATURE FABRICATION FROM NANO-SIZE CERAMIC POWDERS}

\author{
E. J. Gonzalez \\ G. J. Piermarini \\ B. Hockey \\ S. G. Malghan
}

\section{Ceramics Division \\ National Institute of Standards and Technology Gaithersburg, MD 20899}

\section{DISCLAIMER}

\begin{abstract}
This report was prepared as an account of work sponsored by an agency of the United States Government. Neither the United States Government nor any agency thereof, nor any of their employees, makes any warranty, express or implied, or assumes any legal liability or responsibility for the accuracy, completeness, or usefulness of any information, apparatus, product, or process disclosed, or represents that its use would not infringe privately owned rights. Reference herein to any specific commercial product, process, or service by trade name, trademark, manufacturer, or otherwise does not necessarily constitute or imply its endorsement, recommendation, or favoring by the United States Government or any agency thereof. The views and opinions of authors expressed herein do not necessarily state or reflect those of the United States Government or any agency thereof.
\end{abstract}




\section{DISCLAIMER}

Portions of this document may be illegible in electronic image products. Images are produced from the best available original document. 


\section{Collaborators}

S. Danforth, Rutgers University

A. Pechenik, AFOSR

Acknowledgements: Some of the experimental work was conducted by Wei Chen, a guest researcher at the Ceramics Division. Microstructure characterization using small angle neutron scattering was conducted by Dr. Andrew Allen of Ceramics Division.

Disclaimer: Certain trade names and products are mentioned in the text in order to adequately specify the experimental procedure and equipment used. In no case does such identification imply recommendation or endorsement by NIST nor does it imply that the product necessarily is the best available for the purpose. 


\section{TABLE OF CONTENTS}

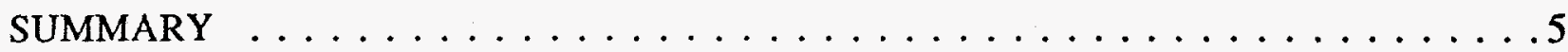

INTRODUCTION $\ldots \ldots \ldots \ldots \ldots \ldots \ldots \ldots \ldots \ldots \ldots \ldots \ldots \ldots \ldots \ldots \ldots \ldots$

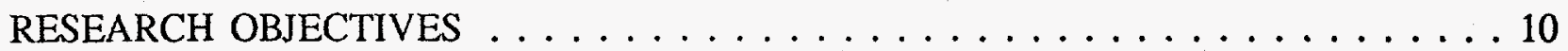

RESULTS AND ACCOMPLISHMENTS $\ldots \ldots \ldots \ldots \ldots \ldots \ldots \ldots \ldots \ldots$

Chapter I

EQUIPMENT FABRICATION AND $\mathrm{Si}_{3} \mathrm{~N}_{4}$ POWDER PROCESSING . . . . . . . . 12

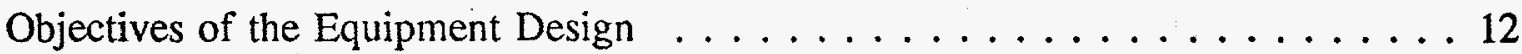

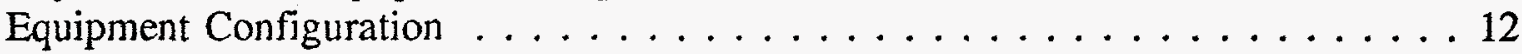

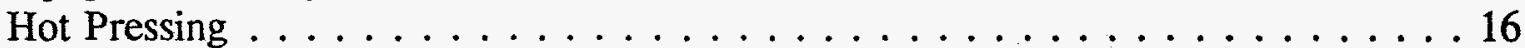

Computer Control and Software Development $\ldots \ldots \ldots \ldots \ldots$

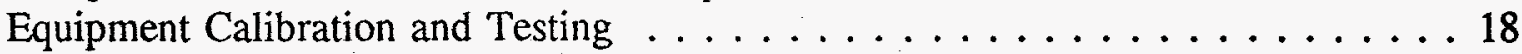

Errors Due to Elastic Deformation . . . . . . . . . . . . . . . 20

Estimate of Error in Pressure and Volume Measurements . . . . . . . . . . 20

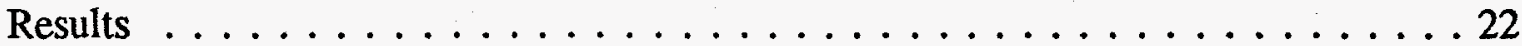

Silicon Nitride Powder Compaction . . . . . . . . . . . . . . 22

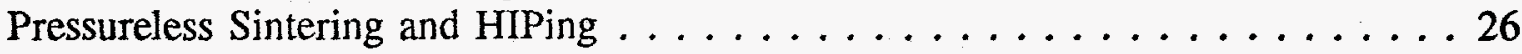

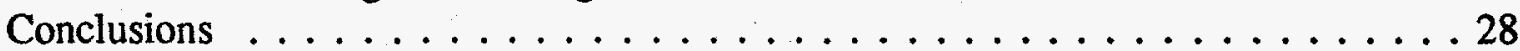

Chapter II

COMPACTION EQUATIONS FOR POWDERS . . . . . . . . . . . . 29

Purpose of Compaction Equations . . . . . . . . . . . . . . . . . . . . . . . . . . . . . . . .

Powder Compaction Equations . . . . . . . . . . . . . . 30

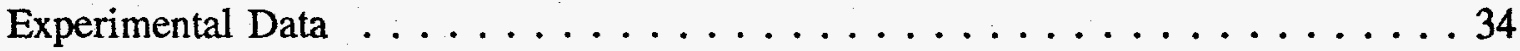

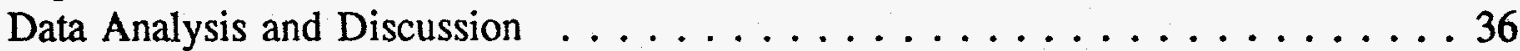

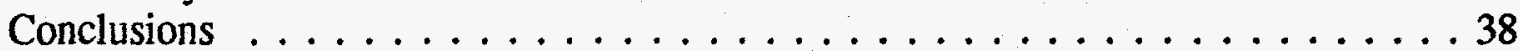

Chapter III

COMPACTION OF $20 \mathrm{~nm} \gamma-\mathrm{Al}_{2} \mathrm{O}_{3}$ POWDER $\ldots \ldots \ldots \ldots \ldots \ldots$

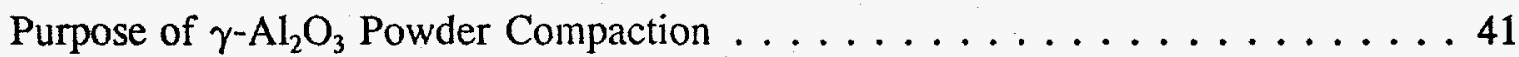

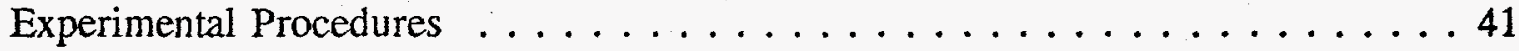

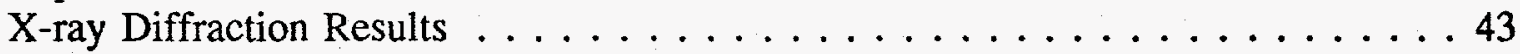

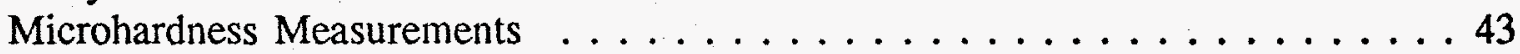

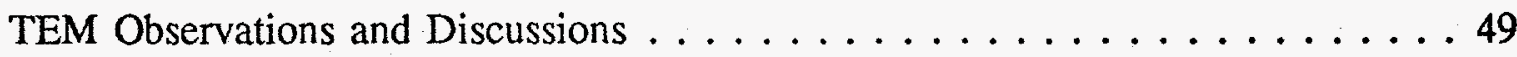

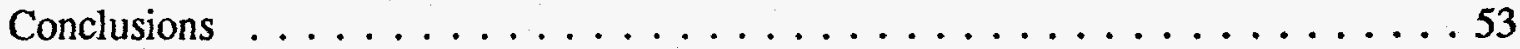




\section{Chapter IV}

$\gamma-\mathrm{Al}_{2} \mathrm{O}_{3}$ PROCESSING IN THE PISTON-CYLINDER DEVICE $\ldots \ldots \ldots \ldots$

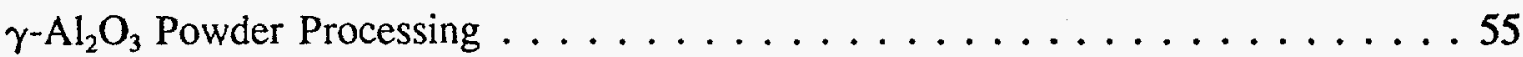

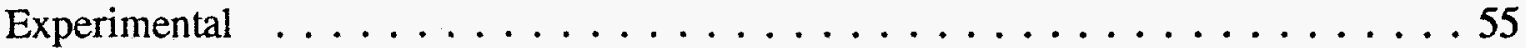

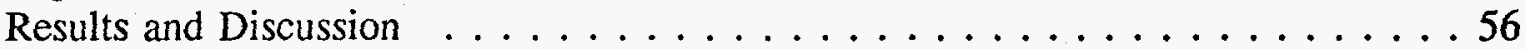

Microstructure . . . . . . . . . . . . . . . . . .62

SANS Characterization of Nanostructured Alumina $\ldots \ldots \ldots \ldots \ldots \ldots$

Conclusions ........................ 72

Chapter V

FUTURE DIRECTIONS $\ldots \ldots \ldots \ldots \ldots \ldots \ldots \ldots \ldots \ldots \ldots \ldots \ldots \ldots \ldots \ldots$

A. Novel Approaches to Silicon Nitride Processing $\ldots \ldots \ldots \ldots \ldots \ldots$

B. Densification of High Density Green Compacts $\ldots \ldots \ldots \ldots \ldots$

C. Collaboration with Nano-Size Powder Producers $\ldots \ldots \ldots \ldots \ldots \ldots$

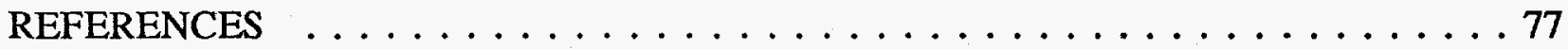




\section{SUMMARY}

The objective of the compaction process is to produce a dense green-state compact from a nanosize powder that subsequently can be sintered at high temperatures to form a dense ceramic piece. High density in the green-state after pressing is of primary importance for achieving high densities after sintering. Large voids, cracks, and other defects in the greenstate are not easily eliminated during sintering and their presence in the sintered body reduces the strength of the ceramic. An understanding of the compaction behavior and rheology of ceramic powders is desirable for the production of defect-free greenware in which particles are packed in the densest possible arrangement. Investigation of the compaction behavior of ceramic powders, therefore, is an important part of characterization of raw ceramic powders and evaluation of their compaction behavior, analysis of interaction between particles, and the study of microstructure of green body (unsintered) during pressure-forming processes.

The compaction of nanosize ceramic particles into high density green bodies is very difficult. For the nanosize materials used in this study (amorphous $\mathrm{Si}_{3} \mathrm{~N}_{4}$ and $\gamma \mathrm{Al}_{2} \mathrm{O}_{3}$ ), there is no evidence by TEM of partial sintering after synthesis. Nevertheless, strong aggregation forces, such as the van der Waals surface forces of attraction, exist and result in moderate precursor particle agglomeration. More importantly, these attractive surface forces, which increase in magnitude with decreasing particle size, inhibit interparticle sliding necessary for particle rearrangement to denser bodies during subsequent compaction. Attempts to produce high density green body compacts of nanosize particles, therefore, generally have been focused on overcoming these surface forces of attraction by using either dispersive fluids or high pressures with or without lubricating liquids. A proper lubricant can improve packing efficiency, but in selecting such lubricants one is severely limited by strongly reacting interfaces between the particles and the small size of openings (nanoscale dimensions) in the structure formed by densely-packed nanosize particles.

In the present work, the use of high pressure has been employed as a means of compacting nanosize powders to relatively high green densities. In addition to high pressures, lubricating mediums such as liquid nitrogen and pentane also have been used to achieve incremental increases in the green body density. Preliminary experiments done using a diamond anvil cell to attain the high pressures showed that high green densities could be achieved with nanosize silicon nitride and gamma alumina. However, the small samples $(0.2 \mathrm{~mm}$ in diameter) produced by this technique limited the full characterization and measurement of their physical properties. To solve the size problem, a pressure/temperature system was designed and built. This system utilizes an Instron screw-driven press in conjunction with a piston/cylinder $(\mathrm{WC} / \mathrm{Co})$ die permitting the fabrication of powder compacts $(3 \mathrm{~mm}$ in diameter and 1-to-2 $\mathrm{mm}$ in thickness) to pressures up to $3 \mathrm{GPa}$ and temperatures between $196{ }^{\circ} \mathrm{C}$ and $1000{ }^{\circ} \mathrm{C}$. The piston/cylinder die can be placed in a confining chamber so that powders can be compacted in various environments including vacuum, liquids and gases. 
Computer controlled measurement procedures were incorporated into the system for pressure calibration, piston displacement (sample volume and density), temperature calibration, and the rate of change of sample density and volume as a function of time and applied load. Also a stainless steel chamber for environmental control of the powder prior to compaction has been built for the piston/cylinder die. This chamber permits the powder to be under vacuum or other atmospheres including gases and liquids immediately before compaction. A bifilar resistance heating coil permits the powder to be heated before, during and after compaction to temperatures as high as $1000{ }^{\circ} \mathrm{C}$. The effects of high pressure on the compaction of nanosize powders was demonstrated on silicon nitride and $\gamma$ alumina using this new system.

A maximum random packing density of $57 \pm 2 \%$ of theoretical was achieved for dry compaction of amorphous nanosize $\mathrm{Si}_{3} \mathrm{~N}_{4}$ powder at a pressure of $2.5 \mathrm{GPa}$ and room temperature. Compaction under liquid nitrogen gave green bodies with an improved packing density of $64 \pm 2 \%$. In both cases the compacts were transparent under visible light, which is an indication of nanoscale, uniform porosity. The higher packing density achieved by compaction under liquid nitrogen indicates that the cryogenic technique is an effective means of obtaining high packing density and small-scale porosity. The green densities for $\gamma$ alumina compacted under dry conditions was $64 \%$ of theoretical density at $2.5 \mathrm{GPa}$.

To achieve additional densification, the high density green compacts of $\mathrm{Si}_{3} \mathrm{~N}_{4}$ were subjected to pressureless sintering at different temperatures from $1200-1600{ }^{\circ} \mathrm{C}$ under flowing nitrogen gas. The samples were not further densified by this heat treatment. The maximum Vickers hardness of about $6 \pm 1 \mathrm{GPa}$ was obtained at a compaction pressure of $2.8 \mathrm{GPa}$ and $1400^{\circ} \mathrm{C}$ sintering temperature. Microstructural characterization revealed that extensive oxidation occurred during sintering probably because a proper inert atmosphere in the furnace was not maintained.

In hot pressing experiments conducted to increase the densification of high density green compacts, we were able to observe a clear indication of increased hardness. In these experiments, the green compacts were produced at $2.8 \mathrm{GPa}$ followed by hot pressing in a specially designed device and pressureless sintering at $1400^{\circ} \mathrm{C}$. A range of experimental conditions was examined in this study. The highest Vickers hardness of $11.0 \mathrm{GPa}$ was obtained from the final sample that was hot pressed at $1.0 \mathrm{GPa}$ and $1000^{\circ} \mathrm{C}$, followed by sintering at $1400{ }^{\circ} \mathrm{C}$. Note that the nominal hardness value of sintered samples without hot pressing was only $6.0 \mathrm{GPa}$. These results have considerable significance since the resulting ceramic was translucent to visible light indicating nanophase microstructure, though the final hardness was far short of the commercial silicon nitride (approximately $20 \mathrm{MPa}$ ).

Sintering studies were also done on $\gamma$ alumina that were pressed to $1.0 \mathrm{GPa}$ and $2.5 \mathrm{GPa}$. Sintering was done for $5 \mathrm{~h}$ periods at fixed temperatures ranging from $900{ }^{\circ} \mathrm{C}$ to $1300{ }^{\circ} \mathrm{C}$. For this material the explanation of the results is complicated by the large microstructural changes that occur during the $\gamma$-to- $\alpha$ phase transformation, which takes place at about 1000 ${ }^{\circ} \mathrm{C}$ to $1100{ }^{\circ} \mathrm{C}$ depending on the initial compaction pressure. From this work two conclusion 
could be drawn: (1) increased compaction pressure enhances the $\gamma$-to- $\alpha$ transition, reducing the transition temperature or, alternatively, increasing the nucleation rate at temperatures from $1000{ }^{\circ} \mathrm{C}$ to $1150^{\circ} \mathrm{C}$; (2) increased compaction pressure leads to increased densification upon heat treatment at still higher temperatures. Our present results show a significant difference in the microstructure, density and hardness of $1.0 \mathrm{GPa}$ and $2.5 \mathrm{GPa}$ compacts sintered at $1300{ }^{\circ} \mathrm{C}$.

In general, it is difficult to obtain full-density material without a coarsening of the pore/grain microstructure. This is because high sintering temperatures are required to eliminate all but enclosed porosity, but at the same time high temperatures cause extensive grain growth. For $\alpha$ alumina derived from transition aluminas, the $\gamma$-to- $\alpha$ phase transition involves nucleation followed by rapid grain growth and also consolidation of porosity. Two different techniques have been reported in the literature by others to produce high density small grain size alumina sintered at relatively low temperatures $\left(1150^{\circ} \mathrm{C}\right)$. One method controls the deleterious coarsening effects associated with the $\gamma-\alpha$ transition by incorporating small sized $(100 \mathrm{~nm}) \alpha$ alumina seeds in sol-gel derived boehmite. With this method high density $(>99.5 \%)$ relatively small grain size $(0.25 \mu \mathrm{m})$ alumina was produced by pressureless sintering at $1150{ }^{\circ} \mathrm{C}$. Another method used slurries of fine grain $\alpha \mathrm{Al}_{2} \mathrm{O}_{3}$ made by conventional suspension techniques to slip-cast samples to relatively high densities (69\%) prior to sintering at $1150^{\circ} \mathrm{C}$. In this case, no phase transformation occurred, yet dense samples with submicrometer grain size were obtained. It appears that the phase transition is not necessary for this result. Homogeneous suspensions (mixtures) with submicron size powders, however, are very difficult to achieve particularly when nanosize particles $(\approx 20$ $\mathrm{nm}$ ) are used. High pressure compaction of nanosize powder, therefore, was utilized in the present work as a means to achieve high density green compacts. In our approach, because the nanosize starting powders contained no additives or seed material, the problem of homogeneity is not an issue. The product was as pure as the starting powder.

In the present compaction studies, a better understanding is required both of how the microstructures develop during sintering under different conditions, and of how the powder and green-body synthesis might affect the sintering thermodynamics. We used small-angle neutron scattering (SANS) to compare the sintering characteristics of a different nanostructured alumina $\left(\mathrm{n}-\mathrm{Al}_{2} \mathrm{O}_{3}\right)$, produced by the sol-gel method, with a previously extensively characterized sintering of nanostructured zirconia $\left(n-\mathrm{ZrO}_{2}\right)$ and yttria $\left(n-\mathrm{Y}_{2} \mathrm{O}_{3}\right)$, produced by a inert-gas-condensation (IGC) technique. The alumina results were similar to those found for the IGC-produced nanostructured materials, i.e., grain-coarsening during sintering associated with a small amount of grain-agglomeration. The microstructural evolution during the sintering of $\mathrm{n}-\mathrm{Al}_{2} \mathrm{O}_{3}$, made from the sol-gel process, proceeds in a similar way to that for $n-Y_{2} O_{3}$ or $n-Z_{2} O_{2}$, made from the IGC process. As with the IGCproduced materials, the phase transition, which takes place within the sintering temperature range studied, does not seem to affect the sintering behavior, apart from the density change

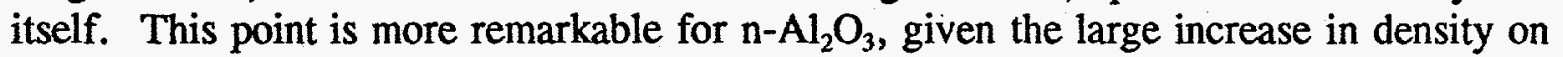
transformation. 
In addition to experimental work, theoretical studies were conducted to model the compaction process. Here, the process of powder compaction is taken to depend on a number of properties including the flow properties of powders under stress, stress distribution within compacts, the distribution of particle-to-particle stresses, hardness of particles, and strength distribution of particles. Two compaction equations (isothermal equations of state) for powders were developed, and experiments on the compaction of various ceramic powders were carried out to examine the usefulness of these equations. A nonlinear least-squares technique was utilized to evaluate these and other published compaction equations for press compaction of submicrometer and nanosize powders. A modified linear least-squares method was developed for fitting experimental data. The root mean square deviation per degree of freedom ( $r m s$ ) for fitting compaction data of both powders using the present equations were reduced by almost one order of magnitude by comparison with fitting to that of the wellknown Cooper and Eaton's equation. The experimental data fitting indicates that our equations yield better results than those from previous equations, and these equations can be applied to chemically different powders, powders with different size of particles, and powders compacted by either pressing or tapping.

Based on these results, our focus for the future studies will have four components: 1 . modification of surface and particle morphology of silicon nitride and alumina to enhance interparticle contact and obtain increased green density; 2 . improved understanding of green state compaction and sintering kinetics to achieve controlled porosity or full density; 3 . characterization of colloidal properties of nanosize powders to enable the preparation of slips that can be used for shape forming; 4. development of standardized powder evaluation procedures to promote collaboration between our project and powder synthesis activities at other laboratories. 


\section{INTRODUCTION}

Recently there has been significant interest in fabricating ceramics from ultrafine powders that consist of nanosize primary particles of $1 \mathrm{~nm}$ to $100 \mathrm{~nm}$ mean diameter. Theoretical predictions by Frenkel [1] and Herring [2] clearly indicate that the rate of densification varies inversely as a function of particle size. Thus, based on this prediction, as particle size decreases from microns to nanometers, a substantial decrease in sintering time can be expected at a given temperature. Indeed, many experimental investigations support this theoretical prediction. For example, Rhodes [3] produced densely-packed compacts of nanosize zirconia particles and observed sintering of the compacts to near theoretical density at much lower temperatures than are used for sintering coarse zirconia particles. Recently, Skandan et al. [4] sintered nanosize titania at $800^{\circ} \mathrm{C}$ which is well below the sintering temperature for conventional titania powders.

These results suggest that nanosize particles as starting materials might offer considerable advantages for fabricating ceramics. However, forming densely-packed compacts from nanosize particles is a very difficult task. Strong aggregation forces, such as the Van der Waals attraction, increase dramatically as particle size decreases. For nanosize particles, the Van der Waals attraction can essentially prevent the particles from sliding and cause agglomeration by diffusion during compaction [5]. As a result of aggregation and subsequent agglomeration of primary particles, compacts of nanosize particles usually have low density after cold pressing. The low density of nanosize particle compacts is due to two factors: (1) large voids and (2) inefficient packing of particles. A proper lubricant could improve packing properties of the nanosize particles, but in selecting such lubricants one is severely limited by strongly reacting interfaces between the particles and the small size of openings in the structure formed by densely-packed nanosize particles.

To demonstrate the concept, that simple molecular liquids can provide efficient lubrication for nanosize particles, Pechenik and Piermarini [6] compacted nanosize silicon nitride particles at liquid nitrogen temperature and actually used liquid nitrogen as a lubricant. The compaction was performed in a diamond anvil cell. This cryogenic compaction approach was successful in producing densely-packed compacts of nanosize particles that sintered close to full density at a much lower temperature than that required for the conventional processing of silicon nitride. As a follow up to this research, we decided to study the cryogenic compaction process in more detail by designing and constructing a special apparatus for fabricating larger samples than the ones made in the diamond cell, which were only $0.2 \mathrm{~mm}$ in diameter. The novel equipment is capable of producing $3 \mathrm{~mm}$ disk-shape samples under vacuum or in a variety of controlled conditions, such as temperatures in the range from $77 \mathrm{~K}$ to $1000 \mathrm{~K}$ and pressures up to $3 \mathrm{GPa}$. In addition, throughout the compaction procedure, continuous measurements of volume of the sample, applied force, and frictional force between the sample and the die walls are performed. This novel system is described in this review paper along with a number of experimental studies on nanosize silicon nitride and related powders. The high pressure cryogenic approach to processing nanosize powders is 
the basis for the present DOE research program at NIST. This report summarizes our results, accomplishments and conclusions obtained during the past three years on the fabrication of nanostructured silicon nitride and related materials from nanosize starting powders by this high pressure compaction process. Based on the conclusions found in this work, we also propose potentially fruitful areas to investigate in the future concerning nanosize particle processing.

\section{RESEARCH OBJECTIVES}

Four major goals were stated at the initiation of the program. They are: (1) to design and build high pressure/temperature equipment for compacting and processing nanosize powders under different environments and temperatures; (2) to include in the design, pressure, volume and temperature measurement capabilities; (3) to produce $p c$ software for the calculation and display of time dependent pressure/temperature parameters and powder rheology properties; and (4) to utilize the system in fabricating nanosize silicon nitride and related powders into compacts for subsequent evaluation of their mechanical properties.

Once we accomplished these goals, during the second year we recognized the need for changing the subsequent goals primarily because of our inability to achieve complete densification of nanosize $\mathrm{Si}_{3} \mathrm{~N}_{4}$ powder. Ten revised major goals are listed below:

1. Complete the design, fabrication, and assembly of the equipment for the cryogenic compaction and measurement of rheology of powders during compaction - Feb. '92

2. Complete fabrication of compacts under nitrogen and other lubricant media - April '93

3. Complete the characterization of pore size distributions with the use of transmission electron microscopy (TEM), phase transformation by $x$-ray diffraction (XRD), and density measurements - July '93

4. Complete the design of a hot pressing device, and hot isostatic pressing (HIP) of compacts - Oct. ' 93

5. Hot pressing and sintering of silicon nitride compacts using belt apparatus - April. '94

6. Experimentation with oxide powders to develop understanding of limitations to densification of nano-scale powders- July ' 94

7. Optimization of powder compaction pressure, rate of compaction, and lubricant conditions to achieve high green density - Oct. '94 
8. Optimization of sintering conditions and pore distribution characterization - Dec. '94

9. Study grain growth as a result of sintering at $1400^{\circ}-1600{ }^{\circ} \mathrm{C}$ and associated changes in mechanical and optical properties. - February ' 95

10. Optimization of processing to achieve the highest optical transparency combined with high hardness and fracture toughness. Mathematical modelling of powder rheology, development of general theory for compacting nano-size particles at cryogenic temperature and room temperature - Dec. '95

\section{RESULTS AND ACCOMPLISHMENTS}

Three of the four initial major goals have been accomplished with a high degree of success. A pressure/temperature system has been designed and built which utilizes an Instron screwdriven press in conjunction with a piston/cylinder $(\mathrm{WC} / \mathrm{Co})$ die permitting the fabrication of powder compacts ( $3 \mathrm{~mm}$ in dia and 1-to- $2 \mathrm{~mm}$ in thickness) at pressures up to $3 \mathrm{GPa}$ and temperatures between $-196^{\circ}$ and $1000^{\circ} \mathrm{C}$. The piston/cylinder die can be placed in a confining chamber so that powders can be compacted in various environments including vacuum, liquids and gases.

Computer controlled measurement procedures have been incorporated into the system for pressure measurement, piston displacement (sample volume and density), temperature calibration, and the rate of change of sample density and volume as a function of time and applied load.

A stainless steel chamber for environmental control of the powder prior to compaction has been built for the piston/cylinder die. This chamber permits the powder to be under vacuum or other environments including gases and liquids immediately before compaction. A bifilar resistance heating coil permits the powder to be heated before, during and after compaction to temperatures as high as $1000^{\circ} \mathrm{C}$.

Although the first three goals have been achieved quite successfully, the remaining goal, the purpose for which the final thrust of the program was intended, i.e., the fabrication of nanostructured silicon nitride compacts by the newly developed technology, has met with limited success. The compacts fabricated by this method have not achieved many of the anticipated superior mechanical properties expected for nanostructured ceramics. While transparency is achieved, the expected high hardness and fracture toughness, and perhaps even full densification have not. This may be because we have not found yet the optimum conditions for processing nanosize powders. The problems associated with this will be discussed later in this report. These are some reasons for revising the goals and milestones of this project. 


\section{Chapter I}

\section{EQUIPMENT AND FABRICATION AND $\mathrm{Si}_{3} \mathrm{~N}_{4}$ POWDER PROCESSING}

\section{Objectives of the Equipment Design}

The equipment was designed to perform at least four functions. First, to produce $3 \mathrm{~mm}$ diameter disk-shaped samples on which accurate measurements of density, hardness, fracture toughness, optical properties, and pore-size distribution can be carried out. Second, to provide a detailed data for the measurement of compaction rheology of powders in the form of volume (or density) of compacting sample as a function of the applied pressure, the rate of pressure application, processing temperature, and atmosphere. To provide complete information about the process, all the above mentioned parameters must be measured continuously and simultaneously. A number of different gasses can be introduced into the environmental chamber under a selected pressure for protection and lubrication of the surface of nanosize particles. From the theoretical studies, we know, that the thickness of the adsorbed coating on particle surfaces and properties of the coating should depend strongly on two parameters: temperature and gaseous pressure inside of the environmental chamber. To study this dependence in detail, the volume and density of a sample at different pressures and temperatures must be measured for different lubricant gases. Due to a large amount of data being accumulated during an experimental run, a real-time computer control of all measurements and experimental procedures is necessary to accomplish this task. Third, to detect and accurately measure phase transitions accompanied by a volume change. The equipment was designed to provide accurate and precise data for development of PV curves. Fourth, to perform hot-pressing of green compacts at temperatures up to $1000 \mathrm{~K}$. The goal was to understand microstructural charges during hot-pressing and sintering. Hot-pressing helps to produce nanograin structures because full density can be achieved at much lower temperatures than by pressureless sintering.

\section{Equipment Configuration}

A $10,000 \mathrm{~kg}$ capacity screw-driven Instron press with two large parallel platens is used to apply load to the die. The servo-controlled drive system permits the selection of platen displacement rates from 0.85 to $850 \mu \mathrm{m} / \mathrm{s}$, a feature which is useful for the study of stress relaxation in a powder during compaction. A $3000 \mathrm{~kg}$ load is required to generate a pressure of $3 \mathrm{GPa}$ on a $3 \mathrm{~mm}$ diameter sample.

The equipment is designed to be used under two different modes of operation for the powder compaction experiments: (1) gas lubrication, and (2) liquid lubrication. In the first mode, a small amount of lubricating cover gas is introduced into the environmental chamber under controlled pressure. The introduced gas condenses on the surface of the particles and the powder is compacted under dry or semidry conditions. The basic design for this first experimental setup is shown in Figure 1. The environmental chamber (14) is designed for 


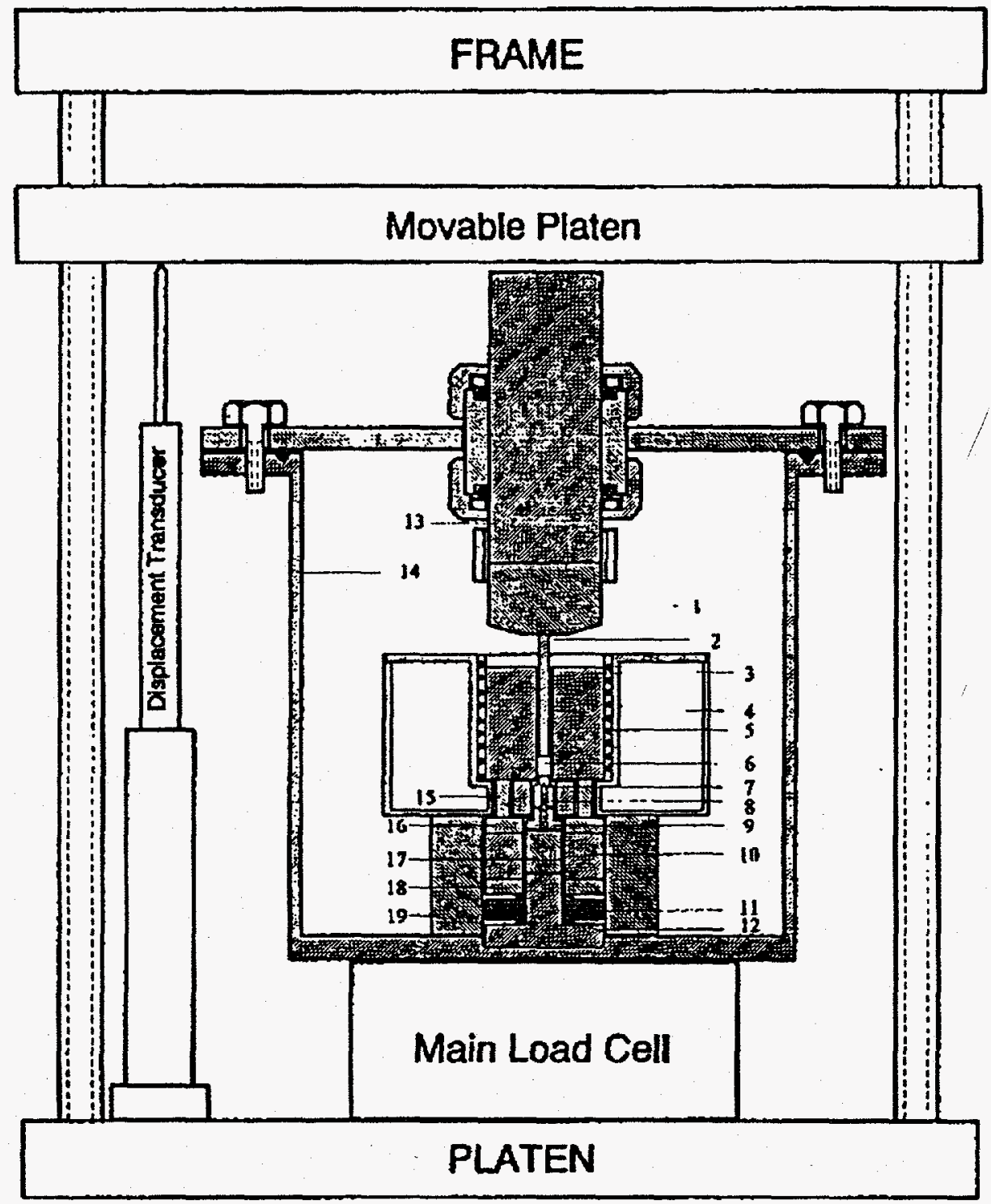

Figure 1. Configuration of "gas lubrication"-type powder compaction assembly. (1) Bridgman anvil, (2) moving punch, (3) die, (4) cooling cylinder, (5) heater, (6) powder, (7) thermocouple, (8) fixed punch, (9) hardening disk, (10) heat insulating ring disk, (11) frictional load cel1, (12) positioning and heat conducting disk, (13) pressure transmission piston, (14) vacuum chamber, (15) frictional load transmission pistons, (16) hardening ring disk, (17) heat insulating disk, (18) hardening ring disk, and (19) plastic positioner. 
isolating the sample in order to control compaction conditions while the movable piston (13), equipped with two O-ring seals, applies force to the compacting piston (2). Lubricant gas can be introduced from a gas tank into the vacuum chamber (14) and the gas pressure is controlled by a vacuum needle valve (not shown). A thermocouple gauge located outside of the chamber on the supply line measures the gas pressure in the chamber. A single-acting (bottom punch fixed) piston-cylinder type device (3) is used for the application of variable pressures up to $3 \mathrm{GPa}$. The piston (2) and the die (3) are made of tungsten carbide and ground to about a $0.1 \mu \mathrm{m}$ finish on the contact surfaces. The bottom end of the cylindrical hole of the die has a small conical shape for easy removal of compacted samples. The temperatures can be varied from that of liquid nitrogen, $77 \mathrm{~K}$, to room temperature. A cooling cylinder (4) and a heater (5) are designed with a coil/wound on a frame surrounding the die. A cooling loop of liquid nitrogen can pass through a heat insulating flange into the environmental chamber.

For cryogenic compaction, the applied load is adjusted continually at low temperatures to maintain the desired pressure. One difficulty is to measure the pressure in nonhydrostatic and low temperature environments. The frictional force on the wall of the die, the punch, and the sample must be taken into account for pressure calibration. As depicted in Figure 1, two load cells are used for pressure measurement. One, the main load cell, measures the primary force applied by the press and is located on the bottom platen of the press. The other load cell (11) measures the frictional load between the punch and die. As far as we know, there are no commercially available load cells designed for use at extreme temperatures. Therefore, we had to incorporate into our design for low temperature compaction, a special thermal insulating mechanical structure to maintain the frictional load cell at room temperature. We used frictional force transmission pistons (15) and heatinsulating (Macor) ring disks (10) to solve this problem. The pistons (15) transmit frictional force from the die to the load cell that operates at room temperature. For low temperature compaction, two ceramic disks $(10,17)$ prevent heat transfer from the room temperature region to the cold region. The average pressure at the bottom of the sample is calculated from the total and frictional load data.

A K-type thermocouple (7) is placed at the center of the fixed punch as near the sample as possible to provide measurement and control of temperature. A displacement transducer is positioned between the two platens of the press, as shown in Figure 1, to measure the thickness of the sample versus the force on the sample for the rheological investigations.

An alternative design of the experimental setup to study the effects of lubricants on compaction of powders is shown in Figure 2. In this design a cryogenic container (3) holds the die (2) and powder sample (4), and a metal (Inconel 600) foil (6) prevents leakage of liquid nitrogen or other lubricating liquids. The load on the sample (total load minus friction) on the fixed punch (5) is transmitted via the metal foil (6), the hardened steel load transmission disk (8), the heat insulating disk (9), and the positioning and heat conducting disks (13) to the main load cell as shown in Figure 2. The frictional load on the die (2) is transmitted to the frictional load cell via frictional transmission pistons (14), the metal foil 


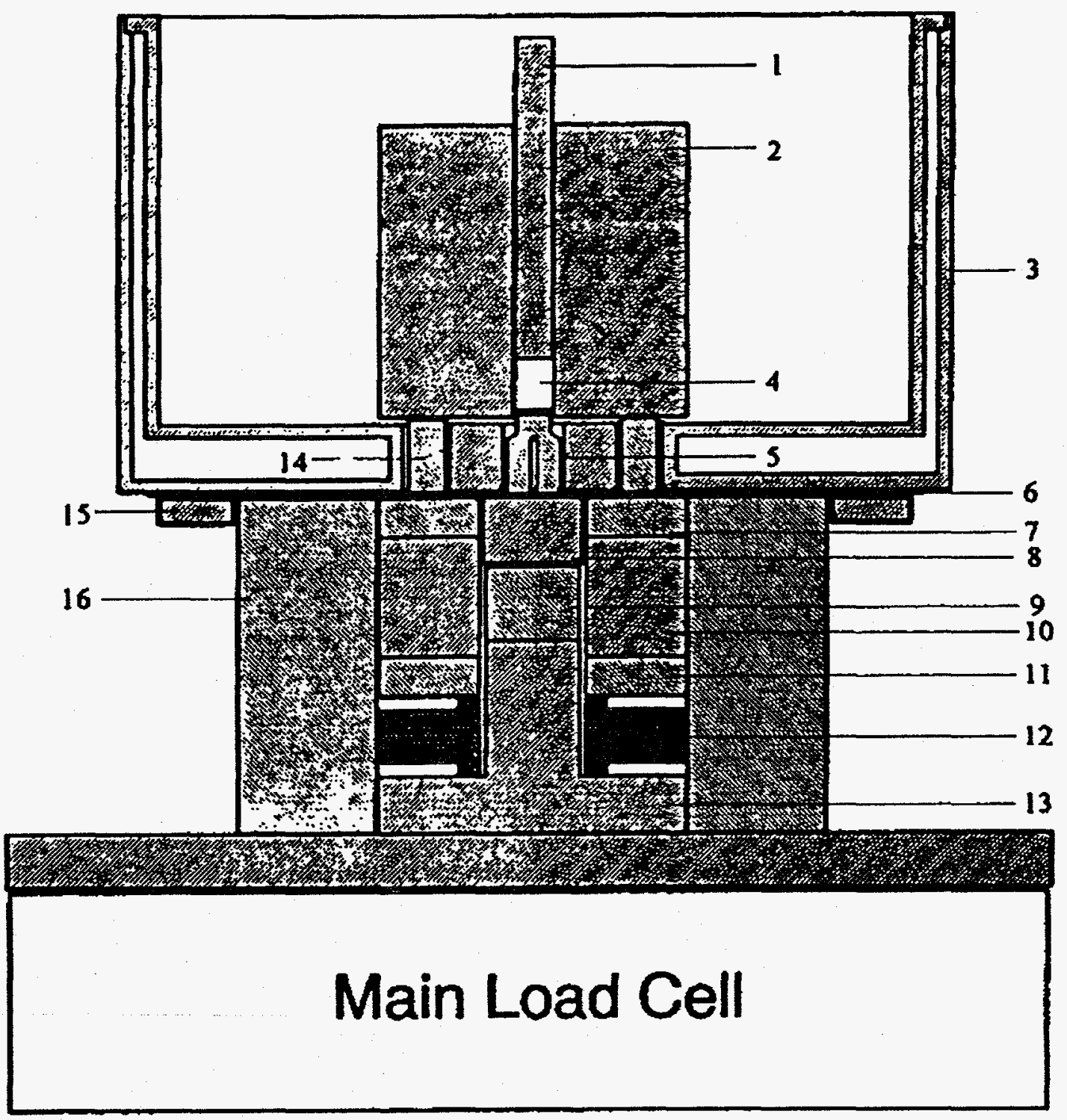

Figure 2. Configuration of "liquid lubrication"-type powder compaction assembly. (1) moving piston, (2) die, (3) cryogenic container, (4) powder, (5) fixed punch, (6) metal foil, (7) hardening ring disk, (8) hardening disk, (9) heat insulating disk, (10) heat insulating ring disk, (11) hardening ring disk, (12) frictional load ce11, (13) positioning and heat conducting disk, (14) frictional load transmission pistons, (15) flange, (16) plastic positioner. 
(6), the hardened steel ring disk (7), the heat-insulating ring disk (10), and the hardened steel ring disk.

\section{Hot Pressing}

Hot-pressing can be performed in a WC/Co die for temperatures up to $1000 \mathrm{~K}$ in two steps. In the first step, a green compact is formed by pressing the powder under controlled conditions. In the second step, the green compact is hot pressed by placing the assembly containing the green compact, die, and punches in a furnace with a capability to apply load. The die and punch for hot-pressing experiments must be surrounded by nitrogen gas environment to prevent oxidation when temperature is higher than $500^{\circ} \mathrm{C}$.

To accomplish this, it was necessary to design a special apparatus to generate high temperature and high pressure. This apparatus shown in Figure 3, called "belt apparatus," was designed and fabricated to carry out hot pressing of $\mathrm{Si}_{3} \mathrm{~N}_{4}$ green compacts. The belt apparatus may be described as a cross between a piston and cylinder and Bridgman anvils. It combines massive support for the pistons with a central die for the sample. The pressure generation is through the compression of a gasket material in the apparatus. The belt apparatus has evolved from Bridgman anvils by first incorporating a well in one of the anvils and compressing a pyrophyllite assembly. However, the pressure limit is quickly reached when the pyrophyllite expands to its limiting volume and halts further compression inside the well. A major advance in the design was made with the realization that the conical profile has the compression of the cone for a given vertical compression stroke. Thus considerable compression of the sample may be obtained before the limiting volume of the gasket is reached. The final step was to double-end the apparatus about a horizontal axis producing a device consisting of two anvils or pistons compressing a sample restricted in a central die.

The piston and die are constructed from tungsten carbide. The piston has a high pressure bearing face approximately $6.4 \mathrm{~mm}$ diameter. The contact diameter between the piston surface and the load-bearing surface is approximately $25 \mathrm{~mm}$. The initial conical portion with a half-angle of $30^{\circ}$ to the vertical extends for about $5 \mathrm{~mm}$ and then there is a smooth curve to the upper surface. The die has an internal profile such that the tapered piston can move freely into it.

The gaskets are usually constructed separately for the upper and lower halves of the apparatus. They consist of two conical pyrophyllite gaskets sandwiching a hollow steel cone. The presence of steel which should be annealed is important since it prevents the thick pyrophyllite gaskets from breaking at low pressures and helps to lower the compressibility of the combination. A cylindrical region approximately $5 \mathrm{~mm}$ diameter and $8 \mathrm{~mm}$ high is left for the high pressure cell assembly which usually consists of samples and heaters inside a pyrophyllite cylinder.

The sample is placed at the center of the internal tube furnace (made by graphite), and surrounded with boron nitride packing powder which can provide a homogeneous 


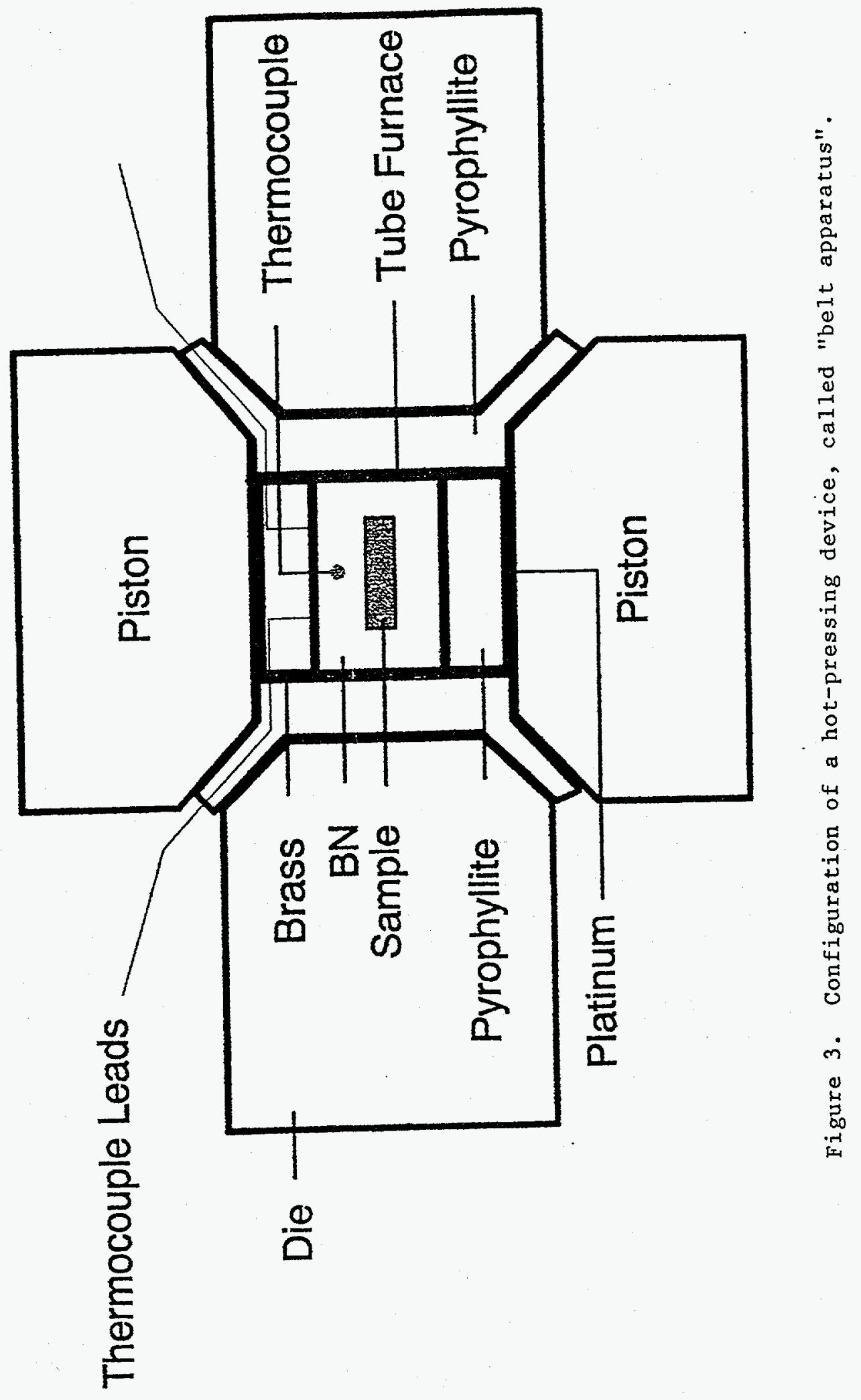


temperature distribution and isostatic pressure around the sample. To be able to generate high temperature within the tube furnace, the die must be protected by a cooling system. A power supply with $7.5 \mathrm{~V}$ and $200 \mathrm{~A}$ is necessary to provide the power needed in this experiment. This high temperature and high pressure device was designed to generate pressures up to $1 \mathrm{GPa}$ and temperatures up to $1000^{\circ} \mathrm{C}$ for studying the sintering behavior of nanostructured green compacts under pressure.

\section{Computer Control and Software Development}

Real-time computer control has been implemented to measure and/or control (1) the temperature of the chamber, (2) the total applied and frictional forces, and (3) piston displacement. The applied pressure and rate of pressure application are calculated from measured forces. The configuration of the computer control setup is shown in Figure 4 . The computer controls temperature from remote points with a temperature control unit by means of a digital-to-analog converter card. A digital multimeter combined with a scanner performs the voltage measurements on the load cells, the displacement transducer and the thermocouples. An IEEE-488 interface is used for communicating between the computer and digital multimeter. The computer controls the sequence of scanning measurements, presets the temperature in the environmental chamber, and conducts auto-determination of steady state temperature.

The control program uses a built-in clock as time counter for the measurement of pressure as a function of time, i.e., the rate of pressure application. The code of the program for control and monitoring the powder processing operation was written in a GFA-BASIC language for MS-Windows on a 486 IBM-compatible personal computer. Eight windows are opened to plot and display experimental data. The following data are displayed graphically in six windows: (1) sample volume vs applied pressure, (2) calculated density vs pressure, (3) calculated density vs time, (4) pressure vs. time, (5) temperature vs. time, (6) load fraction (real load on sample/total load) vs the applied pressure. A numerical data output and picture simulation of the piston position in the die and change of temperature are displayed in windows (7) and (8). During an experimental run, the program estimates the range for each measurement according to the initial scanning measurements and some preset values, and replots all diagrams using an auto-scale subroutine to give an appropriate range and boundary for each quantity. The replotting is performed at a preset time interval.

\section{Equipment Calibration and Testing}

Both load cells were calibrated using a ring-force gauge with a specified uncertainty of $0.5 \%$ at room temperature. Linear expressions of applied voltage as a function of voltage generated by the calibration were fitted using a least-squares routine. During a run the program calculates the load applied to a sample according to the voltage in the load cell by using the calibration functions. The measured frictional force arises from three contributions; (1) friction between the walls of the moving punch and the die, (2) friction between compacting powder and the sample cavity and (3) friction between the fixed bottom 


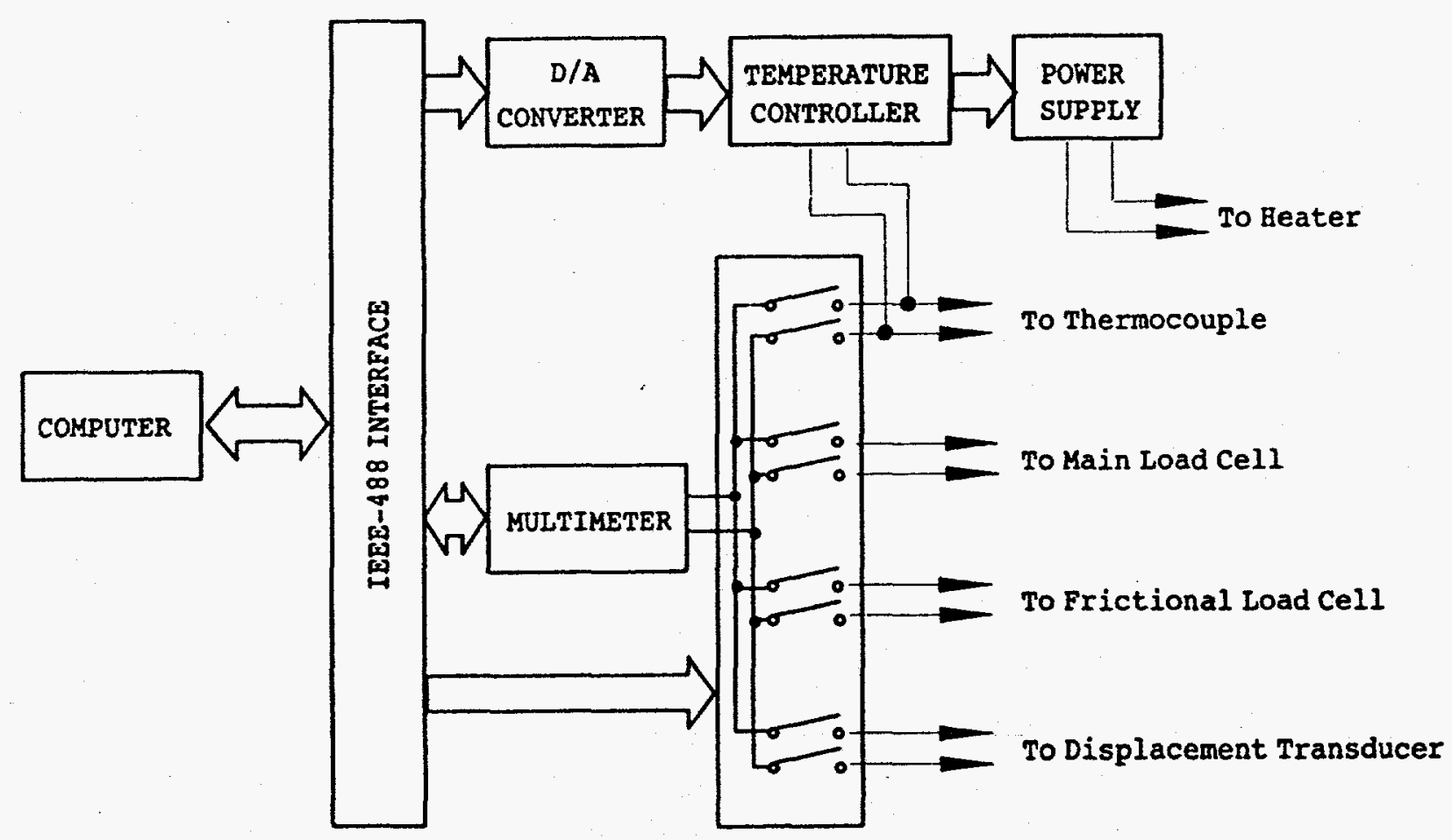

Figure 4. Block diagram of computer control system. 
punch and the die. Because the inserted length of the fixed bottom punch is much shorter than that of the moving punch, its contribution to the total friction force is very small and is considered to be negligible. Therefore, the difference between total load and the frictional force divided by the area of the sample is approximately equal to the average pressure at the bottom of the sample. Since the frictional force between the piston, punch and die is less than the frictional force between powder and die, the error in load measurement on the sample is less than $2 \%$, provided that the load cells and the calibration have a $1 \%$ uncertainty and the inserted length of the fixed punch is less than $4 \%$ of the total length of the die, which is always the case for this experimental design.

\section{Errors Due to Elastic Deformation}

Elastic deformation of the system (all punches, transmission pistons, and disks) vs applied pressure must be taken into account to measure the volume of the sample during compaction. Experimental data indicate that the deformation of the system without any powder in the die is not exactly linear, and there is a small amount of hysteresis in the relationship between the displacement and the applied force. The non-linearity and hysteresis appear in the low load region, and this dependence of deformation vs load is highly reproducible. There are several reasons for these deformation characteristics. The movable platen of the press has some slack in it, and several contact surfaces, for example, the piston and the Bridgman anvil, the high pressure support disks, etc..., adjust under pressure to achieve parallel alignment. This elastic deformation is taken into consideration by the computer program by utilizing a calibration function for both increasing and decreasing pressures. Readings of the displacement transducer are adjusted for equipment deformation, permitting an accurate calculation of sample volume. After calibration, the measurement uncertainty of the displacement of the moving punch is estimated to be $0.01 \mathrm{~mm}$, resulting in a volume uncertainty of $0.07 \mathrm{~mm}^{3}$.

A typical curve of the load fraction (real load/total load) vs pressure for dry compaction of nanosize $\gamma-\mathrm{Al}_{2} \mathrm{O}_{3}$ is shown in Figure 5. The load fraction depends on the type of powder, the magnitude of the gap between the punches and the die, the roughness of contact surfaces, the sample thickness and the lubrication conditions. The contribution of friction for a real load calculation is larger in the lower pressure region.

\section{Estimate of Error in Pressure and Volume Measurements}

To determine the accuracy of the PV curves measured by this apparatus, two well studied materials with known pressure-volume characteristics, rubidium bromide and potassium chloride, were selected. Both alkali halides $(\mathrm{RbBr}$ and $\mathrm{KCl}$ ) at room temperature exhibit face-centered-cubic (fcc) structures which undergo a polymorphic transition to a denser simple cubic (sc) form at elevated pressures. Both materials were in the form of powders with primary particle size in the range of 1 micrometer. X-ray powder diffraction analysis indicated that both materials were in the fcc phase in the form of granular crystalline powders and that the degree of hydration was minimal. Hydration is known to cause 


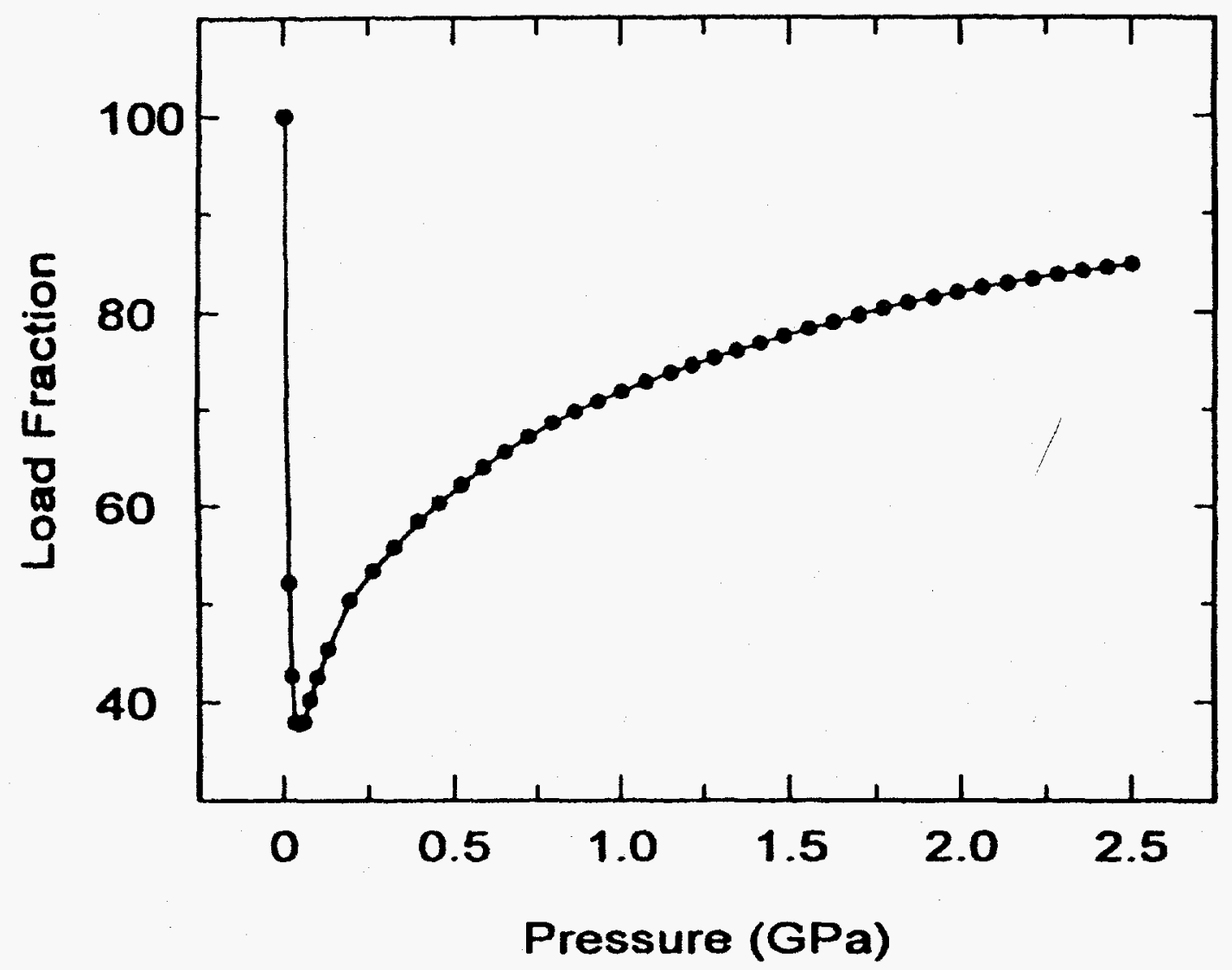

Figure 5. Fraction of real load (total load minus friction) and total load versus pressure for compaction of nanosize $\gamma-\mathrm{Al}_{2} \mathrm{O}_{3}$ powder. 
erroneous results in determining accurate transition pressures for these materials. The results of compaction of $\mathrm{RbBr}$ and $\mathrm{KCl}$ at room temperature are presented as pressure vs. volume curves in Figures 6 and 7, respectively.

The transition pressures and volume changes for these transitions obtained in the present work are listed in Table I with those published earlier [7-9]. The experimental results of this work show good agreement with the published results. The hysteresis behavior of volume versus pressure observed for the phase transitions in $\mathrm{RbBr}$ and $\mathrm{KCl}$ depicted in Figures 6 and 7 is real and is a function of pressure distribution along the walls of the pressure vessel and throughout the compacting sample. A more detailed discussion of this problem was published earlier [7-9], however, our data show that the equipment accurately determined both the pressure of phase transition and the overall specific volume change including the volume change of the transition for these materials.

\section{Results}

During the first and second years (1991-3) of this program completion of the first three goals, as already stated, were achieved successfully. The system's performance capabilities were tested on several powders under different conditions.

Cold compaction of starting powders is a commonly used procedure in the processing of ceramic materials. The objective of the compaction procedure is to produce a dense greenstate compact from the powder that subsequently can be sintered at high temperatures to form a dense ceramic piece. High density in the green-state after cold pressing is of primary importance for achieving high densities after sintering. Large voids, cracks, and other defects in the green-state are not easily eliminated during sintering and their presence in the sintered body reduces the strength of the ceramic. An understanding of the compaction behavior and rheology of ceramic powders is desirable for the production of defect-free greenware in which particles are packed in the densest possible arrangement.

\section{Silicon Nitride Powder Compaction}

Forming densely-packed green compacts from nanosize $\mathrm{Si}_{3} \mathrm{~N}_{4}$ particles is very difficult. A maximum random packing density of approximately $57 \%$ of theoretical was achieved for dry compaction of amorphous nanosize $\mathrm{Si}_{3} \mathrm{~N}_{4}$ powder at a pressure of $2.5 \mathrm{GPa}$ and room temperature. Strong aggregation forces, such as the van der Waals attraction, increase dramatically as particle size decreases. For nanosize particles, the van der Waals attraction forces can prevent the particles from sliding past each other, and, thereby, promote agglomeration by diffusion across particle contact boundaries during compaction. As a result of aggregation and subsequent agglomeration of primary particles, compacts of nanosize particles usually have low densities after cold pressing. The low density is due to two factors: (1) the presence of large voids in the green-state and (2) inefficient packing of particles in the structure of the green-state. We now know that the use of suitable lubricants can improve the packing properties of the nanosize particles, but, in selecting a lubricant, 


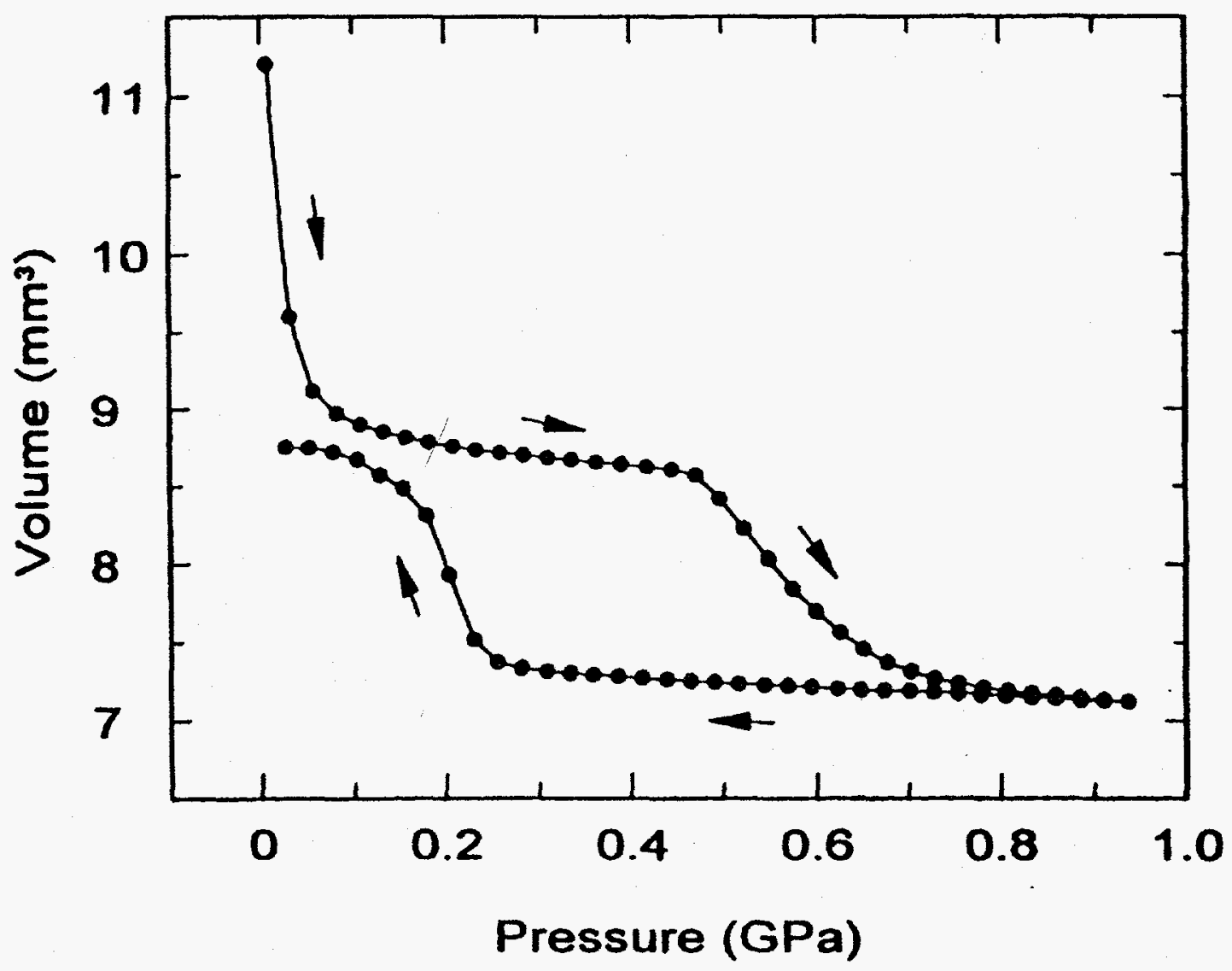

Figure 6. Hysteresis behavior and volume phase transition of $\mathrm{RbBr}$ granular crystalline powders. 


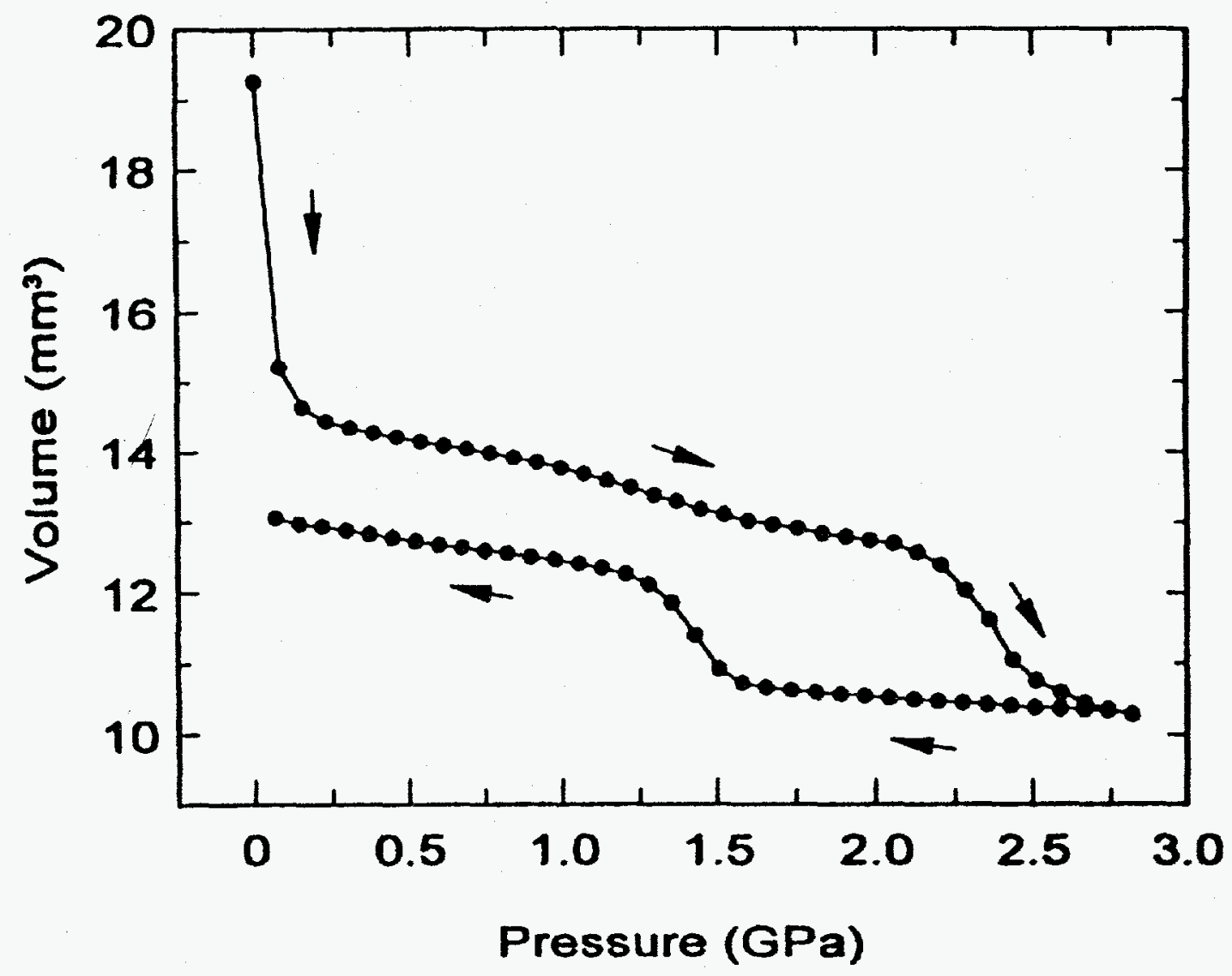

Figure 7. Hysteresis behavior and volume phase transition of $\mathrm{KCl}$ granular crystalline powders. 
Table I. Pressure at transition ( $f c c-s c)$ and volume change for $\mathrm{RbBr}$ and $\mathrm{KCl}$ powders.

\begin{tabular}{lccc}
\hline & RbBr & KCl & REFERENCES \\
\hline PRESSURE & $0.451 \mathrm{GPa}$ & $1.968 \mathrm{GPa}$ & {$[8]$} \\
AT TRANSITION & $0.470 \mathrm{GPa}$ & $2.1 \mathrm{GPa}$ & Present Work \\
\hline$\Delta$ V/V & & & \\
AT T TRANSITION 100 & 13.4 & 13.3 & {$[7]$} \\
& 15.5 & 19.3 & {$[9]$} \\
\hline
\end{tabular}


one is severely limited because of the strongly reacting interface between the particles and the small size of voids in the resulting green microstructure formed by densely-packed nanosize particles [6]. Generally speaking, the diameter of the channels which exist in the structure of densely-packed particles is approximately $1 / 10$ th that of the particle size. Therefore, for a $10 \mathrm{~nm}$ diameter particle, the channel diameter could be approximately $1 \mathrm{~nm}$. Not many molecules can penetrate such small channels. Since the lubricant must be eliminated from the densely-packed structure prior to sintering, one must select a lubricant which consists of very small molecules. Moreover, the selected molecule must adsorb on the surface of the nanosize particles strongly enough to provide good sliding properties during cold compaction, but, it must also be eliminated easily after achieving a densely-packed structure. This could be accomplished by heating in vacuum for a reasonable length of time.

Figure 8 shows a maximum random packing density of approximately $64 \%$ for nanosize amorphous silicon nitride compacted at less than $2.5 \mathrm{GPa}$ pressure under liquid nitrogen. At the same pressure, for a dry compaction of the same powder, the green density was about $57 \%$ of theoretical as stated earlier. These results indicate that cryogenic compaction is an efficient technique to reduce compaction pressure to obtain high packing density and smallscale porosity. The green body produced by liquid nitrogen processing exhibits transparency under visible light which is an indication of nanoscale, uniform porosity. The highest green density of $64 \%$ for nanosize silicon nitride is much smaller than that achieved for gamma alumina powder using either liquid nitrogen or pentane as lubricants. The green densities for $\gamma$ alumina, another nanosize powder studied, are in the range of $74 \%$ of theoretical density. The higher packing density achieved for this material is due to its particle size distribution, lower shear strength and small diffusion coefficient.

\section{Pressureless Sintering and HIPing}

To achieve additional densification, the high density green compacts of $\mathrm{Si}_{3} \mathrm{~N}_{4}$ were subjected to pressureless sintering and HIPing. The highest sintering temperature was $1400^{\circ} \mathrm{C}$ since this is expected to be the threshold temperature for initiation of phase transformation and grain growth.

In one series of tests, the green compacts were sintered without pressure at different temperatures from $1200-1600^{\circ} \mathrm{C}$ under flowing nitrogen gas. The transparency was lost at a sintering temperature of about $1500^{\circ} \mathrm{C}$ as expected because the phase transformation from amorphous to $\alpha$-phase is accompanied by shrinkage and grain growth. Shrinkage in atomic distances is expected to result in physical shrinkage of the particle and, grain growth is expected to destroy the orderly porosity existing in the green body. The overall result is an increase in the scale of porosity which was estimated to be on the order of the wavelength of visible light $(380-780 \mathrm{~nm})$. The XRD, BET (Brunauer, Emmett, Teller equation for physical adsorption on surfaces) and TEM measurements indicate that the phase transformation and grain growth initiate at approximately $1400^{\circ} \mathrm{C}$. Also, it should be noted that the samples were not densified at this pressureless sintering temperature. The maximum Vicker's hardness of about $6 \mathrm{GPa}$ was obtained at a compaction pressure of $2.8 \mathrm{GPa}$ and 


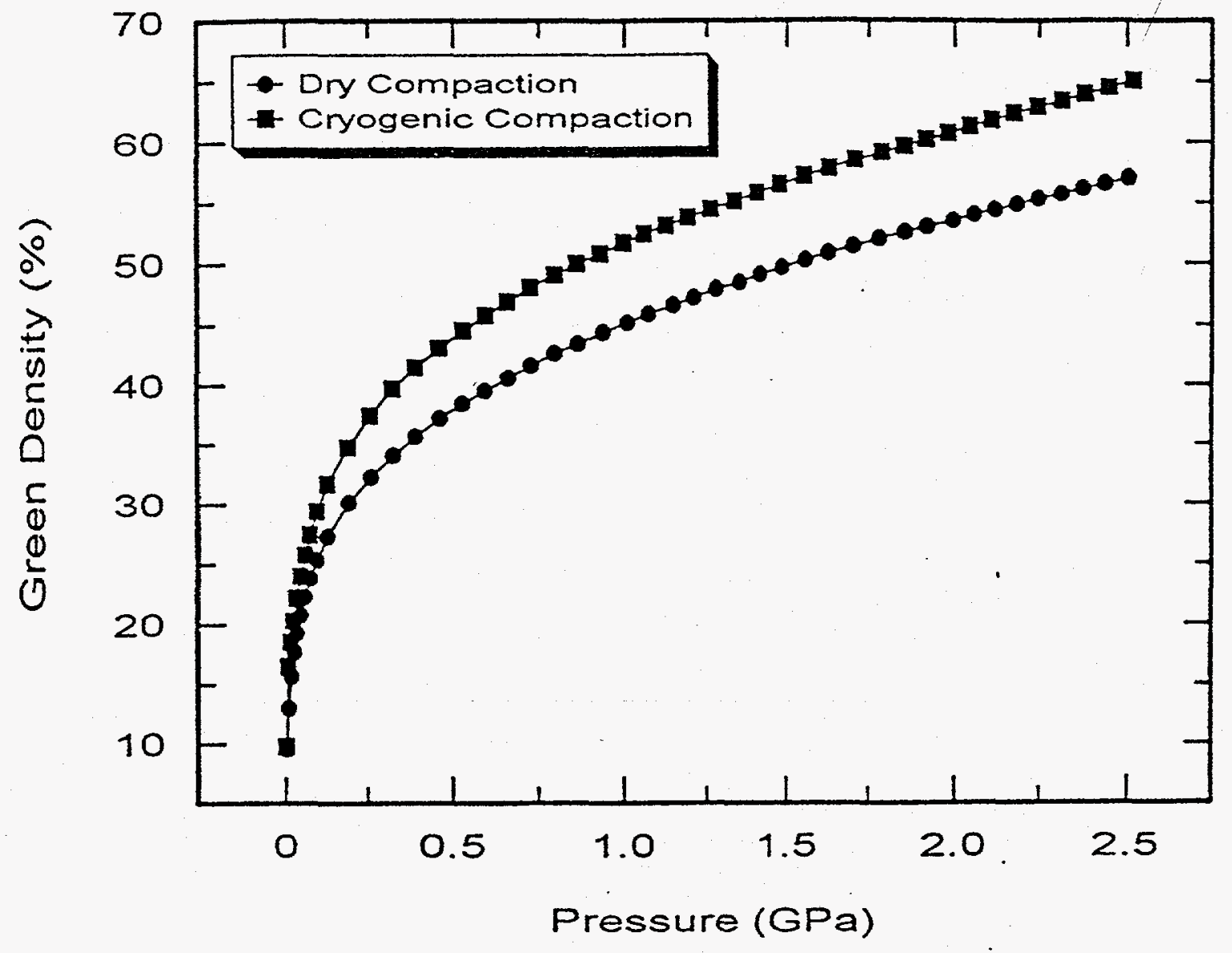

Figure 8. Variation of density of green compacts of nanosize $\mathrm{Si}_{3} \mathrm{~N}_{4}$ as a function of compaction pressure. 
$1400^{\circ} \mathrm{C}$ sintering temperature.

In another series of experiments, HIPing at $200 \mathrm{MPa}$ using nitrogen gas as a pressure transmission medium was attempted to further densify high density green compacts of nanosize $\mathrm{Si}_{3} \mathrm{~N}_{4}$ at 1200,1300 , and $1400^{\circ} \mathrm{C}$. The samples were embedded in $\mathrm{BN}, \mathrm{BN}+\mathrm{Si}_{3} \mathrm{~N}_{4}$, or $\mathrm{Si}_{3} \mathrm{~N}_{4}$ as packing powders. In one case, at $1300^{\circ} \mathrm{C}$ with $\mathrm{BN}+\mathrm{Si}_{3} \mathrm{~N}_{4}$ as packing powders, some densification was observed.

Phase transformations from amorphous to $\alpha$-phase and $\beta$-phase for pressureless sintered and HIPed compacts were studied by TEM and XRD. The transformation point for both processing methods is above $1400^{\circ} \mathrm{C}$. In general, no significant densification was observed by HIPing.

\section{Conclusions}

A novel apparatus has been developed for studying the rheology and time-dependent compaction of ceramic powders under pressures up to $3 \mathrm{GPa}$ in a variety of atmospheres and at temperatures ranging from 77 to $1000 \mathrm{~K}$. The apparatus is used for fabricating diskshaped samples $3 \mathrm{~mm}$ diameter and is capable of measuring volume, density, pressure and rate of change of pressure of powders during the compaction process. In addition, the frictional force between the sample and the walls of the die is measured permitting the force applied to the sample, and thus, the sample pressure to be calculated with a high degree of accuracy.

The effects of high pressure on the compaction of nanosize powders was demonstrated on silicon nitride and $\gamma$ alumina using this new system. Forming densely-packed green compacts from nanosize $\mathrm{Si}_{3} \mathrm{~N}_{4}$ particles is very difficult. A maximum random packing density of approximately $57 \%$ of theoretical was achieved for dry compaction of amorphous nanosize $\mathrm{Si}_{3} \mathrm{~N}_{4}$ powder at a pressure of $2.5 \mathrm{GPa}$ and room temperature. Compaction under liquid nitrogen gave green bodies with improved packing density of approximately $64 \%$. In both cases the compacts were transparent under visible light which is an indication of nanoscale, uniform porosity. The higher packing density achieved by compaction under liquid nitrogen indicates that the cryogenic technique is an effective means of obtaining high packing density and small scale porosity. The green densities for $\gamma$ alumina under dry conditions was $64 \%$ of theoretical density at $2.5 \mathrm{GPa}$. The higher packing density achieved for this material compared to silicon nitride under the same conditions is due to its lower shear strength and diffusion coefficient.

To achieve additional densification, the high density green compacts of $\mathrm{Si}_{3} \mathrm{~N}_{4}$ were subjected to pressureless sintering at different temperatures from $1200-1600^{\circ} \mathrm{C}$ under flowing nitrogen gas. The sintered samples were not further densified by this heat treatment. The maximum Vickers hardness of about $6 \mathrm{GPa}$ was obtained at a compaction pressure of $2.8 \mathrm{GPa}$ and $1400^{\circ} \mathrm{C}$ sintering temperature. Microstructural characterization revealed that extensive oxidation occurred during sintering due to a furnace tube leak. 


\section{Chapter II}

\section{COMPACTION EQUATIONS FOR POWDERS}

\section{Purpose of Compaction Equations}

Investigation of the compaction behavior of ceramic powders is an important part of characterization of raw ceramic powders and evaluation of their compaction behavior, analysis of interaction between particles, and the study of microstructure of green body (unsintered) during pressure-forming processes. The investigation of compaction, directly related to the compaction-forming process, is carried out to estimate the pressure necessary for acquiring a specified density. A number of empirical equations have been suggested. In addition, there have been attempts to derive the powder compaction equation (isothermal equation of state for powder compaction) by applying electron theory of solids, statistical mechanics, physical chemistry, geometry, or plastic/elastic mechanics. These empirical and semiempirical equations, however, are applicable only to limited cases. Even if a certain equation describes a particular powder behavior, it may not be directly applicable to other powders having different properties. Based on Cooper and Eaton's work [10], Takahashi and Suzuki [11] suggest that the compaction behavior be characterized by a transform function in a Laplace transformation instead of studying the compaction equation. This kind of indirect mathematical form is a viable approach, but it can hardly characterize the powder compaction behavior in a physical sense.

The process of powder compaction depends on a number of properties including the flow properties of powders under stress, stress distribution within compacts, the distribution of particle-to-particle stresses, hardness of particles, and strength distribution of particles. As a result, the compaction equation for powders is so complex that it is very difficult to find a general form with a few parameters that can describe the rheology of powder compaction. The principle of superposition (total volume of powder is replaced by a summation of subvolumes which are classified by size of voids) can be used to derive compaction equation for powders. We have developed a new approach to deduce a compaction equation. In addition, experiments on compaction of two ceramic powders were designed for obtaining experimental data to verify the equation. Nonlinear and modified linear least-squares techniques were utilized to fit the experimental data.

One significant problem in the application of a compaction equation is the determination of the initial and final volumes of the sample. Numerical analysis can be applied to press compaction only if both the initial and final volumes of the sample are determined accurately. Direct experimental measurement of initial volume is not accurate because there are many factors that can affect the load-free volume of the powder; for example, electrostatic interaction between particles and container wall, agglomeration of particles, particle size distribution, and flow properties of agglomerates and particles. The prediction of final volume based on theoretical density is also not correct because the latter is measured without the application of external load. Therefore, in the present paper, both initial and final 
volumes were chosen as fitting parameters and their values are determined using experimental data.

Having established the compaction equation, several technically important parameters can be calculated for characterization of powders during compaction. For example, the compaction ratio or the compressibility at zero pressure can predict the average particle size. In addition, compressibility of the powder can be utilized to evaluate flow properties of powders, lubricant conditions, and strength of particles at a fixed pressure during powder compaction.

\section{Powder Compaction Equations}

The isothermal equation of state for a substance is a relationship between the pressure $P$ and volume $V$ corresponding to all possible macroscopic states in which it exists in thermodynamic equilibrium. Most of the isothermal equations of state for physical processes are empirical, although a few can be derived by statistical mechanics. The process of powder compaction is highly complex because it changes from one of easy flow to another of difficult flow typical of condensed matter during compaction. That is, at very low pressure, it behaves like a gas with large compressibility, and at high pressure, it behaves like a condensed matter that exhibits very low compressibility. There is no sharp transformation point between these two states for powder compaction and the change of volume is continuous. The powder compaction equation should therefore describe the behavior of volume changes in the entire pressure range.

By the application of the principle of superposition to this problem, we define a hole (or void) as a contiguous region of empty space within the total volume of the powder compact. The holes in the compact have a distribution of size, denoted by $V_{i}$ for $i=I$ to $N$ where $N$ is the number of discrete volume sizes in the distribution. The volume of particles in the compact is defined by the final volume $V_{\infty}$, which is the net particle volume under extremely high pressure $(P \rightarrow \infty)$. Following the conventional definition for powder compaction, we define fractional volume $V$ as follows:

$$
V^{*}=\frac{V-V_{\infty}}{V_{0}-V_{\infty}}=\sum_{i=1}^{N} \frac{V_{i}}{V_{0}-V_{\infty}}
$$

where $V_{o}$ is the initial volume of powder. The total volume $V$ in equation (1) is a summation of subvolume $V_{i}$ contained in the $i^{\text {th }}$ type of holes and final volume $V_{\infty}$. Each subvolume $V_{i}$ is a function of pressure in an isothermal environment and has a different behavior at different pressures. For example, the subvolume containing large voids can be easily occupied by particles at very low pressure. Smaller voids are removed by forcing rearrangement of particles at higher pressures. The elastic or plastic deformation, and fragmentation of particles also takes place at high pressures. The characteristics of powder compaction on a macroscopic-scale is to exhibit a rapid volume change at very low pressures 
(particularly for nanosize powders) and a slow volume change at higher pressures.

Therefore, each type of hole during compaction plays an important role at a definite pressure segment. To avoid mathematical difficulties, Cooper and Eaton (Table I) suggested that the voids can be classified into two types. Thus the summation in equation (1) reduces to three terms and the equation contains five parameters. The proposed new compaction equation containing five parameters is as follows:

$$
V=a_{1}+a_{2} e^{\frac{1}{1+a_{3} P}}+\frac{a_{4}}{1+a_{5} P}
$$

where $a_{i}(i=1, \ldots, 5)$ are parameters, and $V_{0}=a_{1}+a_{2} e+a_{4}$ and $V_{\infty}=a_{1}+a_{2}$. Though this equation has the same number of parameters as that in Cooper and Eaton's equation, it will be shown later that equation (2) provides a better fit to the experimental data. The rationale for equation (2) is discussed later.

In general, if the summation in equation (1) takes into account all different types of holes, the number $N$ will approach infinity. To obtain an equation of state without discussing detailed mechanisms of void removal, stress distribution, or interaction between particles during powder compaction, we assume that the volume contained in each type of hole is proportional to $f\left(b_{i}, P\right)$ which is a function of the pressure, $P$, and the parameter $b_{i}$ which is related to the $i^{\text {th }}$ type of voids, then

$$
V^{*}=\sum_{i=1}^{N} a_{i} f\left(b_{i}, P\right)
$$

where $a_{i}$ is a proportional parameter characterizing the statistical weight of each type of porosity in the entire pressure region. Equation (3) is a general form of compaction equation for the powder compaction but is unclosed. The function $f\left(b_{i}, P\right)$ can be investigated by empirical considerations using the best fit to experimental data for powder compaction. If we increase the number of types of holes to infinity $(N \rightarrow \infty)$, equation (3) will approach a real process of powder compaction, and, at the same time, will result in an unbounded number of parameters and mathematical difficulties of parameter determination. Therefore, the selection of number of types of holes is critical to characterize the process of powder compaction.

In order to optimize the selection of type of holes, a mathematical method was developed using the Gaussian-Laguerre numerical integration to reduce the number of parameters in equation (3). As shown in equation (4), the summation in equation (3) can be replaced approximately by an integral, and the volume, $V^{*}$, from equation (1) can be expressed as

$$
V^{*}=\lim _{N \rightarrow \infty} \sum_{i=1}^{N} a_{i} f\left(b_{i}, P\right) \approx \int_{0}^{\infty} g(u) f(u, P) d u
$$


Table I. Published powder compaction equations

Athy

$$
\frac{V-V_{\infty}}{V}=\frac{V_{0}-V_{\infty}}{V_{0}} \exp \left(-c_{1} P\right)
$$

Cooper and Eaton

$V=a_{1}+a_{2} \exp \left(-a_{3} / P\right)+a_{4} \exp \left(-a_{5} / P\right)$

Kawakita

$$
\frac{V_{0}-V}{V_{0}}=\frac{a b P}{1+b P}
$$

- Eq. (2)

$$
V=a_{1}+a_{2} \exp \left(\frac{1}{1+a_{3} P}\right)+\frac{a_{4}}{1+a_{5} P}
$$

Eq. (7) $\left[u_{0}=0\right.$ and $u_{i}(i=1, \ldots, n)$ zeros of $n$-order Laguerre polynomials)

$$
V=\sum_{i=0}^{n} \frac{a_{i}}{\left(1+u_{i} \alpha P\right)} \quad(n=3, \ldots, 8)
$$


where $g(u)$ is an unknown

function corresponding to $a_{i}$. Using the Gaussian-Laguerre numerical integration method to calculate the integral, we have

$$
V^{*}=\sum_{i=1}^{n} a_{i}^{*} f\left(u_{i}, P\right)
$$

where, for $i>0, a_{i}^{\prime}=g\left(u_{i}\right) w_{i} \exp \left(u_{i}\right), u_{i}$ is $i^{\text {th }}$ zero of $n^{\text {th }}$ order Laguerre polynomial and $w_{i}$ is the associated weight factor, $n$ is the number of points of the integral. Table I lists zeros, $u_{i}$ $(i=1, \ldots, n)$ of 4 - to 8 -order $(n=4, \ldots, 8)$ Laguerre polynomials. The linear coefficients $a_{i}^{\prime}$ can be determined by experimental $P-V$ data. The function $f\left(u_{i}, P\right)$ can be selected from a set of functions in which the $f\left(u_{i}, P\right)$ should be to describe the experimental characteristic of the total volume versus pressure. The set of functions, in which each function decreases continuously from one to zero when pressure increases from zero to infinity, is given by

$$
f\left(u_{i}, p\right) \in\left\{e^{-u_{i} P}, 1 /\left(1+u_{i} P\right),\left(e^{1 /\left(1+u_{i} P\right)}-1\right) /(e-1),\left[1-\frac{2}{\pi} \arctan \left(u_{i} P\right)\right]\right\} .
$$

Evaluation of a function selection is performed by optimized $r m s$ (the root mean square deviation per degree of freedom) for powder compaction when the number of parameters are fixed. The fitting results indicate that functions $1 /\left(1+u_{i} P\right)$ and $\left\{\exp \left[1 /\left(1+u_{i} P\right)\right]-1\right\} /(e-1)$ in the set (6) are better selections than other functions in the listed set. There is no significant difference between the functions $1 /\left(1+u_{i} P\right)$ and $\left\{\exp \left[1 /\left(1+u_{i} P\right)\right]-1\right\} /(e-1)$ in our problem, but we selected $1 /\left(1+u_{i} P\right)$ because it has a simpler form and can be calculated rapidly. Equation (2) actually consists of both functions that provide contributions at different pressure regions to describe powder compaction rheology. Substituting $I /\left(I+u_{i} P\right)$ into equation (5), and combining with equation(1), we obtain

$$
V=\sum_{i=0}^{n} \frac{a_{i}}{\left(1+u_{i} \alpha P\right)}
$$

where $\alpha$ is a factor with a dimension of inverse pressure, $a_{i}=\left(V_{0}-V_{\infty}\right) a_{i}{ }_{i}$, and $u_{0}=0$. The number of terms in the compaction equation (7) is $n+1$. Equation (7) is given by a partial fraction and is easy to transfer into a closed form but we prefer this form because it has a clear physical meaning, as explained earlier. 
The advantage of equation (7) is that parameters $a_{i}$ are linear, except the scale factor. Therefore, all parameters $a_{i}$ in equation (7) can be determined by linear least-squares, if the scale factor is fixed. Scanning the scale factor around the minimum point of $r m s$, the global minimum $r m s$ can be found by minimization of the function between the rms and the scale factor $\alpha$. The method is called modified linear least-squares in this paper and it converges always.

The total number of independent parameters in the equation of state (7) is $n+2$ (including the scale-factor $\alpha)$. The number of parameters $a_{i}$ were chosen from five to nine $(n=4, \ldots, 8)$ which depend on the accuracy required for fitting. In general, in equation (7), five parameters $a_{i}(n=4)$ can give a fairly good fit and eight or nine parameters $a_{i}(n=7$ or 8$)$ can give a highly accurate fit.

The physical meaning of the compaction equation (7) is that $n$ types of voids can provide major contribution in the powder compaction process. The initial volume $V_{o}$ and the final volume $V_{\infty}$ can be determined as parameters based on experimental data using functions as defined below:

$$
V_{0}=\sum_{i=0}^{n} a_{i} \text { and } V_{\infty}=a_{0}
$$

Therefore, the fractional volume $V^{*}$ is given by

$$
V^{*}=\frac{V-V_{\infty}}{V_{0}-V_{\infty}}=\frac{\sum_{i=1}^{n} \frac{a_{i}}{1+u_{i} \alpha P}}{\sum_{i=1}^{n} a_{i}}
$$

\section{Experimental Data}

The rheology of powder during compaction is dependent on powder properties and the compaction conditions; for instance, flow properties of particles, particle size distribution and shape, agglomeration, and lubricant media have considerable influence on powder rheology. In the experiments, $\boldsymbol{P}-\boldsymbol{V}$ diagrams were obtained under dry compaction at the same rate of pressure application. Two typical examples of volume versus time under dry compaction are shown in Figure 9 in which $\bullet$ and $=$ indicate powder compaction for $0.5 \mu \mathrm{m} \mathrm{Si} \mathrm{N}_{4}$ (over $95 \%$ $\alpha$-phase) and $20 \mathrm{~nm} \gamma-\mathrm{Al}_{2} \mathrm{O}_{3}$, respectively. 


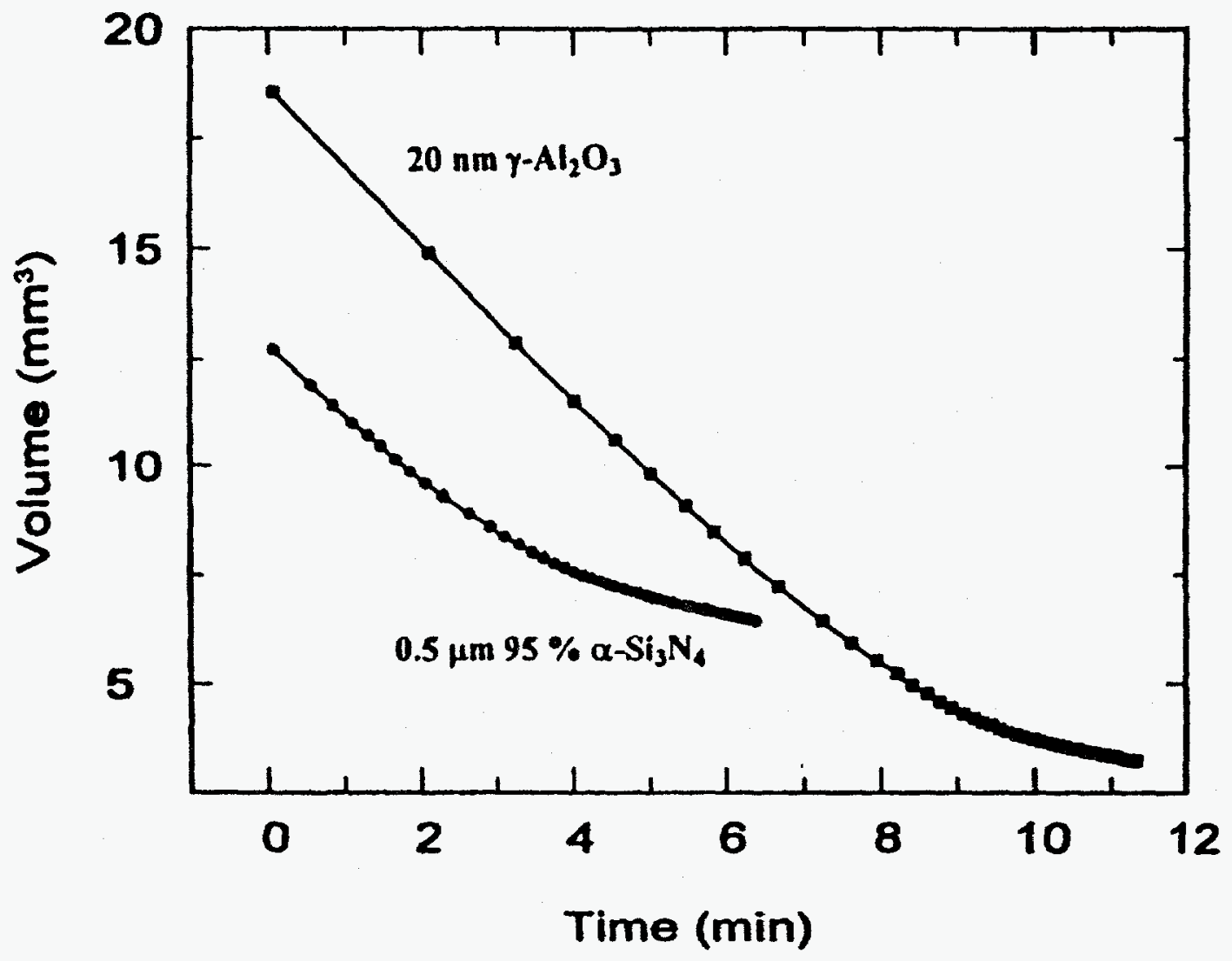

Figure 9. Time dependance of volume for $20 \mathrm{~nm} \gamma-\mathrm{Al}_{2} \mathrm{O}_{3}$ and $0.5 \mu \mathrm{m} \alpha-\mathrm{Si}_{3} \mathrm{~N}_{4}$ powders during compaction using a $2.54 \mathrm{~mm} / \mathrm{min}$ screw displacement. 


\section{Data Analysis and Discussion}

Many equations have been proposed to describe the behavior of powder compaction. Table I lists the Cooper and Eaton, Kawakita, and Athy equations since these are commonly used for describing powder compaction. These equations were found to describe our experimental data to some extent, but there were significant discrepancies. Nonlinear least-squares techniques were used to determine the parameters since the parameters in equation (2) and equations listed in Table I are nonlinear. The behavior of the volume versus pressure for press compaction of powder indicates that compressibility is very large especially for nanosize powders. We define compaction ratio as follows:

$$
\text { Compaction ratio }=\frac{V_{\infty}}{V_{0}}
$$

The ratio is less than one and is a function of particle size distribution, shape, flow properties, and agglomeration of powder. The ratio of compaction is found to be approximately $40 \%$ for submicrometer particles and $10 \%$ for nano-size particles.

A least-squares error is defined for fitting the experimental data as follows:

$$
\chi^{2}=\sum_{i=1}^{N}\left[V\left(a, P_{i}\right)-V_{j}\right]^{2} / W_{i}^{2}
$$

where $P_{i}, a, V_{i}$, and $W_{i}$ are pressure, parameter vector in compaction equation, measured volume, and weighing factor, respectively. The weighing factor can be chosen as $W_{i}=1$ or $W_{i}=1 / V_{i}$. To reduce deviation at high pressure range, the definition of the normalized leastsquares error $\left(W_{i}=1 / V_{i}\right)$ is better than the normal definition $\left(W_{i}=1\right)$ for fitting the experimental data of powder compaction. In equation (11), the normal definition $\left(W_{i}=1\right)$ can increase fitting accuracy at initial pressure range especially for nano-size powder because of volume being large at low pressure which leads to a large contribution in minimization of the function (11). All parameters in the equations listed in Table I are determined by fitting the equations to experimental data using nonlinear least-squares or modified linear leastsquares. Both initial volume $V_{o}$ and final volume $V_{\infty}$, in which the pressure approaches zero or infinity, respectively, were calculated by functions and parameters.

Using the definition of normal least-squares error $\left(W_{i}=1\right)$, a nonlinear least-squares method was utilized to fit experimental data for our equation (2), and to those of Athy, Cooper and Eaton, and Kawakita. The $r m s$ resulting from this analysis for different models and for two different powders are listed in Table II. It is obvious that the rms for our compaction equation (2) is almost one order of magnitude smaller than those of Cooper's and Kawakita's equations. Moreover, it is reduced by an order of magnitude for submicrometer powder and almost by two orders of magnitude for nanosize powders compared with that of Athy's equation. 
Table II. The root-mean-square deviation per degree of freedom (rms for different models using methods of nonlinear least-squares and modified linear least-squares to fit data of $0.5 \mu \mathrm{m} \alpha-\mathrm{Si}_{3} \mathrm{~N}_{4}, 20 \mathrm{~nm}$ $\gamma-\mathrm{Al}_{2} \mathrm{O}_{3}, 0.4 \mu \mathrm{m} \alpha-\mathrm{Al}_{2} \mathrm{O}_{3}, 1.0 \mu \mathrm{m} \mathrm{Y}_{2} \mathrm{O}_{3}, \mathrm{MgO}$, graphite, and $\mathrm{BN}$ powders

\begin{tabular}{|c|c|c|}
\hline Mode1 & $0.5 \mu \mathrm{m} \alpha-\mathrm{Si}_{3} \mathrm{~N}_{4}$ & $20 \mathrm{~nm} \quad \gamma-\mathrm{Al}_{2} \mathrm{O}_{3}$ \\
\hline $\begin{array}{l}\text { Cooper } \\
\text { Athy } \\
\text { Kawakita } \\
\text { Eq. ( } 2 \\
\text { Eq. ( } 7\end{array}$ & $\begin{array}{ll}1.29 \times 10^{-2} & \\
4.83 \times 10^{-2} & \\
3.38 \times 10^{-2} & \\
6.19 \times 10^{-3} & \\
7.34 \times 10^{-3} & (\mathrm{n}=3 \\
6.17 \times 10^{-3} & (\mathrm{n}=4 \\
3.21 \times 10^{-3} & (\mathrm{n}=5 \\
2.97 \times 10^{-3} & (\mathrm{n}=6 \\
1.39 \times 10^{-3} & (\mathrm{n}=7\end{array}$ & $\begin{array}{ll}1.18 \times 10^{-2} & \\
9.67 \times 10^{-2} & \\
6.76 \times 10^{-2} & \\
3.56 \times 10^{-3} & \\
5.25 \times 10^{-3} & (\mathrm{n}=3 \\
3.43 \times 10^{-3} & (\mathrm{n}=4 \\
3.24 \times 10^{-3} & (\mathrm{n}=5 \\
3.34 \times 10^{-3} & (\mathrm{n}=6 \\
3.09 \times 10^{-3} & (\mathrm{n}=7\end{array}$ \\
\hline Mode1 & $0.4 \mu \mathrm{m} \alpha-\mathrm{Al}_{2} \mathrm{O}_{3}$ & $\mathrm{MgO}$ \\
\hline $\begin{array}{l}\text { Cooper } \\
\text { Athy } \\
\text { Kawakita } \\
\text { Eq. ( } 2 \\
\text { Eq. (7 }\end{array}$ & $\begin{array}{ll}1.27 \times 10^{-2} & \\
4.45 \times 10^{-2} & \\
3.67 \times 10^{-2} & \\
3.72 \times 10^{-3} & \\
8.26 \times 10^{-3} & (\mathrm{n}=3 \\
6.58 \times 10^{-3} & (\mathrm{n}=4 \\
1.65 \times 10^{-3} & (\mathrm{n}=5 \\
1.29 \times 10^{-3} & (\mathrm{n}=6 \\
5.47 \times 10^{-4} & (\mathrm{n}=7\end{array}$ & $\begin{array}{ll}1.05 \times 10^{-2} & \\
7.04 \times 10^{-2} & \\
4.24 \times 10^{-2} & \\
6.64 \times 10^{-3} & \\
7.21 \times 10^{-3} & (\mathrm{n}=3 \\
6.46 \times 10^{-3} & (\mathrm{n}=4 \\
4.51 \times 10^{-3} & (\mathrm{n}=5 \\
4.55 \times 10^{-3} & (\mathrm{n}=6 \\
4.59 \times 10^{-3} & (\mathrm{n}=7\end{array}$ \\
\hline Model & $\mathrm{Y}_{2} \mathrm{O}_{3}$ & $\mathrm{BN}$ \\
\hline $\begin{array}{l}\text { Cooper } \\
\text { Athy } \\
\text { Kawakita } \\
\text { Eq. }(2 \\
\text { Eq. (7 }\end{array}$ & $\begin{array}{ll}9.75 \times 10^{-3} & \\
5.92 \times 10^{-2} & \\
3.80 \times 10^{-2} & \\
6.79 \times 10^{-3} & \\
6.65 \times 10^{-3} & (n=3 \\
6.22 \times 10^{-3} & (n=4 \\
2.13 \times 10^{-3} & (n=5 \\
2.20 \times 10^{-3} & (n=6 \\
2.24 \times 10^{-3} & (n=7\end{array}$ & $\begin{array}{ll}5.71 \times 10^{-3} & \\
2.97 \times 10^{-2} & \\
1.65 \times 10^{-2} & \\
2.85 \times 10^{-3} & \\
5.13 \times 10^{-3} & (n=3 \\
4.37 \times 10^{-3} & (n=4 \\
1.34 \times 10^{-3} & (n=5 \\
1.16 \times 10^{-3} & (n=6 \\
7.22 \times 10^{-4} & (n=7\end{array}$ \\
\hline
\end{tabular}

\begin{tabular}{ll}
\hline Mode1 & graphite \\
\hline Cooper & $9.67 \times 10^{-3}$ \\
Athy & $3.96 \times 10^{-2}$ \\
Kawakita & $2.29 \times 10^{-2}$ \\
Eq. $(2$ & $5.10 \times 10^{-3}$ \\
Eq. $(7$ & $8.38 \times 10^{-3} \quad(n=3$ \\
& $7.37 \times 10^{-3} \quad(n=4$ \\
& $3.66 \times 10^{-3} \quad(n=5$ \\
& $3.49 \times 10^{-3} \quad(n=6$ \\
& $2.19 \times 10^{-3} \quad(n=7$ \\
\hline
\end{tabular}


Equation (7) is fitted by a modified linear least-squares method. As mentioned above, the scale factor was scanned around the minimum point of the $r m s$, thus all $a_{i}$ parameters are linear for minimization of equation (11). The $r m s$ as a function of the scale factor $\alpha$ is shown in Figure 10 for eight parameters $(n=7)$. The best scale factor $\alpha$ is calculated by minimization of second order interpolation function around the minimum point of $r m s$. The scanning step of scale factor $\alpha$ should be adjustable and is reduced by an order of magnitude when it approaches the minimum point of $r m s$.

The residuals of Cooper and Eaton's equation, equation (2), and equation (7) with eight parameters $(n=7)$ are demonstrated in Figure 11 for compaction of submicrometer and nanosize powders. The $r m s$ values for compaction of both of these powders using equation (7) with different numbers of parameters $(n=4, \ldots, 8)$ are listed in Table II. A highly accurate fit to our experimental data for these powders was obtained using equation (7) with eight or nine parameters $(n=7,8)$. A good fit to the experimental data is necessary to determine the extrapolation points, initial volume $V_{0}$ and the final volume $V_{\infty}$. Therefore, it is possible to characterize powders by this new approach if we combine these equations, compaction ratio, and compressibility. The compaction equations (2) and ( 7 can be applied to various powders, powders containing different size of particles, and for powders compressed by either uniaxial pressing or tapping compaction.

\section{Conclusions}

Two compaction equations for powders were developed. A new mathematical approach was used to handle the problem when the principle of superposition is employed for derivation of the compaction equation (7). This is a general method that can be applied to study similar problems in other fields. An experimental system was designed to develop powder compaction experimental data which was used to evaluate the compaction equations and other published equations. The rms for the fit of submicrometer and nano-size powders compaction using our equations were reduced by almost one order of magnitude in comparison with those of Cooper and Eaton's equation. 


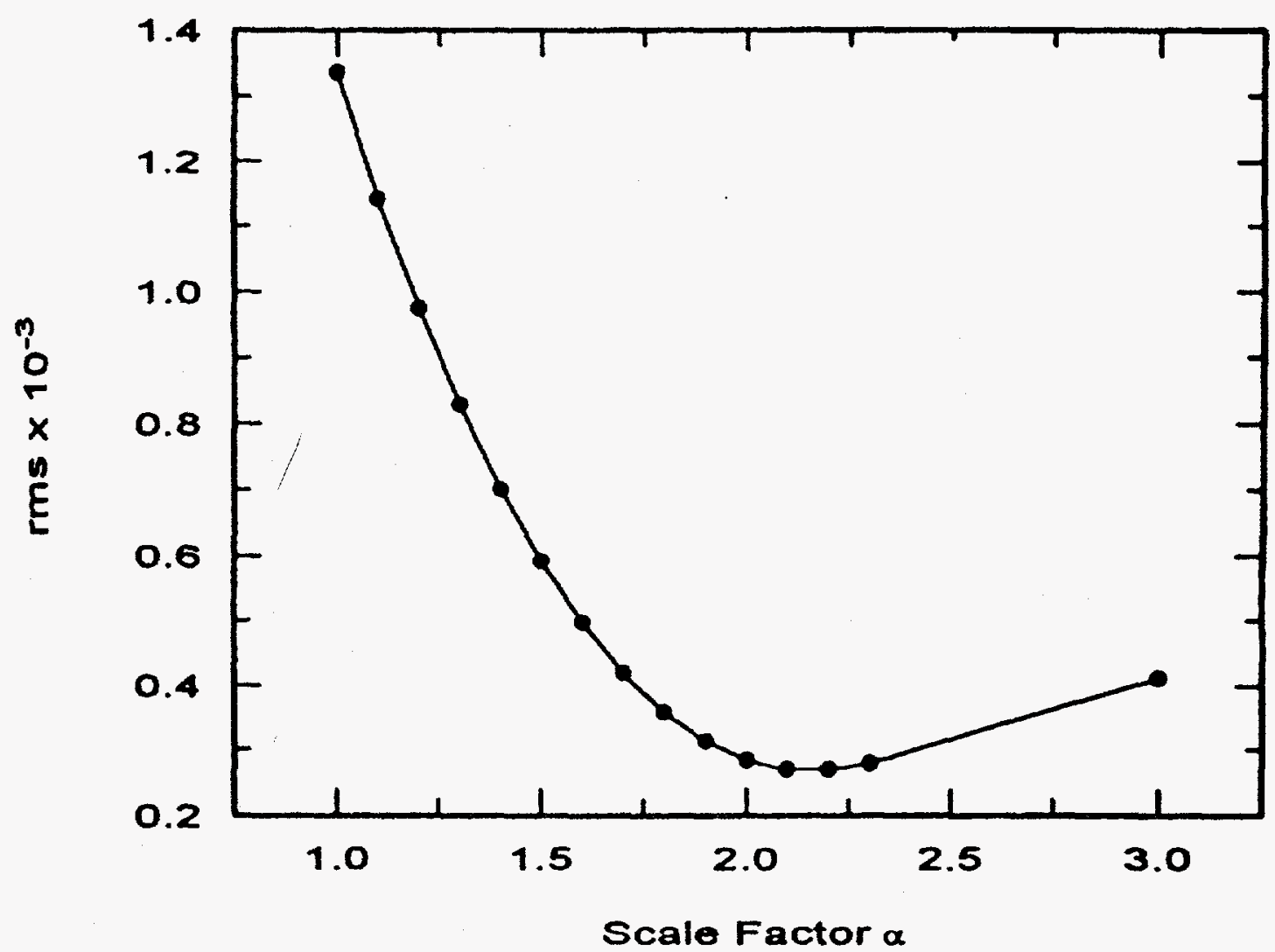

Figure 10. The root-mean-square deviation per degree of freedom (rms) vs. scale factor $\alpha$ in Eq. (7) $(n=7)$ around the minimum point of rms. 


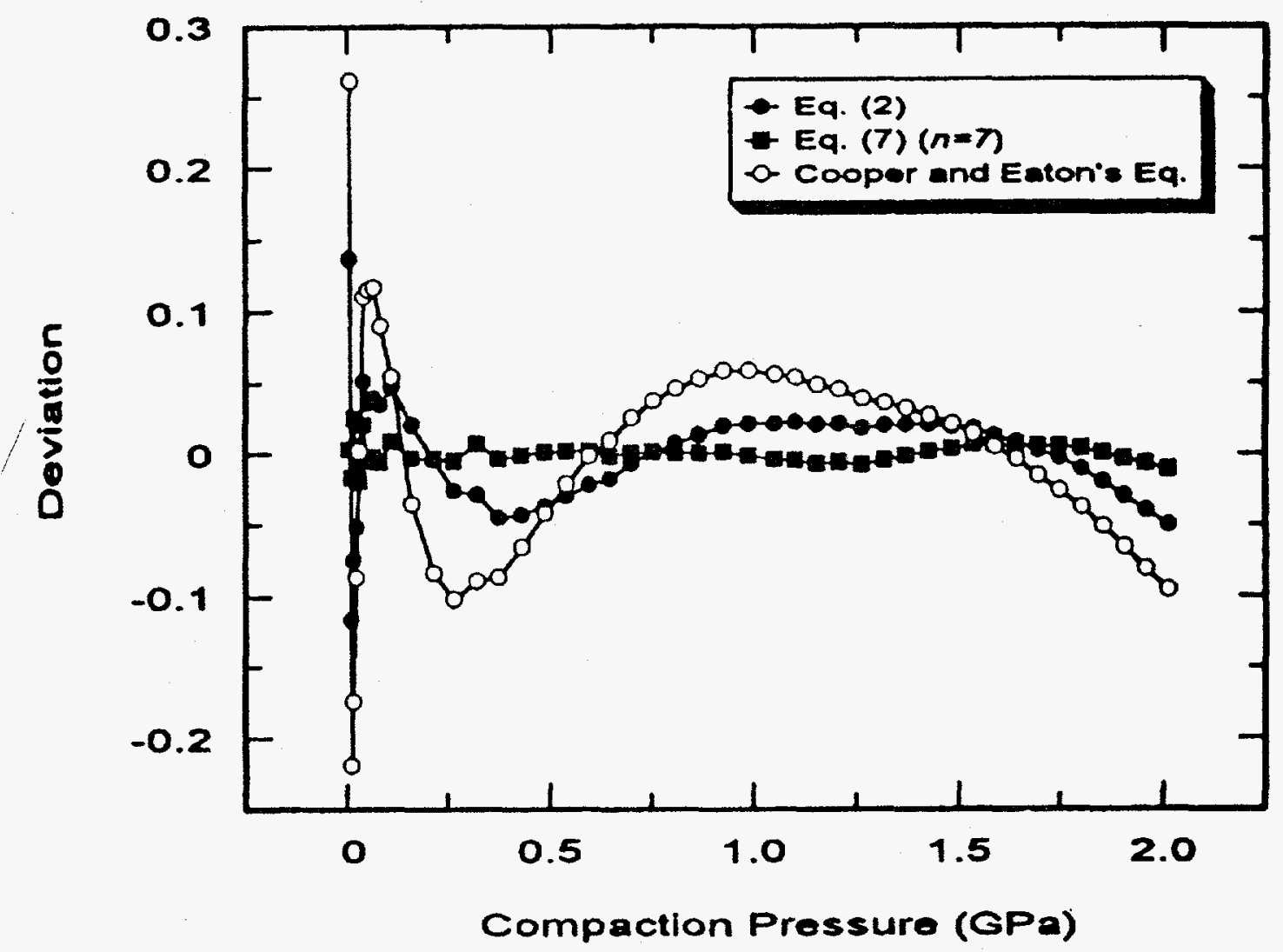

Figure 11. Deviation of different compaction equations and experimental data for $\alpha$ phase $\mathrm{Si}_{3} \mathrm{~N}_{4}$ powder. 


\section{Chapter III}

\section{COMPACTION OF $20 \mathrm{~nm} \gamma-\mathrm{Al}_{2} \mathrm{O}_{3}$ POWDER}

\section{Purpose of $\gamma-\mathrm{Al}_{2} \mathrm{O}_{3}$ Powder Compaction}

The advantage of using nanosize particles rather than microsize particles is that lower temperatures may be possible for sintering $[13,14]$. This phenomenon can be exploited to fabricate ceramic materials that, until now, were not possible to make by conventional sintering methods, because of their thermodynamic instability at the required sintering temperatures. An example of such a material is $\gamma-\mathrm{Al}_{2} \mathrm{O}_{3}[15,16]$. While it is relatively straightforward to produce $\alpha-\mathrm{Al}_{2} \mathrm{O}_{3}$ ceramics, no one, to our knowledge, has reported the successful fabrication of a high density bulk polycrystalline ceramic of $\gamma-\mathrm{Al}_{2} \mathrm{O}_{3}$. Nanosize particles of $\gamma-\mathrm{Al}_{2} \mathrm{O}_{3}$, therefore, are of interest in the present work.

Few data were found in the literature on the fabrication and mechanical properties of bulk $\gamma$ $\mathrm{Al}_{2} \mathrm{O}_{3}$. In previous work utilizing a diamond anvil high pressure cell (DAC) and energy dispersive $\mathrm{x}$-ray diffraction, we measured the compression of nanocrystalline $\gamma-\mathrm{Al}_{2} \mathrm{O}_{3}$ powder from which the isothermal bulk modulus and Young's modulus were determined [17]. However, measurements have been reported on the hardness of thin films of $\gamma-\mathrm{Al}_{2} \mathrm{O}_{3}[16,18]$.

In the present work, a number of compacting conditions were explored to achieve randomclose-packing of nanosize particles of $\gamma-\mathrm{Al}_{2} \mathrm{O}_{3}$. Without first producing a homogeneous compact of random-closed-packed particles, the green-state body cannot be sintered to high density because coarse porosity is not eliminated via surface diffusion, the predominant mechanism for sintering compacts of nanosize particles [15]. Our earlier study on the compaction of nanosize particles of silicon nitride showed that dense packing was not achieved by using high pressures alone [19]. It was found that liquid nitrogen $\left(\mathrm{LN}_{2}\right)$ provided an excellent lubricant for moving the silicon nitride particles closer together. The hardest compacts were those that were fabricated under $\mathrm{LN}_{2}$. In light of this previous work, $\mathrm{LN}_{2}$ also was used here to compact nanosize particles of $\gamma-\mathrm{Al}_{2} \mathrm{O}_{3}$ and the results were compared with room temperature compactions. Both methods produced transparent greenstate compacts which were then heat treated under vacuum. Hardness was measured before and after heat treatment. In addition, the compacts were analyzed by energy dispersive $\mathrm{x}$-ray diffraction to identify the crystallographic phases present and by transmission electron microscopy (TEM) to characterize microstructure.

\section{Experimental Procedures}

The starting nanosize $\gamma-\mathrm{Al}_{2} \mathrm{O}_{3}$ powder used in this work was a commercially available material, Aluminum Oxide C, supplied by Degussa AG, Geschäftsbereich Anorganische Chemieprodukt, Frankfurt, Germany. It has an average particle diameter of $20 \mathrm{~nm}$. Angle dispersive $\mathrm{x}$-ray powder diffraction measurements on the starting powder indicated the presence of primarily $\gamma$ phase with some $\delta$ phase, estimated from diffraction intensities to be 
$<10 \%$ by volume. The powder was used as-received without any prior treatment and was handled in the ambient environment.

The starting powder was precompacted in a WC/Co die under $0.1 \mathrm{GPa}$ and then subsequently compacted in a DAC under pressures ranging from 1 to $3 \mathrm{GPa}$. The initial compactions were carried out at two different temperatures, (1) room temperature (RT) and (2) $\mathrm{LN}_{2}$ temperature. A molybdenum gasket was used to confine the sample between the two opposed anvils in the DAC and served as the sample container. The maximum size of the compacts fabricated by the DAC in this work was $0.2 \mathrm{~mm}$ in diameter by $0.15 \mathrm{~mm}$ in thickness. Pressures were measured by the shift of the ruby fluorescence $\mathrm{R}_{1}$-line. For this purpose, a small ruby sphere (about $10 \mu \mathrm{m}$ in diameter) serving as the pressure sensor was included with the sample. The DAC and the ruby fluorescence pressure measurement technique, as well as the energy dispersive $\mathrm{x}$-ray method are described elsewhere $[19,20]$.

In the case of room temperature compaction, the precompacted starting material was initially pressed to transparency. Typically, transparency was reached at about $1 \mathrm{GPa}$. However, final sample pressures exceeded this value and ranged from 2-to-4 GPa. The final sample pressure was reached in two ways, (1) by one pressure cycle, and (2) by multiple (normally two) pressure cycles. It was found that hardness was independent of the number of cycles used to reach the final sample pressure at room temperature.

The compaction of the $\gamma$-alumina sample under $\mathrm{LN}_{2}$ (cryogenic compaction) was performed according to the following procedures. The gasketed DAC, containing both the $\gamma-\mathrm{Al}_{2} \mathrm{O}_{3}$ precompacted $(0.1 \mathrm{GPa})$ sample and the small ruby pressure sensor, was first sealed and isolated from the external environment at $\mathrm{RT}$ by applying a nominal load to the gasket. The DAC was then immersed in a $\mathrm{LN}_{2}$ bath. After about 10 minutes it reached equilibrium with the $\mathrm{LN}_{2}$. When temperature equilibrium was attained, the load on the gasket in the DAC was reduced to zero, thereby breaking the seal between the gasket and diamond surface and exposing the precompacted $\gamma-\mathrm{Al}_{2} \mathrm{O}_{3}$ powder to $\mathrm{LN}_{2}$. After 1 minute, the cell was resealed by applying the load to produce pressures from 1 to $3 \mathrm{GPa}$ on the sample which now included some liquid nitrogen. The pressurized DAC was then removed from the $\mathrm{LN}_{2}$ bath and warmed to RT. At RT, the sample pressure was measured and defined as the initial compaction pressure. Because the load on the sample is applied through a set of remote spring washers, we know from previous experience that no significant increase in pressure is expected with the increase in temperature. Pressure cycling at RT was then carried out and consisted of reducing the pressure to ambient atmosphere and then increasing it again to the desired maximum pressure defined as the final compaction pressure (always $3 \mathrm{GPa}$ for these $\mathrm{LN}_{2}$ experiments). The pressure cycling procedure was carried out usually 2 or 3 times until the $\mathrm{LN}_{2}$ had been eliminated from the $\gamma-\mathrm{Al}_{2} \mathrm{O}_{3}$ sample.

After final compaction and removal from the DAC, the transparent green-body compact of nanosize particles of $\gamma-\mathrm{Al}_{2} \mathrm{O}_{3}$ was evaluated by measuring the hardness of the sample using a Vickers microhardness indentor at a fixed load of $50 \mathrm{~g}$. Optical clarity was evaluated by microscopy examination. The energy dispersive $\mathrm{x}$-ray powder diffraction technique was used 
to determine the polymorphic phases present.

In the final step, the transparent green-body compacts produced by both $\mathrm{RT}$ and $\mathrm{LN}_{2}$ compaction procedures were heat treated in a tube furnace under $100 \mathrm{~Pa}$ vacuum at $800{ }^{\circ} \mathrm{C}$ for $10 \mathrm{~h}$. Heating and cooling rates of $5{ }^{\circ} \mathrm{C} / \mathrm{min}$ were used in the heat treatment procedure. The molybdenum gasket was found to be chemically inert to $\gamma-\mathrm{Al}_{2} \mathrm{O}_{3}$ at the $800{ }^{\circ} \mathrm{C}$ heat treatment condition. After heat treatment, the optical transparency, microhardness and $\mathbf{x}$-ray characterization were again evaluated. The microstructure of the heat treated and green-state compacts were also characterized by TEM.

\section{X-ray Diffraction Results}

Typical energy dispersive $\mathrm{x}$-ray powder diffraction patterns for $\gamma-\mathrm{Al}_{2} \mathrm{O}_{3}$ fabricated under different conditions are shown in Figure 12. Also shown in this figure are line diagrams representing the peak positions and intensities of the diffraction patterns for the $\gamma$ and $\delta$ phases of alumina [21]. The energy dispersive $x$-ray pattern for the nanosize starting powder (a) shows only peaks arising from the $\gamma$ phase. However, from angle dispersive $x$-ray diffraction measurements, where more accurate peak profiles can be obtained, we know that the starting powder contained $\delta$ phase estimated to be $<10 \%$, a level apparently not detected by our energy dispersive technique. In (b), and (c), are shown the x-ray patterns of the samples that were initially compacted at $\mathrm{LN}_{2}$ temperature to $1.2 \mathrm{GPa}$ and $1.6 \mathrm{GPa}$, respectively, and then cycled twice to a final compaction pressure of $3 \mathrm{GPa}$ at $\mathrm{RT}$, followed by pressureless heat treatment at $800^{\circ} \mathrm{C}$ for 10 hours at $100 \mathrm{~Pa}$ vacuum. In (d), is shown the $\mathrm{x}$-ray pattern for the two-cycle room temperature compaction of the nanosize starting powder to $3 \mathrm{GPa}$ final compaction pressure, followed by the same heat treatment procedure described above. In this $\mathrm{x}$-ray pattern for $\gamma-\mathrm{Al}_{2} \mathrm{O}_{3}$, there may be evidence for the presence of a minor amount of $\delta$ alumina indicated by the splitting of a major $\gamma$ phase diffraction peak. The peak that could be due to the $\delta$ phase is identified by the small arrow, but we cannot rule out that this splitting may also be due to statistical noise. Note that $\mathrm{x}$-ray pattern (c) contains an extra peak attributed to Mo, the gasket material. As far as the energy dispersive $\mathrm{x}$-ray diffraction measurements are concerned, the fabricated compacts (b), (c) and (d) in Figure 12 indicate the presence of primarily $\gamma-\mathrm{Al}_{2} \mathrm{O}_{3}$.

\section{Microhardness Measurements}

While optical transparency in the green-state compact is necessary, it is not a sufficient condition for achieving dense packing of nanosize particles [19]. Optical transparency indicates that particles are packed such that the pores are reduced in size to below $100 \mathrm{~nm}$ and suggests sample uniformity. Also, it should be noted that a nanosize particle compact of $40 \%$ density could have similar optical transparency as a $60 \%$-dense compact. Thus, optical clarity alone cannot be used as an indicator for characterizing density or fine scale homogeneity of particle packing. On the other hand, the shear strength of a compact, characterized by measuring Vickers hardness, is thought to be a reliable parameter to characterize density of particle packing because it depends strongly on the coordination 


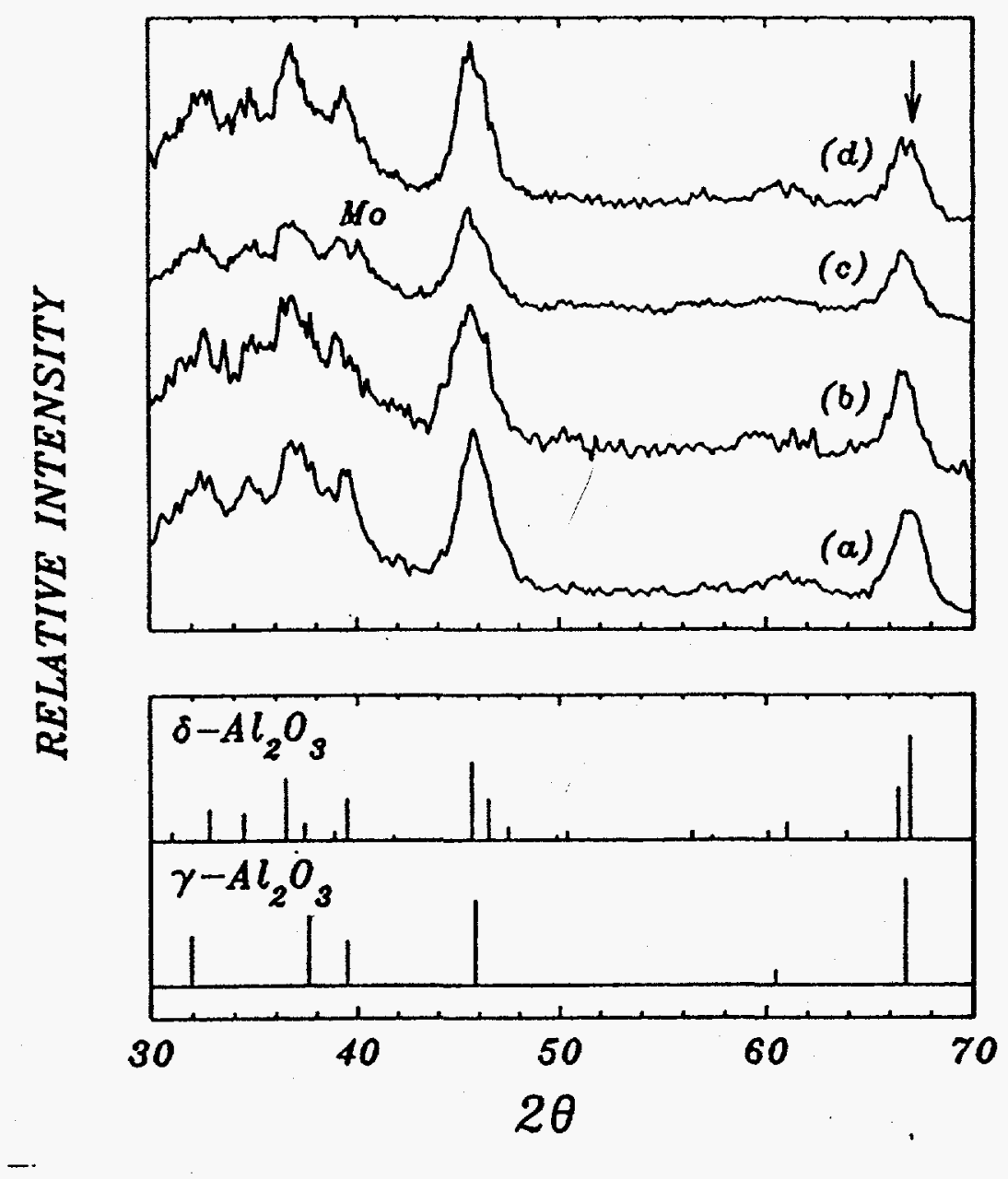

Figure 12. Energy dispersive $\mathrm{x}$-ray powder diffraction patterns of $\mathrm{Al}_{2} \mathrm{O}_{3}$ under the following conditions: (a) nanosize starting powder used in these experiments; (b) starting powder compressed to $1.2 \mathrm{GPa}$ under $\mathrm{LN}_{2}$ and then cycled twice to $3 \mathrm{GPa}$ at $\mathrm{RT}$ to form a compact (the pressure was reduced to ambient between cycles), followed by pressureless heat treatment at $800^{\circ} \mathrm{C}$ for 10 hours in vacuum; (c) same as procedure (b) except that the initial low-temperature compaction was to $1.6 \mathrm{GPa}$ (Mo identifies an extraneous diffraction peak due to the molybdenum gasket used); (d) two-cycle compaction of starting powder to $3 \mathrm{GPa}$ at RT followed by the heat treatment procedure given in (b) and (c). The small arrow located at a peak maximum in (d) identifies a diffraction peak from $\delta-\mathrm{Al}_{2} \mathrm{O}_{3}$. Line diagrams for the $\gamma$ and $\delta$ phases of alumina are also shown. 
number of the particle arrangement. Accordingly, Vickers microhardness was used in this work to compare the quality and efficiency of particle packing.

Figures 13 and 14 summarize our hardness measurements done before and after heat treatment $(\mathrm{HT})$ as a function of the compaction pressure applied at RT and at $\mathrm{LN}_{2}$ temperature, respectively. The HT procedure was the same for all the $\gamma-\mathrm{Al}_{2} \mathrm{O}_{3}$ samples $(800$ ${ }^{\circ} \mathrm{C}$ for 10 hours under $100 \mathrm{~Pa}$ vacuum) so that relative differences are due to the compaction conditions. The general features of both Figures 13 and 14 are similar. The hardness after heat treatment $\left(\mathrm{H}_{2}\right)$ appears to be strongly dependent on the hardness before heat treatment $\left(\mathrm{H}_{b}\right)$. In both cases, the ratio $\mathrm{H}_{a} / \mathrm{H}_{b}$ is roughly constant at about 1.5 . Furthermore, the hardness before heat treatment appears to be directly dependent on the pressure and temperature of compaction.

In Figure 13, for samples compacted at RT for pre-and post-HT, the hardnesses were not as high as the values measured in the cryogenic samples, indicating less dense compacts, even though they were also optically transparent. For $2 \mathrm{GPa}$, the hardness of the RT sample is much lower than the one measured for the $\mathrm{LN}_{2}$ sample at this same initial pressure, in both conditions, before and after heat treatment. Another interesting result shown in Figure 13 is that the hardness reaches a limiting value both for the green body and the heat treated compact and is nearly constant for the compaction pressure between 3 and $4 \mathrm{GPa}$. The $\mathrm{x}$-ray pattern shown in Figure 12(d), represents the $\mathrm{Al}_{2} \mathrm{O}_{3}$ sample pressed at $\mathrm{RT}$ to $3 \mathrm{GPa}$ and then heat treated.

In Figure 14, for the pressure range up to $2 \mathrm{GPa}$, the hardness increases with the applied initial pressure and then decreases abruptly at $3 \mathrm{GPa}$. The highest hardness (approximately 9 $\mathrm{GPa}$ ) was obtained with the initial compaction pressure under $\mathrm{LN}_{2}$ between 2.0 and $2.5 \mathrm{GPa}$. When pressures exceeding this range were used, lower hardnesses were obtained. Note that precompaction under $\mathrm{LN}_{2}$ at $3 \mathrm{GPa}$ followed by ambient compaction at $3 \mathrm{GPa}$ (standard procedure), resulted in a sample hardness comparable to that obtained for RT compaction identified on the hardness axis in Figure 14 as triangles. This result indicates that all beneficial effects of cryogenic compaction are lost when the pressure exceeds roughly 2.5 GPa.

The unexpected decrease in hardness observed for the powder compacted initially at $3 \mathrm{GPa}$ under $\mathrm{LN}_{2}$ may be explained by referring to the equilibrium pressure/temperature phase diagram for nitrogen. Of interest here are the successive phase transformations that occur in $\mathrm{N}_{2}$ with increasing pressure at different temperatures. The temperature of concern here is approximately $77 \mathrm{~K}$, the equilibrium temperature at which the $\gamma-\mathrm{Al}_{2} \mathrm{O}_{3}$ powders were initially compacted. According to this pressure/temperature phase diagram for $\mathrm{N}_{2}$, there are three solid phases, beta, gamma and delta, which exist between ambient pressure and 2.5

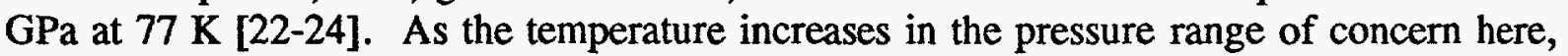
both the gamma and delta phases transform to the beta polymorph which is the form that is in equilibrium with the liquid phase. At RT and $2 \mathrm{GPa}$, only the liquid phase of nitrogen is stable and is, therefore, present with the powder compact. However, if the powder is 


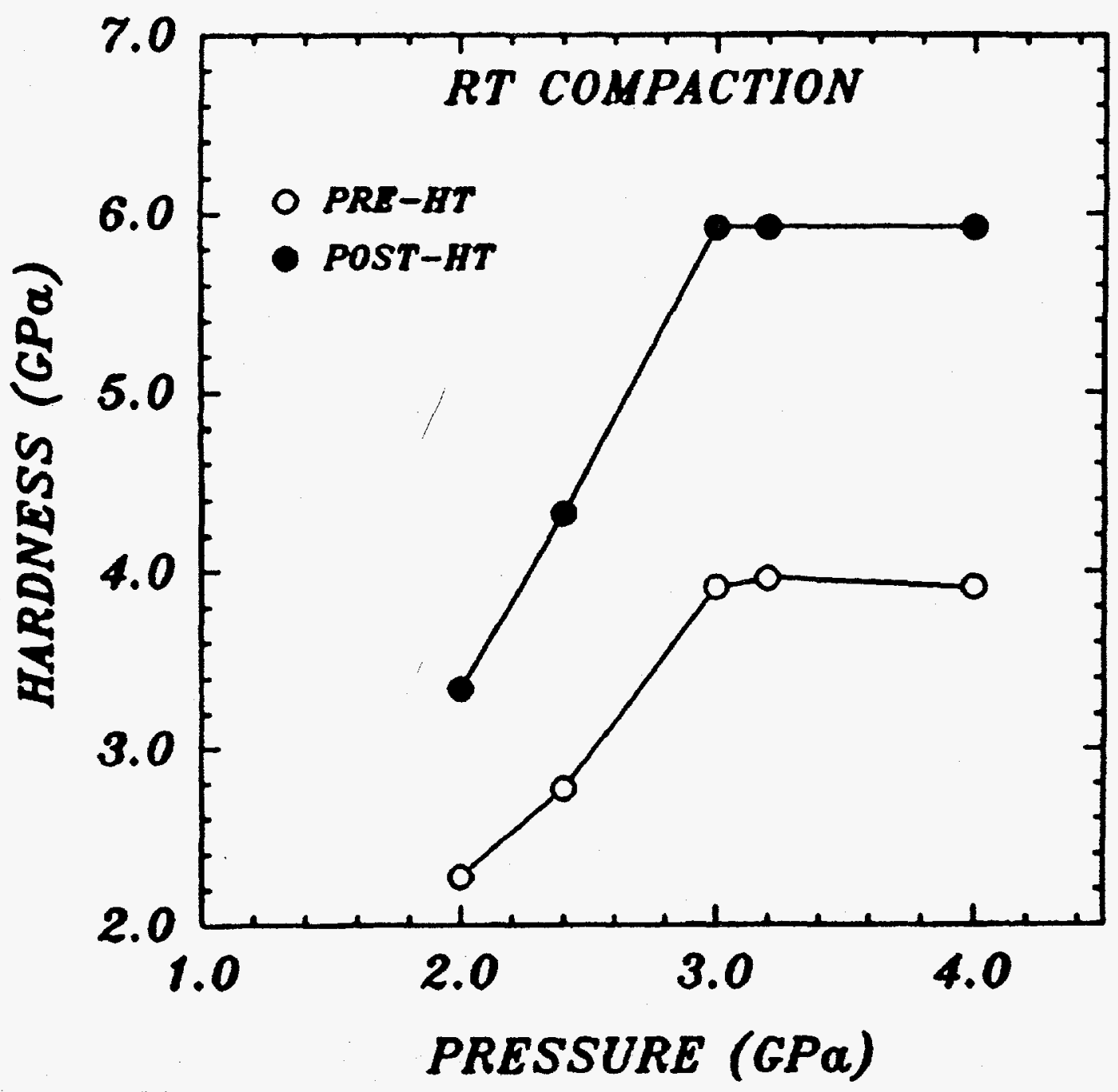

Figure 13. Hardness of transparent $\gamma-\mathrm{Al}_{2} \mathrm{O}_{3}$ compacts as a function of final pressure used to compact the powder at room temperature (RT) before and after heat treatment $(\mathrm{HT})$. 


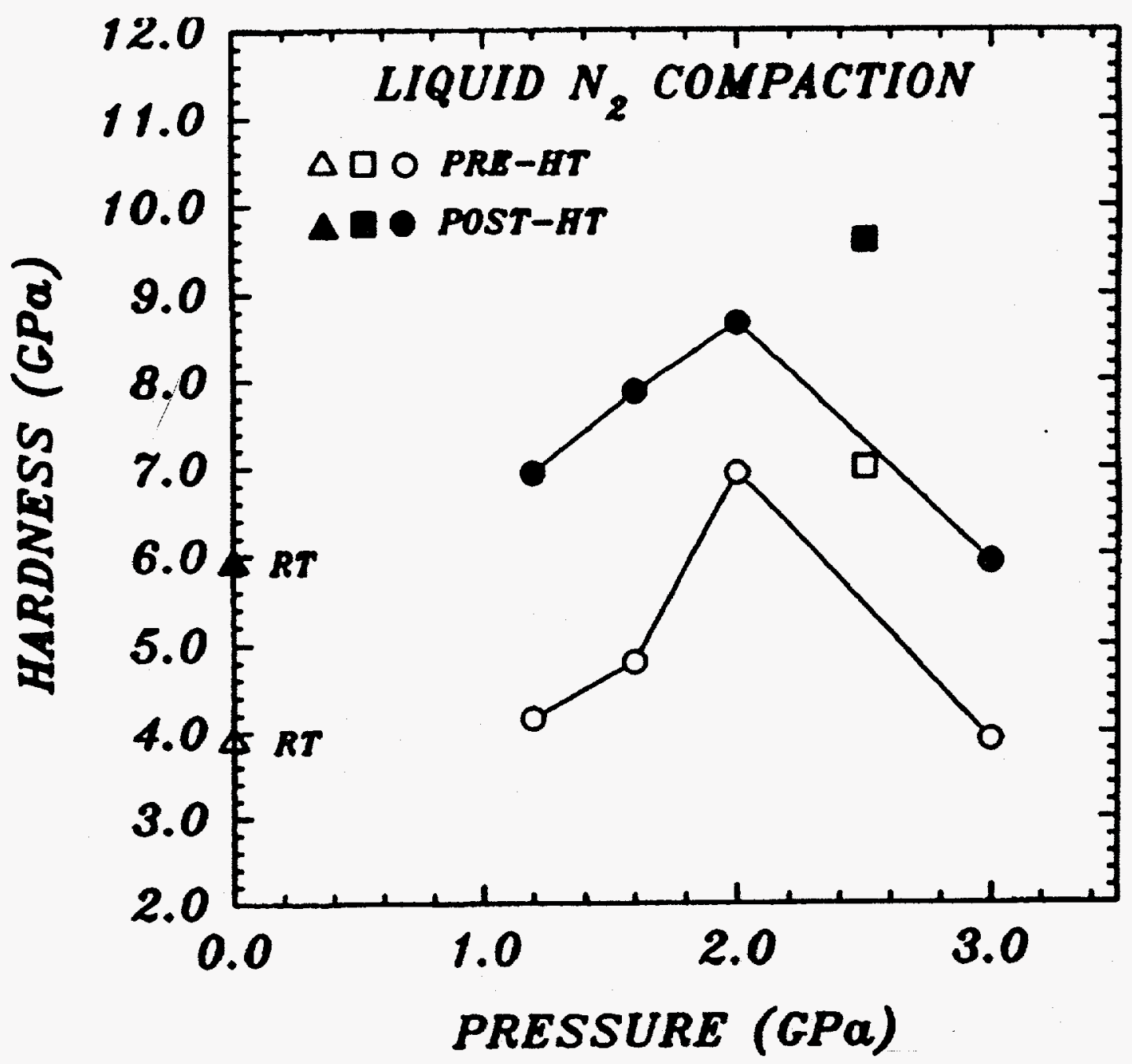

Figure 14. Hardness of transparent $\gamma-\mathrm{Al}_{2} \mathrm{O}_{3}$ compacts as a function of initial compaction pressure used to compress the powder under the liquid nitrogen. The two triangles on the hardness axis designate the measured limiting hardness for green-state and heat treated (HT) compacts pressed to $3.0 \mathrm{GPa}$ at RT (from Figure 2). These values are shown as a reference mark to be compared with the $\mathrm{LN}_{2}$ compaction results. The solid (post-HT) and open (pre-HT) square symbols designate measured hardness values for the sample heated to $100^{\circ} \mathrm{C}$ to avoid the $\beta$ phase of $\mathrm{N}_{2}$ prior to retrieval of the green-state compacts. 
pressed initially to $3 \mathrm{GPa}$ at $77 \mathrm{~K}$, then we are on or very near to the phase boundary between the $\epsilon$ and $\delta$ polymorphs so that either polymorph or a mixture of both solid phases of nitrogen may exist. When the temperature increases to ambient, the alumina sample may be subjected to the effects of several phase transformations, each involving an expansion to a less dense phase. For example, if the $\epsilon$ phase is produced at low temperature by applying a pressure of $3 \mathrm{GPa}$, then, on warming to RT, the $\epsilon$ phase transforms to the delta phase which in turn transforms to the beta phase. At $3 \mathrm{GPa}$ the stable phase at $\mathrm{RT}$ is the $\beta$ phase rather than the liquid as is the case at lower pressures. Thus, the initial dense packing of the alumina powder achieved by compacting to $3 \mathrm{GPa}$ at low temperatures is significantly altered when the temperature is increased to ambient. This is a consequence of the successive expansions that the solid nitrogen, trapped in the interstices of the powder, undergoes when it transforms from the $\epsilon$ phase, to the $\delta$ phase and ultimately to the $\beta$ phase. But this may not be the complete explanation is only part of the explanation. An additional factor must be considered when the solid $\beta$ phase, trapped in the interstices of the alumina powder, melts.

At RT, $\mathrm{LN}_{2}$ transforms to solid $\beta-\mathrm{N}_{2}$ at $2.44 \mathrm{GPa}$. The $\beta$ phase of nitrogen has a molar volume that is about $20 \%$ less than the molar volume of the liquid phase $[23,24]$. When $\beta$ $\mathrm{N}_{2}$ melts on lowering the pressure on the compact at RT, the nitrogen pressure-transmitting medium experiences a $20 \%$ expansion. Since most of the solid nitrogen occupies interstices in the powder compact, the resulting expansion upon melting tends to reopen the structure of the compacted powder, thereby decreasing its bulk density. Thus, the mechanism that permits an efficient particle packing under $\mathrm{LN}_{2}$ must also include the phenomena of phase transformations that the surrounding nitrogen medium experiences. The solid-to-liquid phase transformation, in particular, involves a significant increase in molar volume of the $\mathrm{N}_{2}$. However, the manner in which the phase boundary is traversed to produce the melt is also important because it will have a greater or lesser effect on reopening the compressed structure. If the boundary is traversed by lowering the pressure at constant temperature to produce the liquid, as in the case of the $3 \mathrm{GPa}$ run, then there will be a larger net expansion than when the melt is produced by increasing the temperature at constant pressure. In the former case, while the transition volume is the same, to produce the liquid the pressure has to be lowered and, because of considerable hysteresis in the transition pressure, the final state can be at a substantially lower pressure and thus have a larger sample volume than in the latter case. Thus, the particles are not as well packed when the solid/liquid boundary is crossed by lowering the pressure.

To test our supposition of the roles that the various phases of nitrogen play in the cryogenic compaction process, we fabricated a compact of $\gamma-\mathrm{Al}_{2} \mathrm{O}_{3}$ following a procedure which avoided the presence of the solid $\beta-\mathrm{N}_{2}$ phase at the final compaction pressure of $3.0 \mathrm{GPa}$. An initial cryogenic compaction of $2.5 \mathrm{GPa}$ was used. At the final RT compaction pressure of $3.0 \mathrm{GPa}$, the solid $\beta-\mathrm{N}_{2}$ phase was melted by increasing the temperature to $373 \mathrm{~K}$. At this temperature and pressure only liquid nitrogen exists in the $\gamma-\mathrm{Al}_{2} \mathrm{O}_{3}$ sample. On retrieval of the green body from these conditions, the hardness of the transparent compact was measured to be $7.0 \mathrm{GPa}$ (open square symbol in Figure 14). This value is comparable to the hardness found for the green-state sample processed at 2.0 GPa shown also in Figure 14. The green 
body was then heat treated according to the procedure followed in our earlier experiments. The hardness of the heat treated transparent compact was then measured and found to be 9.6 $\mathrm{GPa}$ (solid square symbol in Figure 14, a value significantly larger than the highest hardness found earlier for the heat treated sample processed at $2.0 \mathrm{GPa}$ and plotted in Figure 14. It is of interest to compare the $\mathrm{H}_{2} / \mathrm{H}_{b}$ ratio for these two compacts with the other values. The lowest ratio is 1.25 , and is for the sample with highest hardness, $8.7 \mathrm{GPa}$, cryogenically compacted at $2.0 \mathrm{GPa}$. It also has the least difference between the hardnesses before and after heat treatment. The ratio, 1.37 , for the sample of concern here, indicates that increased packing efficiency, and, therefore higher hardness, can be achieved by avoiding the presence of the solid $\beta$ phase of nitrogen at the final compaction pressure. Thus, it appears that the liquid state of nitrogen plays an important role in processing nanosize powders of $\gamma-\mathrm{Al}_{2} \mathrm{O}_{3}$ by cryogenic compaction.

Comparison of the results plotted in Figures 13 and 14 revealed that cryogenic compaction produces harder samples at much lower pressures. Since all samples were heat treated under the same conditions, the only difference was in the processing before heat treatment, so the microhardness results must be related to the process of compaction. In the earlier work with $\mathrm{Si}_{3} \mathrm{~N}_{4}$ [6], it was clear that $\mathrm{LN}_{2}$ played an important role as a lubricant in the compaction process. The present results on $\gamma-\mathrm{Al}_{2} \mathrm{O}_{3}$ support this earlier conclusion and have also extended our understanding of the mechanism involved in this cryogenic lubrication process.

\section{TEM Observations and Discussions}

In order to determine whether the observed differences in hardness with processing conditions can be related to microstructural differences, selected samples were examined by TEM. These samples included one green-body compact, pressed under $\mathrm{LN}_{2}(\mathrm{H} \approx 4 \mathrm{GPa})$, and five heat treated samples. Three of the heat treated samples were compacted in $\mathrm{LN}_{2}$ and had hardnesses of approximately 7,8 , and $10 \mathrm{GPa}$. The other two were compacted at ambient temperature and had hardnesses of approximately 4 and $6 \mathrm{GPa}$. With the exception of one sample which was ion milled to electron transparency, TEM sample preparation simply involved fragmenting the compacts and then containing the fragments between two grids with predeposited, holey carbon films. Representative views, illustrating the microstructure of the nanoscale aluminas are shown in Figures 15 and 16(a-c). A typical large-area electron diffraction pattern is included as an insert in Figure 15.

TEM examination of these samples, including the ion-milled sample where there was no fragmentation of the specimen, revealed no significant differences in microstructure. With reference to Figure 15, each sample can be similarly described as a uniform aggregate of nanoscale particles. Selected area electron diffraction gave "spotted" ring patterns, largely consistent with cubic $\gamma-\mathrm{Al}_{2} \mathrm{O}_{3}$. The presence of the tetragonal $\delta-\mathrm{Al}_{2} \mathrm{O}_{3}$ phase, established as a minor constituent by angle dispersive $\mathrm{x}$-ray diffraction, could only be inferred from the excessive widths of individual rings in these patterns. 


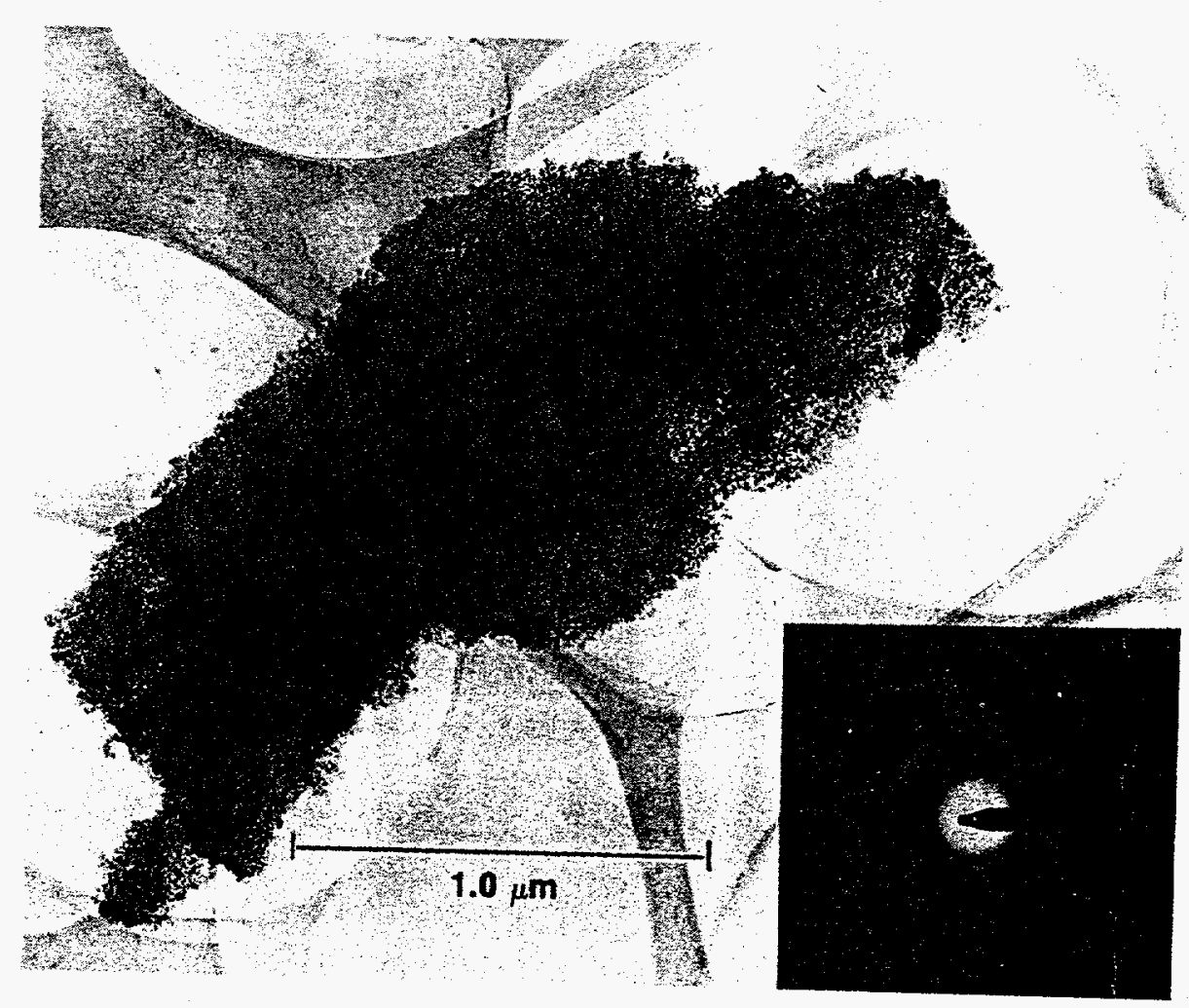

Figure 15. Fragment from compact exhibiting highest hardness (nearly $10 \mathrm{GPa}$ ) attained in this study. Note uniform distribution of particles and interconnected porosity. Electron diffraction (insert) confirmed major particle phase is cubic $\gamma-\mathrm{Al}_{2} \mathrm{O}_{3}$. 
As illustrated in Figure 16, both green-state, 16(a), and heat treated compacts, 16(b\&c), consist of densely packed particles of irregular, but nearly spherical, shape. Particle sizes ranged from approximately 5 to $40 \mathrm{~nm}$, but were most commonly 15 to $20 \mathrm{~nm}$ in size, corresponding to the quoted starting powder size. In all cases, the surfaces of individual particles appear rough due to fine-scale surface asperities. These asperities are evident not only along the edges of particles, but also are evident along the junctions separating adjacent contacting particles. While it was not possible in this study to further characterize the nature of the interparticle junctions, it is important to note that heat treatment did not result in any resolvable changes in these junctions. Finally, all samples, including the ion-milled specimen, appeared to contain a similar, appreciable volume fraction of open or interconnected porosity. Thus, the observed porosity cannot be considered an artifact related to the fracture process used in TEM sample preparation. Distinct differences in porosity could not be reliably established, regardless of differences in processing conditions or measured hardness. Here, however, it should be noted that the void structure only can be defined with reasonable certainty within small regions at the fragment edges, which are about three particle diameters or less in thickness. At best, comparative results from such regions (as in Figure 16 showed that void dimensions never exceeded the average particle size (15 $20 \mathrm{~nm}$ ) and were typically much smaller. Accordingly, it appears that for even the lowest compaction pressures, the level of particle packing achieved can be classified as "random dense packing". The significance of this result is that at such levels of particle packing, the network of interconnected particles becomes load bearing, and stress-induced changes in the structure and density of the compact with increased pressure require relative displacements of the particles, i.e., interparticle sliding. Here, structural changes to the particles, due to either plastic deformation or fracture of the particles, or to heat treatment (as will be discussed), are not considered relevant based on our observations.

The absence of discernable differences in porosity in the TEM results complicates discussion of the effect of compaction pressure on the structure and hardness of these compacts. On the one hand, the observed increase in green-state hardness with increased pressure may be due to small, but significant, increases in particle packing density, defined only by correspondingly small decreases in the sizes of distributed voids. On the other hand, it is also possible that the nature of the stresses acting on the compact changes as dense packing is achieved and results in constrained compression rather than pure hydrostatic compression. Under such conditions, deformation of the compact can occur with little change in density. As deformation involves particle sliding, particle realignment occurs and leads to an increased resistance to further deformation due to particle interlocking. This increased resistance to deformation is ultimately reflected in the measured hardness. In any case, it appears that any change in the structure of particles with increased pressure occurs by particle sliding and the associated particle realignment results in more efficient packing. Moreover, because changes in structure occur by interparticle sliding, they will be governed largely by the elastic/plastic properties of the particles, the nature of forces binding the particles, and the properties of the interparticle or "void space" phase. On this basis, the pronounced effect of compaction under liquid nitrogen appears directly related to the increase 

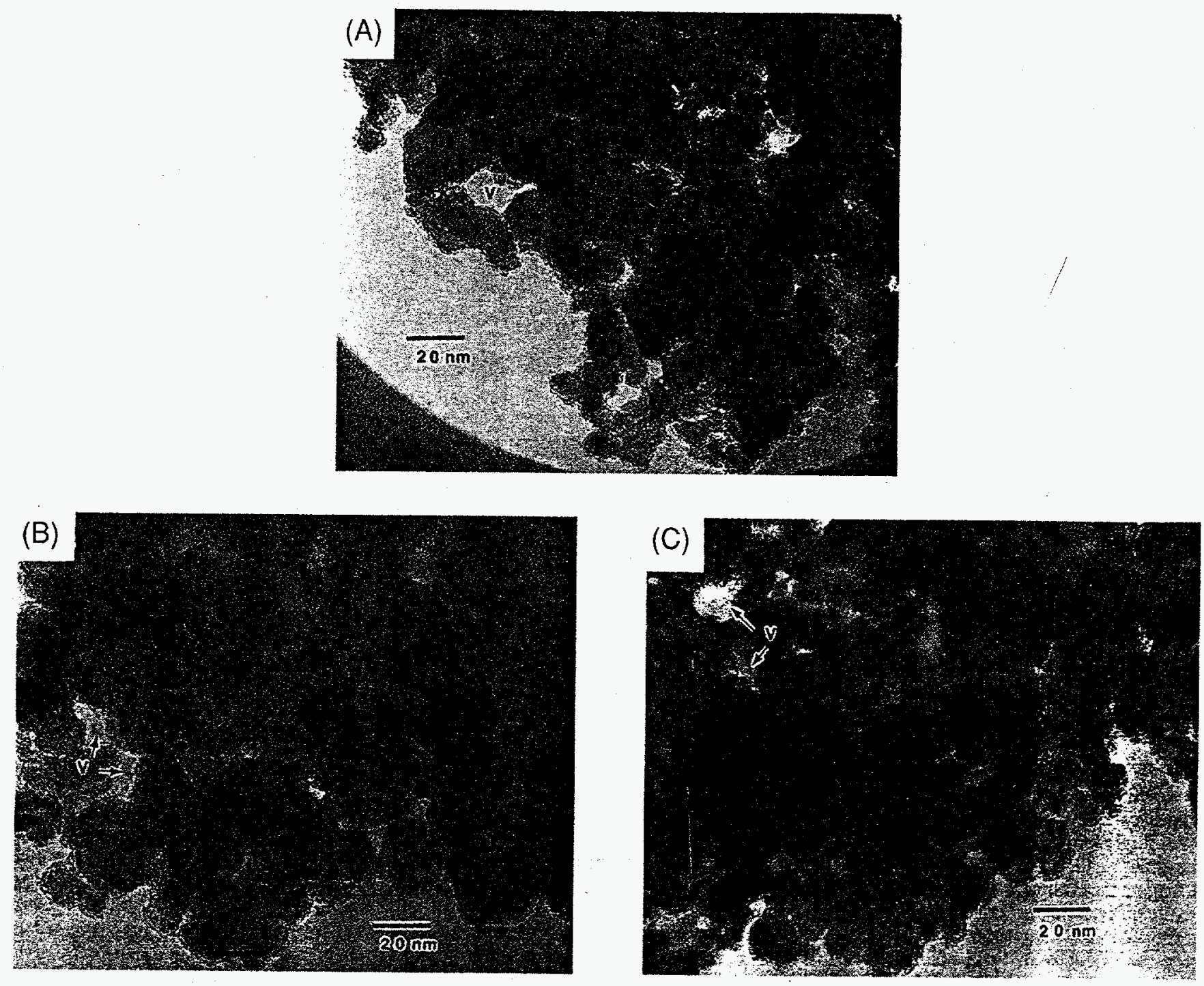

Figure 16. Comparative views of particle microstructure in compacts produced under different conditions and exhibiting different hardness: (a) green-body, $\mathrm{LN}_{2}$ compacted, $\mathrm{H}=4 \mathrm{GPa}$; (b) heat treated, ambient temperature compacted, $\mathrm{H}$ $=4 \mathrm{GPa}$; (c) heat treated, $\mathrm{LN}_{2}$ compacted, $\mathrm{H}=10 \mathrm{GPa}$. Note microstructural similarity and dimensions of large voids $(\mathrm{V})$ relative to particle sizes. 
in elastic modulus of the particles at low temperatures and to the presence of a liquid intergranular phase. As discussed earlier, liquid nitrogen appears to act as an effective lubricant, allowing particle rearrangement to more efficiently and, possibly, denser packed structure at lower pressures.

The effect of heat treatment on hardness cannot be similarly explained in terms of particle rearrangement or densification. In fact, comparative observations on green-state compacts and heat treated compacts, e.g., Figures 16(a) vs. 16(b) and 16(c) revealed no apparent changes in particle size, shape, and surface texture or in the appearance of the particle contact junctions. This leads to the conclusion that only extremely limited transport, whether by intrinsic (bulk), surface, or interfacial diffusion, occurred during the heat treatment at 800 ${ }^{\circ} \mathrm{C}$. Thus, the roughly $50 \%$ increase in hardness universally realized by this heat treatment cannot be attributed to various microstructural changes that normally occur by diffusion during sintering. Instead, we are led to the tentative conclusion that pressureless heat treatment brings about a change in the nature of the forces acting across the contact junctions. Conceivably, heat treatment results in a change from strictly surface force attraction (e.g., Van der Waals) to one that includes interatomic bonding, e.g., covalent interactions. Considering the irregular structure of the junctions between particles, interatomic bonding would appear to be limited to the small junctions formed by surface asperity contact. Admittedly, this conclusion is speculative and can only be resolved when complete characterization of the particles, particularly in the surface regions, is carried out.

\section{Conclusions}

By employing high pressure/low temperature processing procedures, nanosize particles of $\boldsymbol{\gamma}$ alumina can be fabricated into optically transparent, monolithic $\gamma-\mathrm{Al}_{2} \mathrm{O}_{3}$ ceramic with Vickers hardness greater than $9 \mathrm{GPa}$. The processing procedure utilizes pressures up to $3.0 \mathrm{GPa}$ and uses liquid nitrogen lubrication to achieve dense packing of the nanosize particles to form transparent green-state compacts. The transparent green-body is then pressureless heat treated at $800^{\circ} \mathrm{C}$ for 10 hours in vacuum. The physical state of the nitrogen lubricant (solid or liquid depending upon the processing pressures used) plays an important role in achieving random-close-packing of the nanosize particles with the liquid-state most effective for producing densest packing. Energy dispersive $x$-ray powder diffraction patterns revealed that the fabricated compacts consisted mainly of $\gamma$-alumina. TEM observations showed no detectable differences in particle packing density of samples compacted at both $\mathrm{RT}$ and $\mathbf{L N}_{2}$. Moreover, even after heat treatment no changes in microstructure were detected by TEM. Thus, the observed increase in hardness for $\mathrm{LN}_{2}$ compacted samples is probably due to a very small improvement in packing density, facilitated by $\mathrm{LN}_{2}$ lubrication, undetectable by TEM. Finally, the further increase in hardness brought about by heat treatment at $800^{\circ} \mathrm{C}$, which also cannot be attributed to a microstructural change, appears to be brought about by a change or shift in the nature of the binding forces holding the particles together. Contact junction strengthening may possibly occur by a change from strictly surface forces (Van der Waals) to one that includes some degree of interatomic bonding. As far as we are able to determine, this is the first time that transparent bulk $\gamma-\mathrm{Al}_{2} \mathrm{O}_{3}$ ceramic bodies have been 
fabricated from nanosize particles. At this point, all work on $\gamma-\mathrm{Al}_{2} \mathrm{O}_{3}$ has been limited to diamond cell compaction. To further explore the densification processes in $\gamma-\mathrm{Al}_{2} \mathrm{O}_{3}$ in detail, we used the piston-cylinder device describe earlier. 


\section{Chapter IV}

\section{$\gamma-\mathrm{Al}_{2} \mathrm{O}_{3}$ PROCESSING IN THE PISTON-CYLINDER DEVICE}

\section{$\boldsymbol{\gamma}-\mathrm{Al}_{2} \mathrm{O}_{3}$ Powder Processing}

Sintering of alumina at relatively low temperatures, 1000 -to- $1150{ }^{\circ} \mathrm{C}$, has been reported in the literature [25-27]. In many cases, a solid state phase transformation has been exploited to aid sintering at these temperatures to produce high density polycrystalline alumina with submicron grain-size. For example, Messing et. al. [26] have studied the effects of seeding transitional oxides of alumina (boehmite) with $\alpha$ alumina to lower the sintering temperature and increase the kinetics of the transformation to $\alpha \mathrm{Al}_{2} \mathrm{O}_{3}$. Sol-gel techniques were employed in order to obtain homogeneous mixtures of the transitional oxides and the $\alpha \mathrm{Al}_{2} \mathrm{O}_{3}$ seeds. Sol-gel methods, however, suffer from sever cracking during the drying or "curing" period. Yeh and Sacks [27] made slurries of fine grain $\alpha \mathrm{Al}_{2} \mathrm{O}_{3}$ by conventional suspension techniques for alumina which were used to slip-cast samples to relatively high bulk densities (69\%). The samples, sintered at $1150{ }^{\circ} \mathrm{C}$ in air, had relative densities $>99.5 \%$ and an average grain size of $0.25 \mu \mathrm{m}$. In this case, a phase transformation was not used, yet dense samples with submicron grain size were obtained. It appears that the phase transition is not necessary for this result. In this work it is important to have a uniform density in the green body to reduce internal stresses that occur during inhomogeneous densification. Making homogeneous suspensions (mixtures) with submicron size powders, however, is very difficult and is particularly so when nanosize particles $(\approx 20 \mathrm{~nm})$ are used. High pressure compaction of nanosize powder in the present work, therefore, was thought of as a means to achieve high density green compacts.

In Chapter I, we showed that by increasing the compacting pressure, an increase in greenbody bulk density can be achieved. However, we have yet to demonstrate that the gain in green-body density has a significant effect on the densification process. To investigate this problem further, we studied nanosize $\gamma$ alumina as a model material. While the thermodynamically stable phase of alumina, $\gamma \mathrm{Al}_{2} \mathrm{O}_{3}$, is obviously the better choice, we were unable to obtain nanosize particles of the $\alpha$ phase commercially.

$\gamma-\mathrm{Al}_{2} \mathrm{O}_{3}$ transforms to $\alpha-\mathrm{Al}_{2} \mathrm{O}_{3}$ at $\approx 1150^{\circ} \mathrm{C}$. The kinetics of the transformation has been studied by Dynys and Halloran [28] who reported that the rate of transition is strongly dependant on the mechanical pretreatment of the powder. They showed that mechanical milling of the powder can reduce the time for complete transformation at $1150{ }^{\circ} \mathrm{C}$. In addition, the authors reported that compaction under different loads changed the transformation kinetics. From their work, it appears that both compaction and milling involve the creation of large contact stresses which can cause an increase in the internal energy of the material. For example, lattice defects can be created, and these can act as heterogeneous nucleation sites for the transformation. This variability in the transformation kinetics complicates the interpretation and understanding of our compaction and sintering 
results obtained in the present study. Nevertheless, the study of $\gamma-\mathrm{Al}_{2} \mathrm{O}_{3}$ gives us a closer look at the effects of high pressure compaction and green-body density on the sintering of nanosize powders.

\section{Experimental}

Green compacts of $\gamma-\mathrm{Al}_{2} \mathrm{O}_{3}$ (Dugussa Corporation) were made using the Instron Press described earlier. Two sets of green compacts were produced at room temperature with no added lubricant. One set was pressed to $1.0 \mathrm{GPa}$, the other to $2.5 \mathrm{GPa}$. The displacement rate of the piston during loading and unloading sequences was $0.25 \mathrm{~mm} / \mathrm{min}$. Each sample was $\approx 10 \mathrm{mg}$ in weight and produced a $3 \mathrm{~mm}$ diameter compact disk $\approx 1 \mathrm{~mm}$ in thickness. After pressing, samples were carefully weighed and dimensions measured with an electronic caliper in order to calculate their bulk density.

Sintering experiments were conducted in an alumina tube furnace under the rough vacuum of a mechanical pump. Samples from both compaction pressures were sintered at 1000, 1100, 1200 , and $1300{ }^{\circ} \mathrm{C}$ for $5 \mathrm{hr}$, employing heating and cooling rates of $300^{\circ} / \mathrm{hr}$. After the heat treatments, the weight and volume of the samples were remeasured to determine the extent of densification.

To further understand the densification process, SEM and TEM were used to characterize the samples. Sample preparation for SEM required polishing with 6,3 and $1 / 4$ micron diamond, and 0.025 colloidal silica. TEM preparation required standard ceramographic techniques such as grinding, polishing, dimpling and argon ion milling. In addition to the microscopy work, $\mathrm{x}$-ray diffraction was used to identify phase composition.

\section{Results and Discussion}

As previously mentioned, the bulk density of the samples was determined by weighing the samples and calculating the volume from the measurement of physical dimensions. In this calculation, it is assumed that the samples are perfect right circular cylinders. However, this is not the case in many instances. For example, Figure 17 shows a micrograph of the top surface of a sample pressed at $2.5 \mathrm{GPa}$ and sintered at $1300^{\circ} \mathrm{C}$. It is evident that pieces from the top surface of the sample are missing. The shape of the fracture surface suggest delamination due to density gradients within the sample. This is typical of uniaxially pressed samples, and it is also expected to occur to a greater extent during high pressure compaction. Density gradients result from friction between the powder and the die wall which inhibits rearrangement. Eliminating density gradients in uniaxially pressed samples is practically impossible. For these reasons, it is important to study the density results carefully. In many cases, the calculated density underestimates the actual density of the samples. However, we have been very careful to show the statistical significance of our results when necessary. In addition, the example in Figure 17 is an extreme case, and not all samples showed the same behavior. 


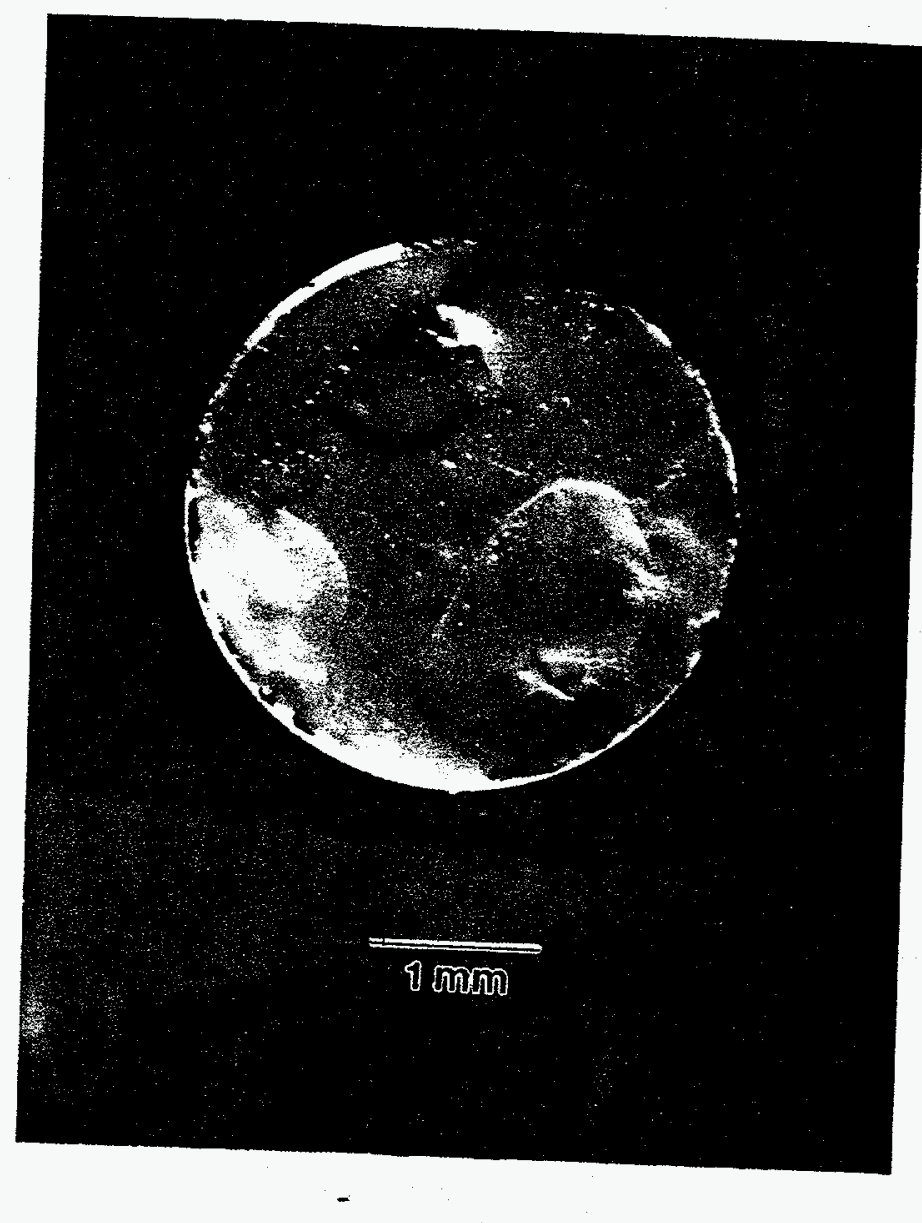

Figure 17. $\quad \gamma-\mathrm{Al}_{2} \mathrm{O}_{3} 2.5 \mathrm{GPa}$ compacted sample sintered at $1300^{\circ} \mathrm{C}$ for $5 \mathrm{hr}$. Top surface shows evidence of significant delamination occurring during sintering. 
Figure 18 shows a plot of green-body densities for samples pressed at $1.0 \mathrm{GPa}$ and $2.5 \mathrm{GPa}$. The average density is $2.00 \mathrm{~g} / \mathrm{cm}^{3}$ and $2.37 \mathrm{~g} / \mathrm{cm}^{3}$, respectively, which correspond to $54 \%$ and $65 \%$ of theoretical density $\left(3.67 \mathrm{~g} / \mathrm{cm}^{3}\right)$. Although the graph shows significant scatter in the data points, the two densities are statistically different within a $95 \%$ confidence interval.

Figure 19 shows the results of the sintering experiments for the samples pressed to $1.0 \mathrm{GPa}$. The plot shows a comparison of density of the green and sintered samples. It is apparent that the density increases with sintering temperature. However, samples sintered at $1000{ }^{\circ} \mathrm{C}$ do not show any measurable densification. Figure 20 shows similar systematic behavior in the data for $2.5 \mathrm{GPa}$ pressed samples. The average density at each sintering temperature is summarized in Figure 21 . The density increases monotonically for both compaction pressures and approach each other at a density of $\approx 3.3 \mathrm{~g} / \mathrm{cm}^{3}$, or $83 \%$ of the theoretical density of $\alpha \mathrm{Al}_{2} \mathrm{O}_{3}$. It is also of interest to note that the $2.5 \mathrm{GPa}$ compacted sample sintered at $1000{ }^{\circ} \mathrm{C}$ showed a slight increase in density which was not observed in the $1.0 \mathrm{GPa}$ samples. At this stage of our study, it was critical to determine the microstructure and phase fraction of $\alpha$ and $\gamma$ phase to gain further understanding of the densification process.

\section{Microstructure}

Figure 22 shows a TEM micrograph of a green-body compacted at $2.5 \mathrm{GPa}$. Both x-ray diffraction and electron diffraction results on these samples confirmed that they are predominantly $\gamma-\mathrm{Al}_{2} \mathrm{O}_{3}$. As seen on Figure 22 , the $\gamma$ particles are equiaxed with an average equivalent spherical diameter of $\approx 20 \mathrm{~nm}$. More generally, observations on 1.0 and 2.5 GPa compacts indicate a random dense packed particle structure with uniform interconnected porosity. For both compaction pressures, the pore dimensions were less than the particle size. As a consequence, the $16 \%$ difference in packing density between the samples compacted at 1.0 and $2.5 \mathrm{GPa}$ was not resolved in TEM.

The samples sintered at $1000{ }^{\circ} \mathrm{C}$ have a completely different microstructure. Figure $23(\mathrm{a}-\mathrm{b})$ shows, in comparison, TEM micrographs of the samples sintered at $1000^{\circ} \mathrm{C}$ for the 1.0 and $2.5 \mathrm{GPa}$ compaction pressures. The sample compacted at $1.0 \mathrm{GPa}$ consists of a mixture of equiaxed particles of $\gamma$ phase and isolated clusters of predominantly $\alpha$ phase. Even at this temperature, necking between $\gamma$ particles, indicative of $\gamma$ phase sintering, was not resolved in TEM. The isolated $\alpha$ clusters grow in a wormy or spongy structure with continuous porosity. X-ray diffraction results corroborate that both the $\gamma$ and $\alpha$ phases of $\mathrm{Al}_{2} \mathrm{O}_{3}$ are present in the $1.0 \mathrm{GPa}$ pressed samples. In contrast, the samples pressed at $2.5 \mathrm{GPa}$ are made up of all $\alpha$ phase. The microstructure is spongy or wormy with continuous porosity similar to the isolated $\alpha$ clusters in the $1.0 \mathrm{GPa}$ samples. Again, $\mathrm{x}$-ray diffraction confirmed that the $2.5 \mathrm{GPa}$ samples contained $\alpha-\mathrm{Al}_{2} \mathrm{O}_{3}$, exclusively.

It should be noted that the spongy $\alpha$ phase structure actually consists of interconnected individual grains, ranging in size from about $100 \mathrm{~nm}$ to nearly $1 \mu \mathrm{m}$. As illustrated in Figure $23 \mathrm{~b}$, where regions of dark contrast define areas of common orientation, the grains 


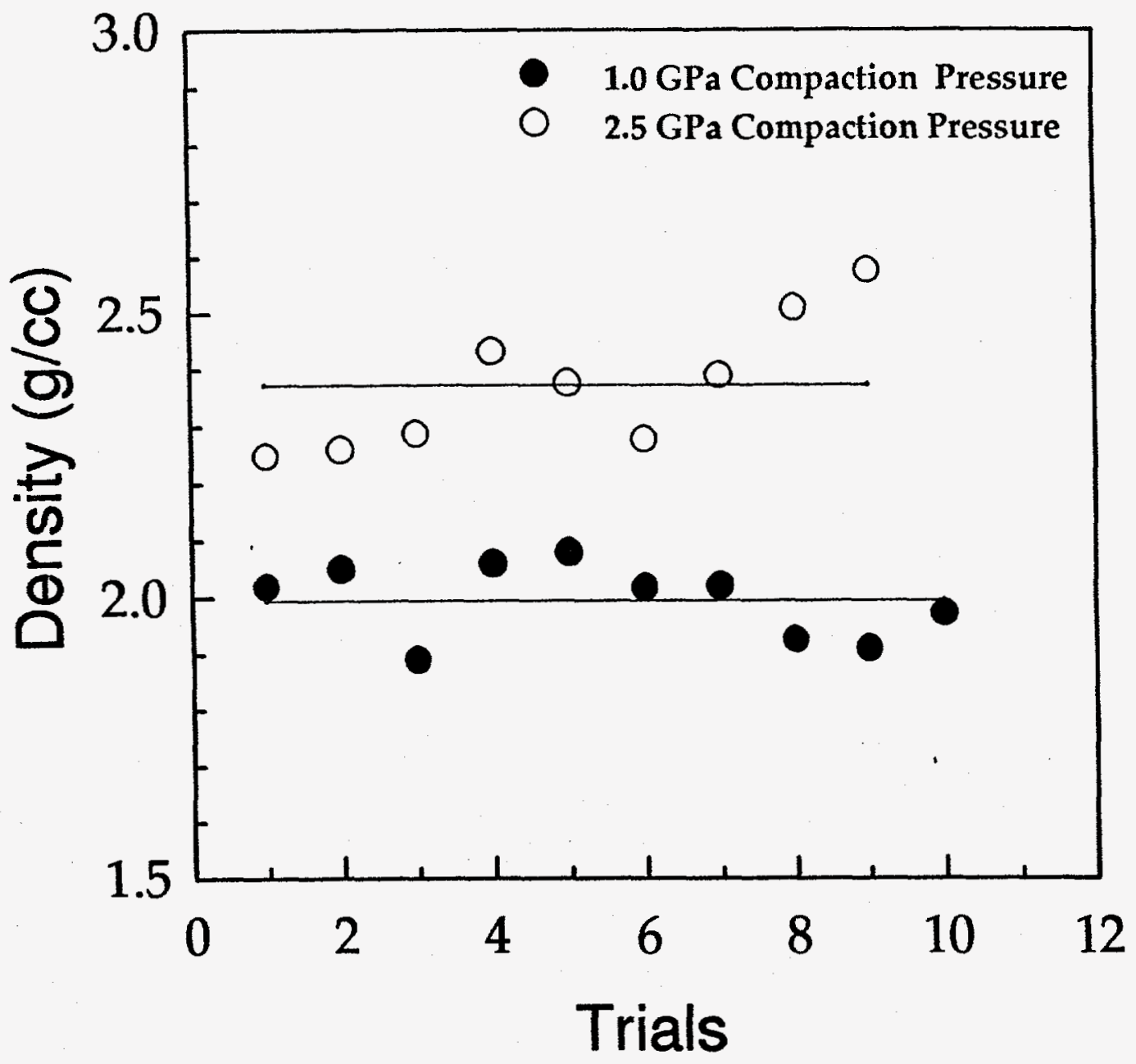

Figure 18. Plot shows the scattering of a representative number of density measurements for $\gamma$-alumina samples pressed at 1 and $2.5 \mathrm{GPa}$. The 1 and $2.5 \mathrm{GPa}$ compacted had average densities of 2 and $2.37 \mathrm{gm} / \mathrm{cm}^{3}$, respectively. 


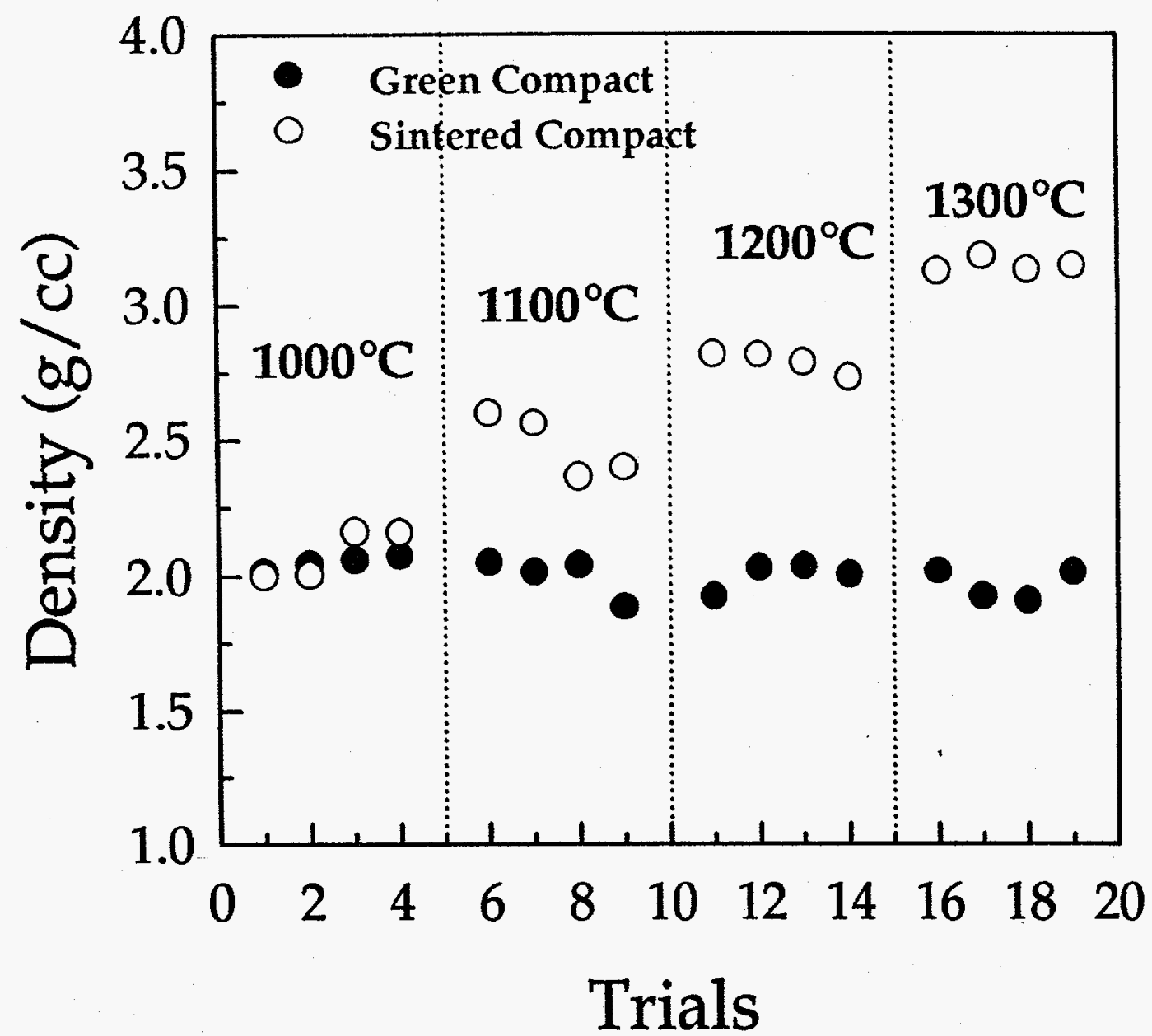

Figure 19. Plot shows the density of $1 \mathrm{GPa}$ compacted $\gamma$-alumina samples sintered at $1000,1100,1200$, and $1300^{\circ} \mathrm{C}$ in comparison to the density of the green bodies. 


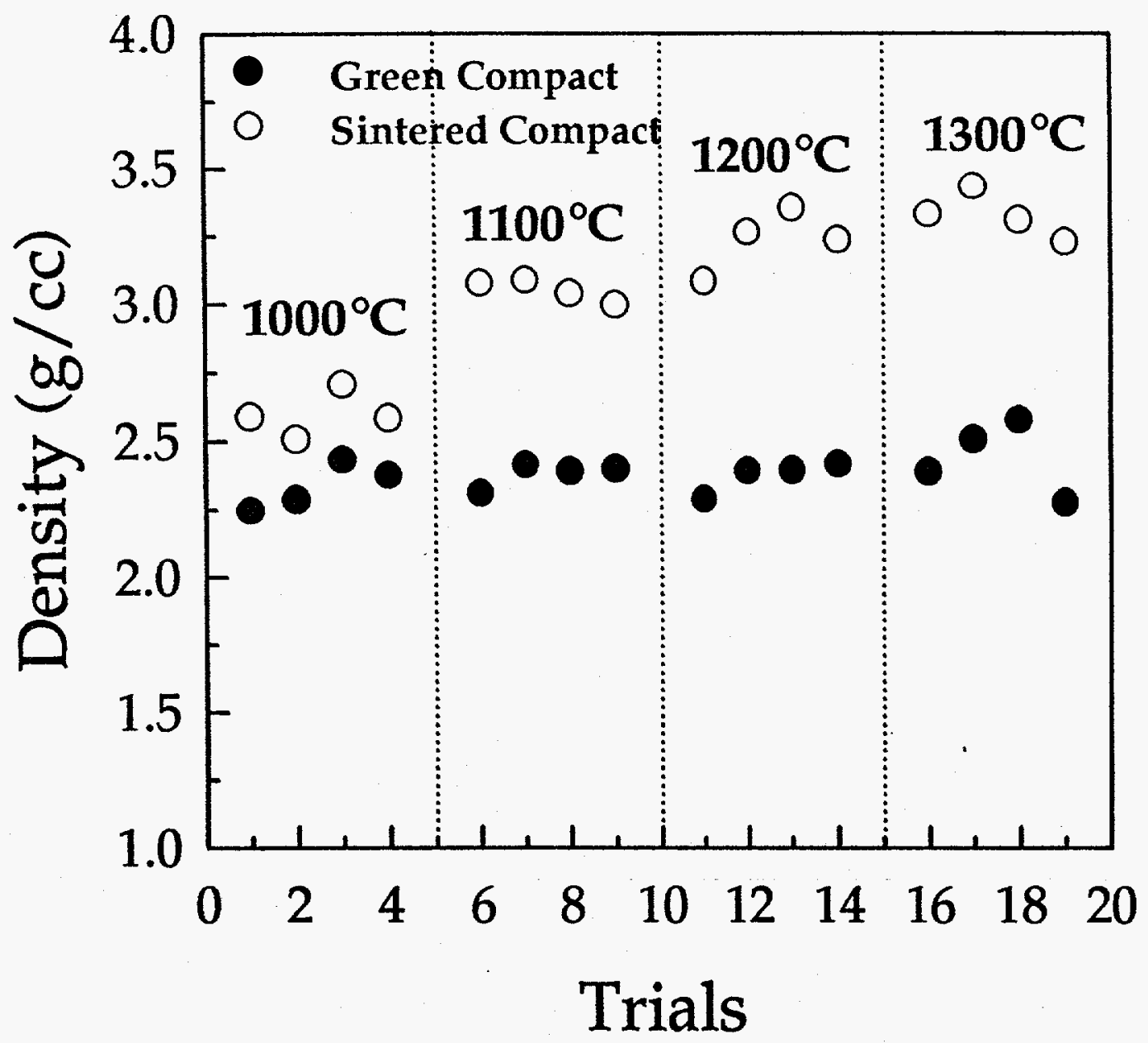

Figure 20. Plot shows the density of $2.5 \mathrm{GPa}$ compacted $\gamma$-alumina samples sintered at $1000,1100,1200$, and $1300^{\circ} \mathrm{C}$ in comparison to the density of the green bodies. 


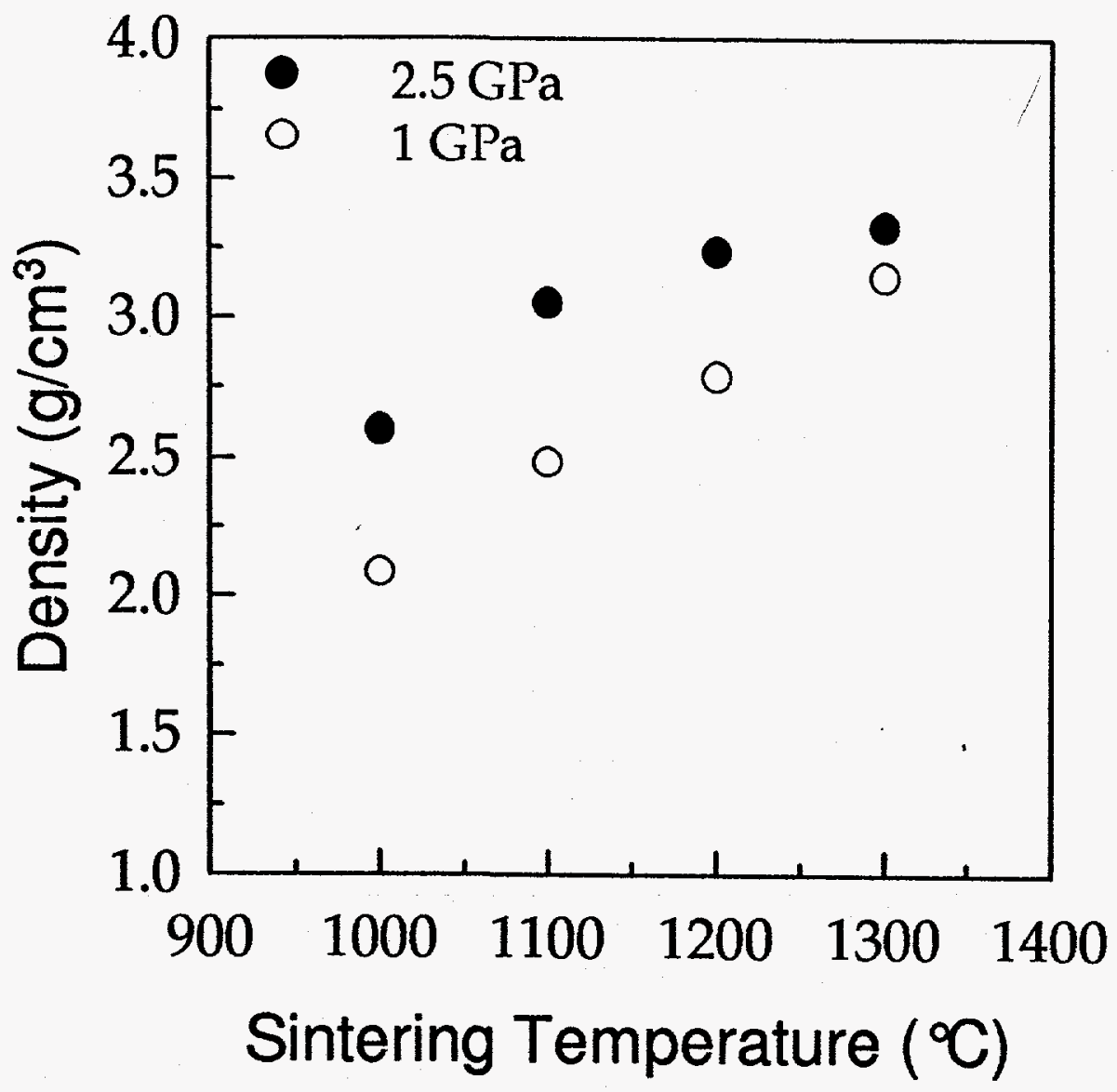

Figure 21. Plot shows monotonic increase in density with sintering temperature for sample $\gamma$-alumina compacted at $1 \mathrm{GPa}$ and $2.5 \mathrm{GPa}$. 


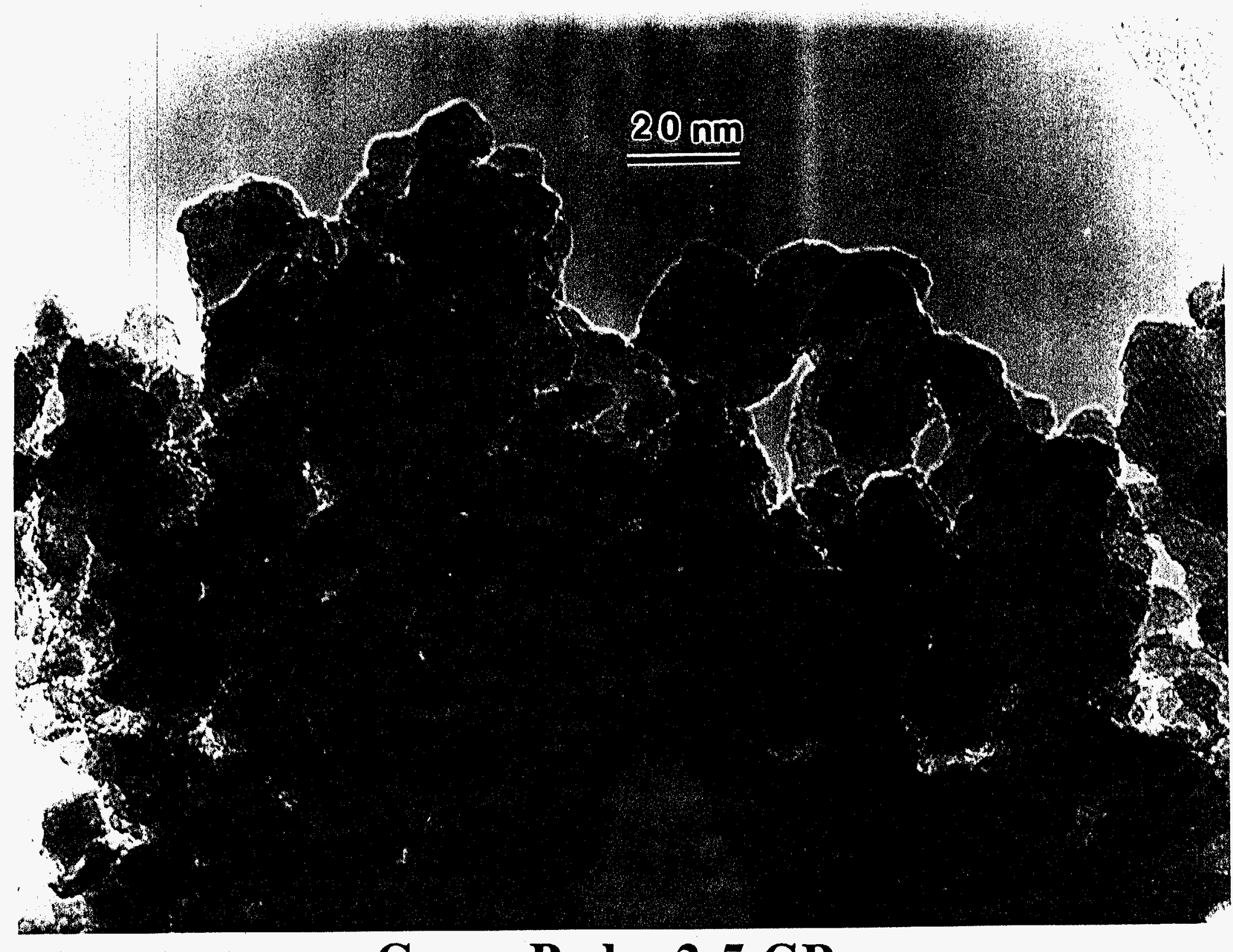

\section{Green Body; 2.5 GPa}

Figure 22. TEM brightfield image shows the microstructure of a green body of $\gamma-\mathrm{Al}_{2} \mathrm{O}_{3}$ compacted at $2.5 \mathrm{GPa}$. 


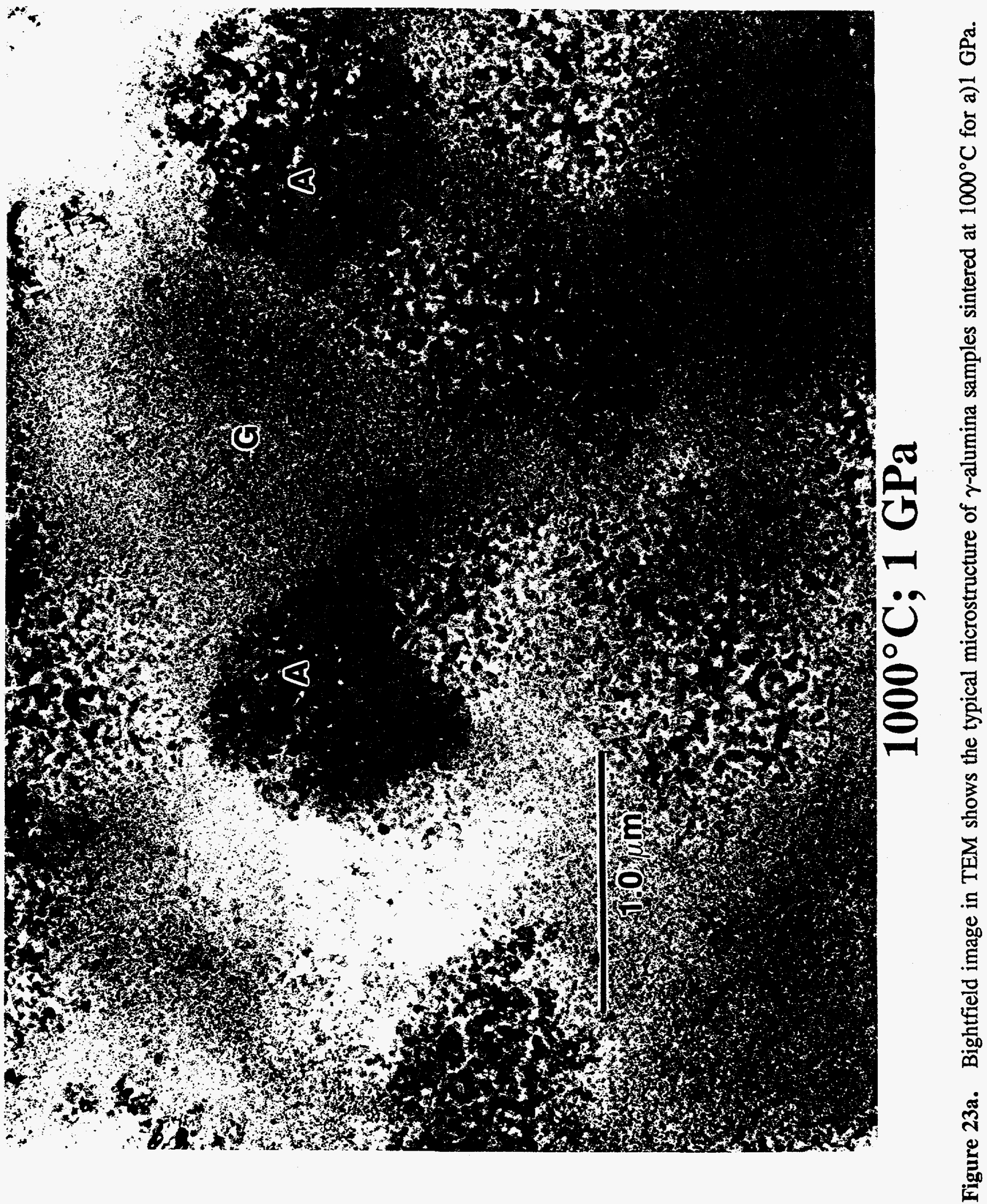




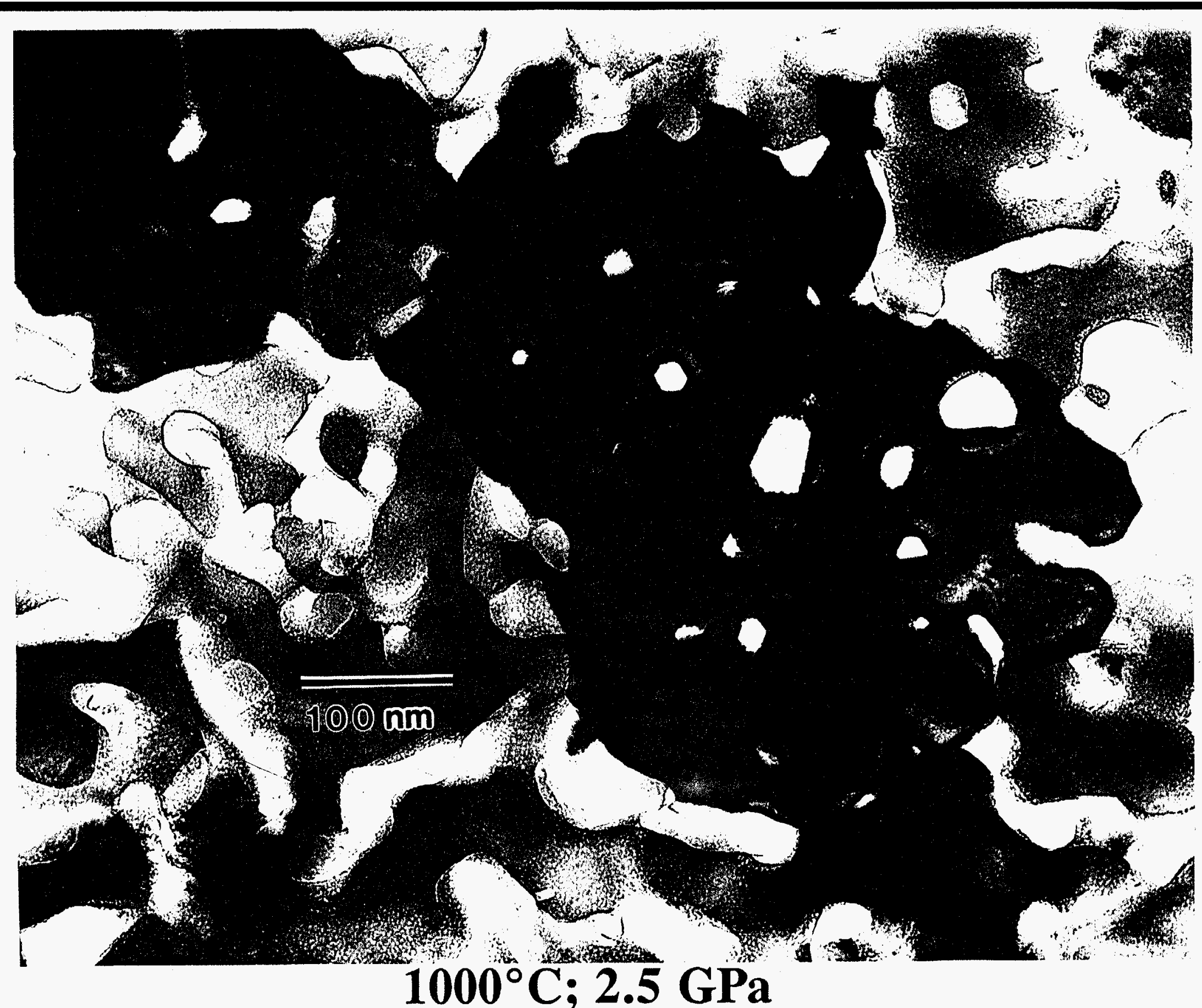

Figure 23b. Bightfield image in TEM shows the typical microstructure of $\gamma$-alumina samples sintered at $1000^{\circ} \mathrm{C}$ for b) $2.5 \mathrm{GPa}$. 
have a complex morphology, and the boundaries connecting adjacent grains are typically 50 to $100 \mathrm{~nm}$ in length.

Surface area and pore size distribution analysis (BET) was done on a green and $1000{ }^{\circ} \mathrm{C}$ sintered body (2.5 GPa compacted sample). The average pore size for the green-body was 5 $\mathrm{nm}$, consistent with a packing coordination number of 4 . The sintered sample at $1000{ }^{\circ} \mathrm{C}$, however, exhibited an average pore size of $42 \mathrm{~nm}$ and could be resolved in the TEM micrograph shown in Figure 23b. However, the porosity determined by TEM ranges in size from 100 to $300 \mathrm{~nm}$ which is an order of magnitude larger than the pore size measured in the BET. The average surface area also decreased during sintering suggesting neck formation and some densification in agreement with the observed microstructure.

As mentioned earlier, the $2.5 \mathrm{GPa}$ samples showed some densification at $1000^{\circ} \mathrm{C}$, while the $1.0 \mathrm{GPa}$ samples did not. It is evident that the samples have different grain morphologies which contribute to the differences in densities. Another reason for this difference in density may be because the theoretical density of $\alpha-\mathrm{Al}_{2} \mathrm{O}_{3}\left(3.987 \mathrm{~g} / \mathrm{cm}^{3}\right)$ is larger than the density of $\gamma-\mathrm{Al}_{2} \mathrm{O}_{3}\left(3.67 \mathrm{~g} / \mathrm{cm}^{3}\right)$. The samples pressed to $2.5 \mathrm{GPa}$ experienced significant shrinkage during the transformation from $\gamma$-to- $\alpha$ phase (given the same mass), and, as a result, yielded higher bulk densities. The amount of $\alpha$ phase produced in the $1.0 \mathrm{GPa}$ samples, however, is so little that the change in volume associated with the transition is insignificant and cannot be measured by our technique.

We studied microstructural changes in the samples sintered at $1300{ }^{\circ} \mathrm{C}$. The density of these samples did not exceed $83 \%$ of theoretical. It was determined by $\mathrm{x}$-ray diffraction that both 1.0 and $2.5 \mathrm{GPa}$ compacted samples were $100 \% \alpha-\mathrm{Al}_{2} \mathrm{O}_{3}$. The $1.0 \mathrm{GPa}$ samples are made up of a combination of the wormy grain structure and equiaxed micron sized grains of alumina (Figure 24). Significant porosity is visible, and necking between grains is evident. In contrast, the $2.5 \mathrm{GPa}$ compact exhibited only an equiaxed grain morphology (Figure 25). No evidence for the spongy $\alpha$ phase structure was observed in these samples. Figure 26 shows in comparison SEM backscattered images of the 1.0 and $2.5 \mathrm{GPa}$ compacted samples, which again clearly shows the two different grain morphologies.

As originally anticipated, the processing of alumina from $\gamma$ phase particle compacts is strongly influenced by the $\gamma$-to- $\alpha$ transformation. Our results confirm the earlier observations of Dynys and Halloran [25] that agglomerates of nanosize $\gamma$ particles do not simply transform into agglomerates of similarly sized $\alpha$ particles. Instead, transformation appears to involve heterogeneous nucleation followed by a period of rapid, almost explosive, growth which may involve close-to-melting conditions. This growth involves the rearrangement of from hundreds to many thousands of $20 \mathrm{~nm} \gamma$ particles into single crystal grains of $\alpha$ phase, ranging in size from 0.1 to 1 micron. With this consolidation of the solid phase, there is a corresponding rearrangement of porosity into pores of micron dimensions. This large scale change in microstructure, brought about by the transformation, clearly complicates the discussion of the effect of initial compaction pressure on the densification that occurs during heat treatment. Nevertheless, the results obtained so far do indicate a 


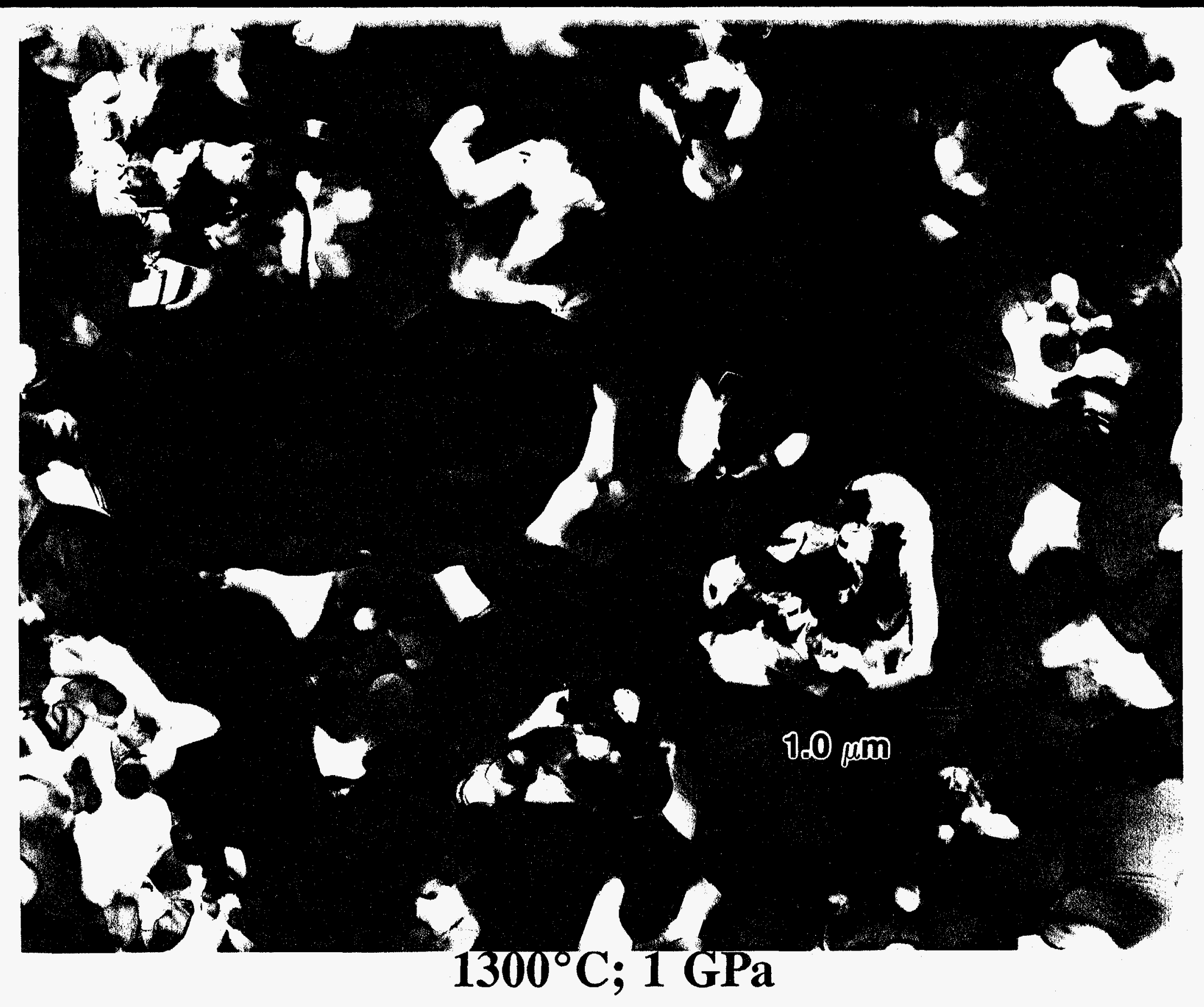

Figure 24. TEM brightfield image of $1 \mathrm{GPa}$ compacted $\gamma$-alumina sample sintered at $1300^{\circ} \mathrm{C}$. 


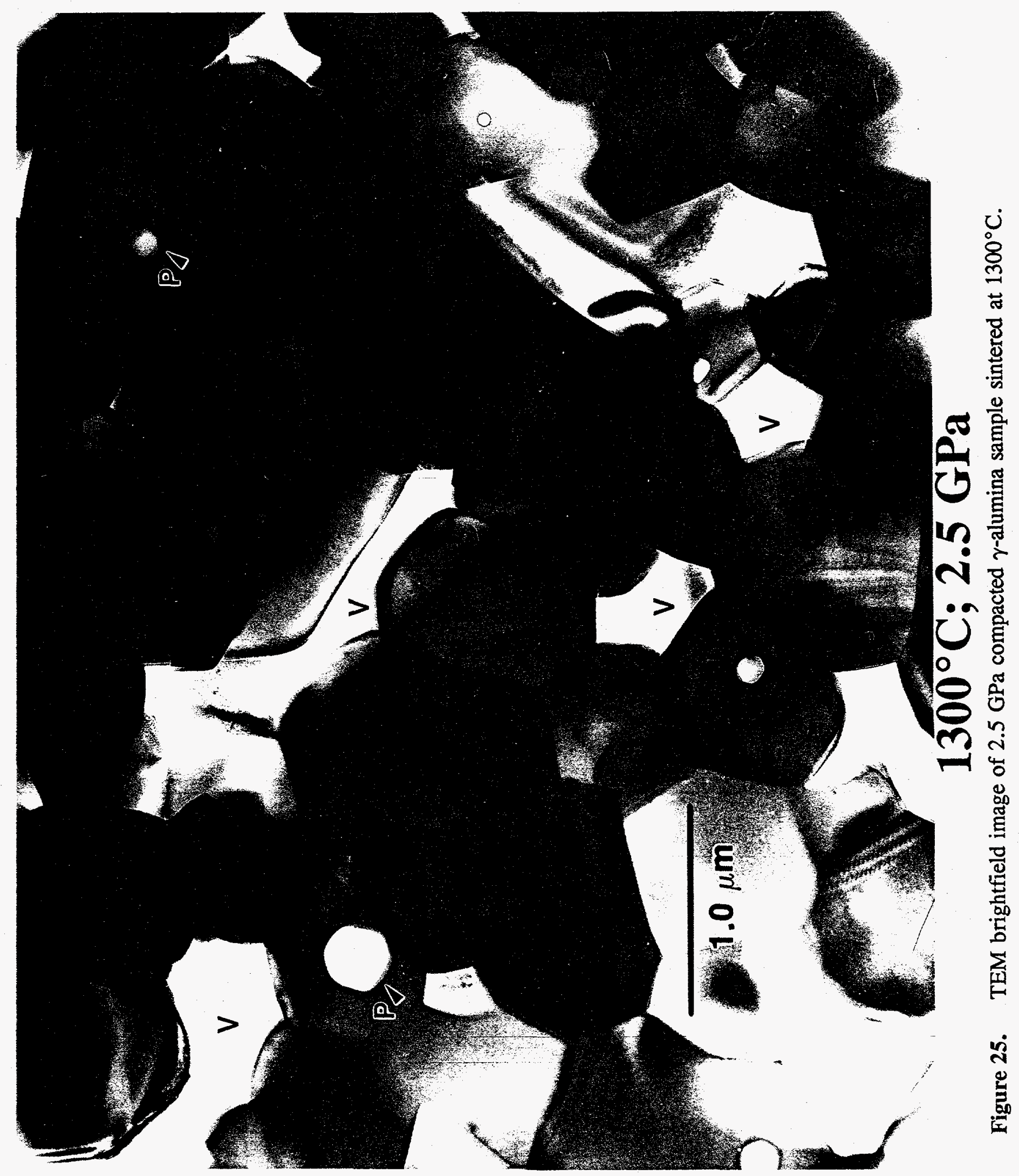



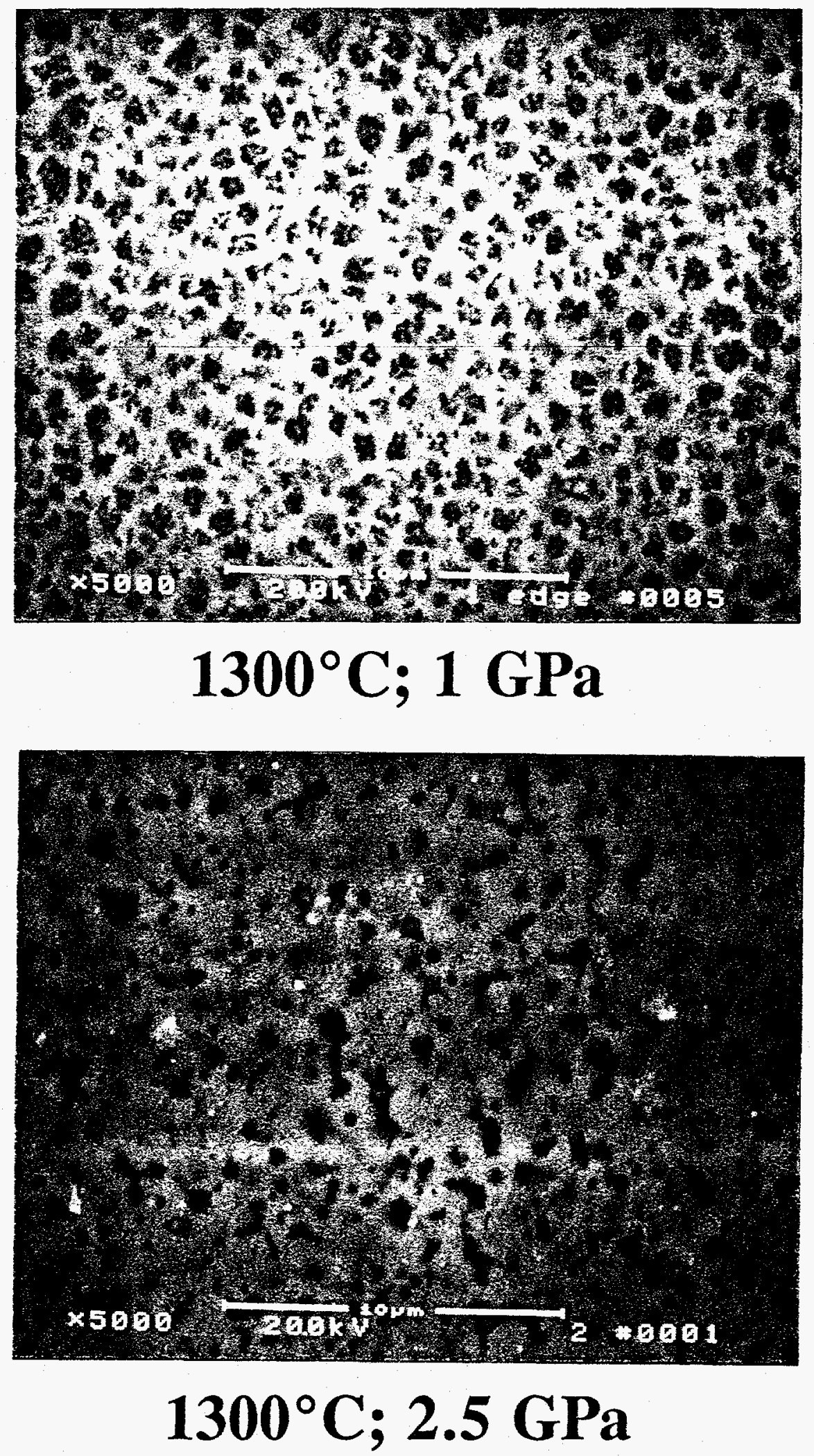

Figure 26. SEM micrograph shows in comparison the microstructure of 1 and 2.5 GPa compacted samples $\gamma$-alumina sintered at $1300^{\circ} \mathrm{C}$. 
two-fold effect of compaction pressure on the sintering of alumina from nanosize $\gamma$ particles.

First, increased compaction pressure enhances the $\gamma$-to- $\alpha$ transition, reducing the transition temperature or, alternatively, increasing the nucleation rate at temperatures from 1000 to $1150^{\circ} \mathrm{C}$. Evidence for this is based on the observations that for compacts pressed to 2.5 $\mathrm{GPa}$, complete conversion to $\alpha$-phase occurs within $5 \mathrm{~h}$ at $1000^{\circ} \mathrm{C}$, while those pressed to $1.0 \mathrm{GPa}$ showed less than $50 \%$ conversion to $\alpha$-phase. These compacts were completely converted to $\alpha$-phase at $1100{ }^{\circ} \mathrm{C}$.

Second, increased compaction pressure leads to increased densification upon heat treatment at still higher temperatures. Our present results show a significant difference in the microstructure, density and hardness of 1.0 and $2.5 \mathrm{GPa}$ compacts sintered at $1300{ }^{\circ} \mathrm{C}$. For $2.5 \mathrm{GPa}$ compacts, this heat treatment results in equilibrium or facetted $\alpha$ phase grains of 1 micron or larger dimensions. Adjacent grains tend to be connected by straight grain boundaries of nearly grain size dimensions. Although considerable porosity is retained, it is in the form of distributed voids at multigrained junctions, and isolated pores are within the grains. By contrast, $1300^{\circ} \mathrm{C}$ heat treatment of $1.0 \mathrm{GPa}$ compacts results in limited formation of facetted shaped grains and retention of large ( $1 \mu \mathrm{m}$ and larger) porous structures, reminiscent of the initial spongy $\alpha$ structure. Here we note that the change from what has been termed spongy $\alpha$ structure to a facetted grain structure must involve diffusive transport as there is a change in both grain shape and size. Accordingly, the observed differences in microstructures for 1.0 and $2.5 \mathrm{GPa}$ compacts, after heat treatment at 1300 ${ }^{\circ} \mathrm{C}$, strongly suggests a relative increase in transport kinetics associated with increased compaction pressure. Further study, however, will be required to elucidate the underlying reasons for these observed effects.

The microstructures created are interesting, however. The spongy structure of $\alpha \mathrm{Al}_{2} \mathrm{O}_{3}$ should find use as high temperature gas filtration membranes and as human implant materials. Furthermore, this material can be infiltrated with liquid metals or glasses to form composites with interesting properties.

\section{SANS Characterization of Nanostructured Alumina}

Nanostructured ceramic oxides, having grain sizes less than $100 \mathrm{~nm}$, are of technological importance both during intermediate-stage processing and as final product materials. They enable the rapid sintering of small-grained, full-density samples at substantially reduced temperatures (less than $1000^{\circ} \mathrm{C}$ ). For ceramics, they also offer the prospect of combining good formability during processing with enhanced final-product mechanical properties. In practice, it is difficult to obtain full-density material without a coarsening of the pore/grain microstructure. Therefore, a better understanding is required both of how the microstructures develop during sintering under different conditions, and of how the powder and green-body synthesis might affect the sintering thermodynamics. 
We have been interested in comparing the sintering characteristics of nanostructured alumina ( $\mathrm{n}-\mathrm{Al}_{2} \mathrm{O}_{3}$ ), produced by the sol-gel method in Ceramics Division, with a previous extensive characterization of sintering in nanostructured zirconia $\left(n-\mathrm{ZrO}_{2}\right)$ and yttria $\left(n-\mathrm{Y}_{2} \mathrm{O}_{3}\right)$, produced by the inert gas-condensation (IGC) technique at Rutgers University. Specimens $0.5-1 \mathrm{~mm}$ thick and $4-6 \mathrm{~mm}$ in diameter were sufficient in size to permit absolutecalibrated small-angle neutron scattering (SANS) studies to elucidate the microstructure of the $5 \mathrm{n}-\mathrm{Al}_{2} \mathrm{O}_{3}$ samples studied. These comprised the dry-compacted $(1.5 \mathrm{GPa})$ green-body and 4 samples sintered by hot-pressing $(2.5 \mathrm{GPa})$ for 1 hour at $800{ }^{\circ} \mathrm{C}, 900^{\circ} \mathrm{C}, 1000^{\circ} \mathrm{C}$ and $1100{ }^{\circ} \mathrm{C}$.

Figure 27 shows the radially-summed absolute-calibrated SANS cross-section, d $\Sigma / d \Omega$ (absolute intensity), as a function of the scattering wavevector $Q\left[Q=\left(4 \pi /{ }_{\circ}\right) \sin (\phi / 2)\right.$, where $\phi$ is the angle of scatter and is the neutron wavelength] for the $\mathrm{n}-\mathrm{Al}_{2} \mathrm{O}_{3}$ samples. These data exhibit the same hallmarks as SANS from IGC-produced nanostructured materials: graincoarsening during sintering, as measured by the narrower profile, and the interparticle interference peak that develops for part of the densification range. The fitted lines are based on a grain/pore microstructural model, previously developed for the studies of IGC-produced nanostructured ceramics, in which it is assumed that the primary scattering features are mildly oblate pores between the grains. In the green-body, some scattering at low scattering wavevectors, $Q$ (where $Q=(4 \pi / \lambda) \sin \left(\phi_{\mathrm{s}} / 2\right), \lambda$ is the neutron wavelength and $\phi_{\mathrm{s}}$ is the angle of scatter), is attributable to the presence of coarser pores, associated with a small amount of grain-agglomeration. The interpore interference peak is apparent over a density range in which relatively monodispersed grains separate discrete nearest-neighbor pores while there is still a high number density of the latter in the system. It moves to lower $Q$ and eventually disappears as full density is approached.

From the model, the mean grain diameters, $D_{\text {grain }}$, and the polydispersities of the grain/pore size distributions were inferred. Also, the nanostructured grain/pore surface areas and porosities were determined. These values were compared with the total solid/pore surface areas (measured directly from the Porod $\mathrm{Q}^{-4}$ scattering at high $\mathrm{Q}$ ) and with the total porosities (from density measurements). Figure 28 shows the variation of $\mathrm{D}_{\text {grin }}$ vs. the sample density. As with the IGC-produced systems, the nanostructured grain/pore model accounts for most of the surface areas in the microstructures, particularly for the denser samples. This is a strong indication that most of the pore volumes are also accounted for. However, for the denser samples, comparison of the SANS porosities with the total porosities is complicated by the large volume change (more than $20 \%$ volume contraction) accompanying the $\gamma$ - $\alpha$ phase transformation in $\mathrm{n}-\mathrm{Al}_{2} \mathrm{O}_{3}$. While the green-body and the samples sintered at $800^{\circ} \mathrm{C}$ and $900{ }^{\circ} \mathrm{C}$ are assumed to be entirely $\gamma$-phase, those sintered at $1000^{\circ} \mathrm{C}$ and $1100{ }^{\circ} \mathrm{C}$ are largely $\alpha$-phase. The SANS and total porosities can only be reconciled if some $\gamma$-phase is assumed to persist for the $1000^{\circ} \mathrm{C}$ and $1100{ }^{\circ} \mathrm{C}$ sintering temperatures: $20.0 \%$ and $10.7 \%$, respectively. Although the samples were too small and irregular to obtain accurate volume fractions for each phase, $x$-ray diffraction confirmed that the residual $\gamma$-phase present is of the right order. With these assumptions and the $D_{\text {grain }}$ variation shown in Figure 28 , it is 


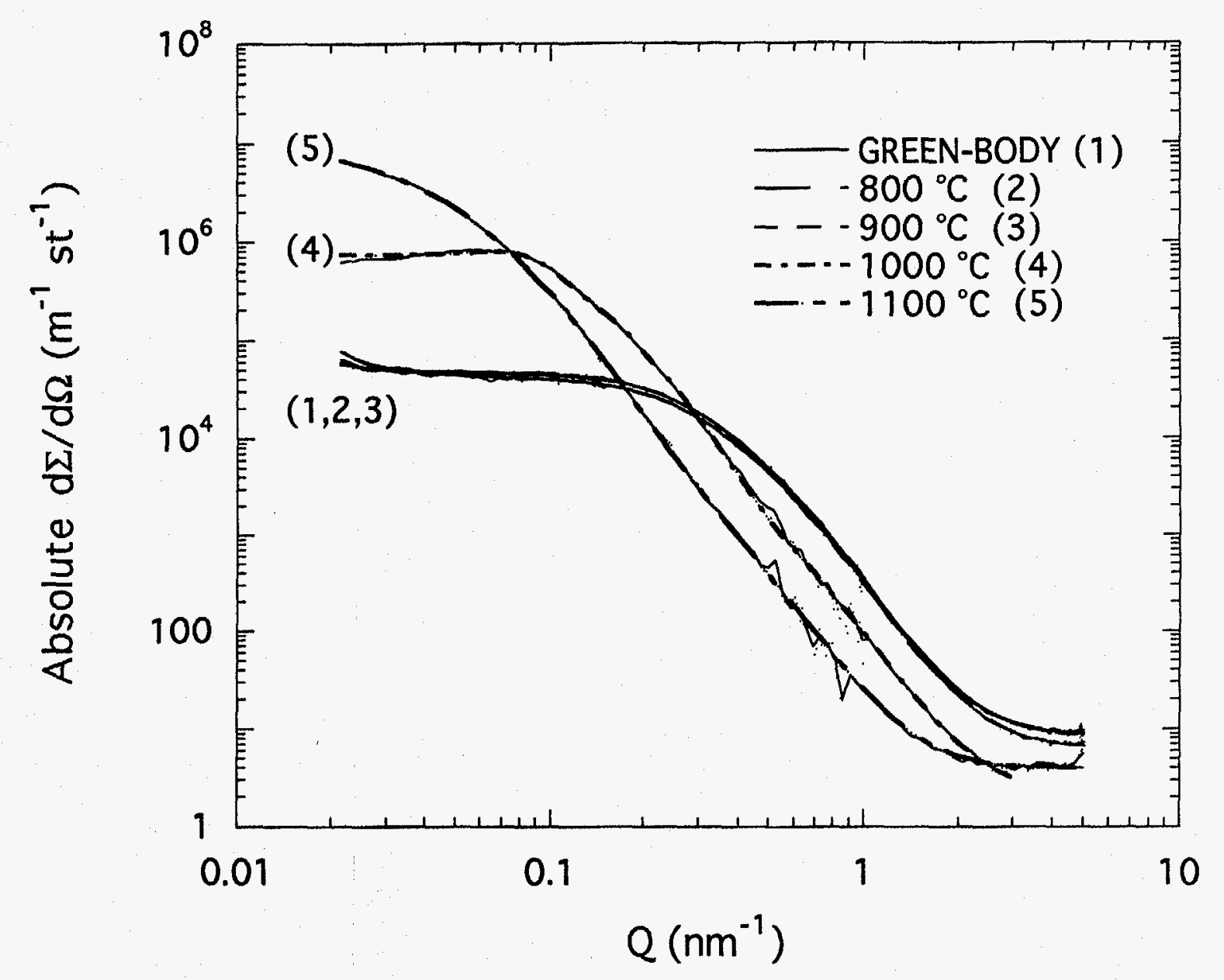

Figure 27. The radially-summed absolute-calibrated SANS data for the nanostructured alumina samples. 


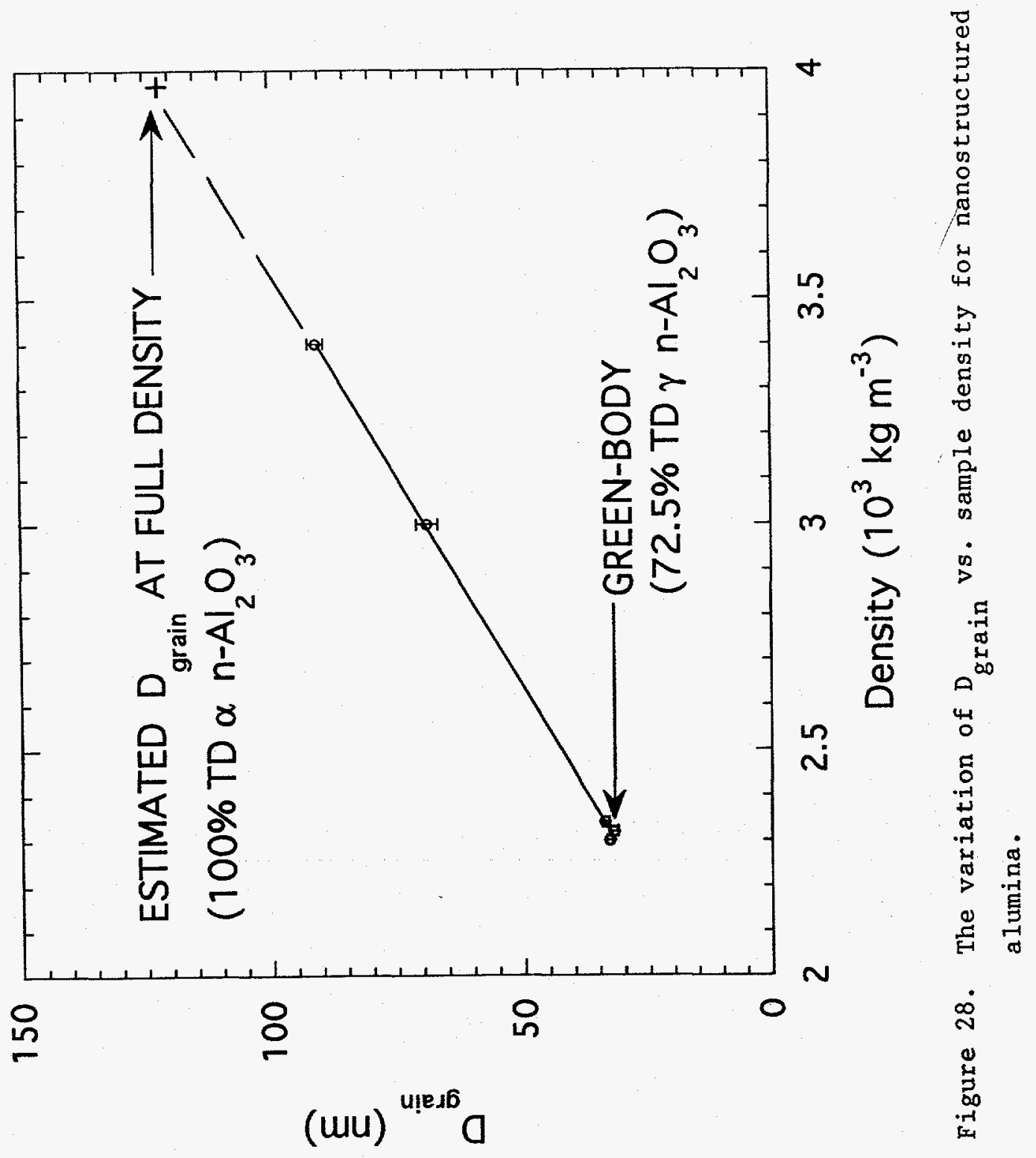


estimated that the present $\mathrm{n}-\mathrm{Al}_{2} \mathrm{O}_{3}$ green-body could be sintered to full density with $\mathrm{D}_{\text {grain }} \approx$ $125 \mathrm{~nm}$.

It is of interest that the microstructural evolution during the sintering of $\mathrm{n}-\mathrm{Al}_{2} \mathrm{O}_{3}$, made from the sol-gel process, proceeds in a similar way to that for $\mathrm{n}-\mathrm{Y}_{2} \mathrm{O}_{3}$ or $\mathrm{n}-\mathrm{ZrO} \mathrm{O}_{2}$, made from the IGC process. As with the IGC-produced materials, the phase transition, which takes place within the sintered density range studied, does not seem to affect the sintering thermodynamics, apart from the density change itself. This point is more remarkable for $\mathrm{n}$ $\mathrm{Al}_{2} \mathrm{O}_{3}$, given the large increase in density on transformation.

\section{Conclusions}

Compaction and sintering studies were done on $\gamma$ alumina pressed to 1.0 and $2.5 \mathrm{GPa}$. Sintering was done for $5 \mathrm{~h}$ periods at fixed temperatures ranging from $900^{\circ}$ to $1300^{\circ} \mathrm{C}$. For this material the explanation of the results is complicated by the large microstructural changes that occur during the $\gamma$-to- $\alpha$ phase transformation, which takes place at about 1000 to- $1100{ }^{\circ} \mathrm{C}$ depending on the initial compaction pressure. From this work, ten significant conclusions can be drawn concerning the processing of $\gamma$ alumina nanosize powder utilizing the piston/cylinder device. They are listed as follows:

(1) Random dense packing of $\gamma$ alumina nanosize powder can be achieved at high compaction pressures ( $\geq 1 \mathrm{GPa}$ ).

(2) Increased compaction pressure results in a corresponding increase in green body density, specifically from $54 \%$ theoretical at $1.0 \mathrm{GPa}$ to $65 \%$ theoretical at $2.5 \mathrm{GPa}$.

(3) Green body hardness values reflect the final compaction pressure.

(4) Heat treatment at $900^{\circ} \mathrm{C}$ does not result in sintering and densification and produces only a modest increase in hardness.

(5) Increased compaction pressure enhances the $\gamma$-to- $\alpha$ phase transformation, effectively increasing the nucleation rate, or, alternatively, lowering the transition temperature.

(6) Heterogeneous nucleation of the $\alpha$ phase in nanoscale $\gamma$ alumina compacts is invariably followed by a period of rapid growth which results in a coarsening of both the solid phase and the interconnected porosity. Although this microstructural coarsening decreases the internal surface area, reduction of the volume fraction of porosity is not apparent. As a consequence, densification is limited to the solid phase component and corresponds to the relative increase in density, accompanying the $\gamma$-to$\alpha$ phase transition, $3.67-$ to $-3.99 \mathrm{~g} / \mathrm{cm}^{3}$, respectively.

(7) Increased compaction pressure appears to enhance the thermally activated sintering processes at temperatures between 1100 and $1300^{\circ} \mathrm{C}$, resulting in "equilibrium" 
microstructures of higher density and hardness at lower temperatures.

(8) Despite the enhancement of sintering kinetics with increasing green body density at temperatures below $1300{ }^{\circ} \mathrm{C}$, the results, based on density measurement and microstructural evaluation, indicate that the final density is independent of the initial density. The consequence of this is that full densification is not achieved by pressureless sintering. It appears that a similar volume fraction of closed porosity is retained.

(9) Nevertheless, increased green body density leads to sintered $\alpha$ phase bodies of roughly $83 \%$ of theoretical density at lower sintering temperatures $\left(1300\right.$-to- $\left.1400{ }^{\circ} \mathrm{C}\right)$ and times.

(10) Increased compaction pressure (green body density) appears to have no effect on the final density of the product sintered at temperatures above approximately $1400{ }^{\circ} \mathrm{C}$. Increased compaction density, however, does effect how fast you achieve $83 \%$ of theoretical density when the sintering temperatures are below $1400{ }^{\circ} \mathrm{C}$.

The microstructural evolution, during the sintering of sol-gel synthesized nanostructured alumina, was characterized by small-angle neutron scattering (SANS). A measure of the undisturbed pore/grain microstructure over a $1-200 \mathrm{~nm}$ range was obtained. Furthermore, several microstructural parameters that are statistically representative of the microstructural evolution during sintering were measured. These parameters include the mean grain and pore diameter, widths of the pore and grain size distributions, and the pore/grain interfacial surface area. The conclusions are that broad similarities exist in the sintering of nanostructured materials fabricated by different processing routes. These include a surprising absence of microstructural effects associated with the frequently encountered metastablestable phase transitions. For the sol-gel synthesized alumina, SANS has shown that temperatures above $900{ }^{\circ} \mathrm{C}$ are required for effective sintering of $35 \mathrm{~nm}$ grained green bodies, but full density might be achievable, with a mean grain diameter coarsened to approximately $125 \mathrm{~nm}$. 


\section{Chapter V}

\section{FUTURE DIRECTIONS}

A. Novel Approaches to Silicon Nitride Processing

1. Surface modification of silicon nitride powder to enhance surface reactivity.

a. Vacuum treatment at various low temperatures

b. Surface oxidation layer removal by organic reductants

2. Consolidation by preparation of suspensions in organic solvents.

a. Characterization of colloidal properties of silicon nitride powder in organic solvents, and dispersants

b. Preparation of colloidal suspensions (30-50\% by weight)

c. Preparation of green compacts and their processing to full density

3. Homogeneity improvement by sol-gel method of powder processing.

This sol-gel derived addition approach to the processing of silicon nitride can be used to add other sintering aids in addition to alumina.

B. Densification of High Density Green Compacts

1. Sintering kinetics to understand and quantify progression of porosity closure.

2. Hot forgoing to promote instant reduction in porosity and enhancement of interparticle contact.

3. Densification mechanism as a function of green density and sintering time/temperature.

4. Evaluation of sintered ceramic for membrane applications.

C. Collaboration with Nano-Size Powder Producers

1. Standard procedures for evaluation of powders by compaction.

2. Tailoring powder properties for enhanced consolidation in conjunction with Sandia National Laboratory, Pacific Northwest Laboratory and others. 


\section{REFERENCES}

1. J. Frenkel, "Viscous Flow of Crystalline Bodies under the Action of Surface Tension", J. Physics (U. S. S. R.) 8 p. 386 (1945).

2. C. Herring, "Effect of Change of Scale on Sintering Phenomena", J. Appl. Phys., V. 21, pp. 301-303 (1950).

3. W. H. Rhodes, "Agglomerate and Particle Size Effects on Sintering Yttria-Stabilized Zirconia", J. Am. Ceram. Soc., 64 [1] 19-22 (1981).

4. G. Skandan, H. Hahn, and J. C. Parker, "Nanostructured $\mathrm{Y}_{2} \mathrm{O}$ : Synthesis and Relation to Microstructure and Properties", Scripta Metallurgical, Vol. 25, 2389-2393 (1991).

5. M. D. Sacks and J. A. Pask, "Sintering of Mullite-Containing Materials: II, Effect of Agglomeration", J. Am. Ceram. Soc., 65, 70 (1982).

6. A. Pechenik, G. J. Piermarini, and S. C. Danforth, "Fabrication of Transparent Silicon Nitride from Nanosize Particles", J. Am. Ceram. Soc., 75[12], 3283-88 (1992).

7. P. W. Bridgman, "The Pressure Transitions of the Rubidium Halides", Z. Krist., 67, 363 (1928).

8. P. W. Bridgman, "The Compression of twenty-one Halogen Compounds and Eleven Other Simple Substances to $100,1000 \mathrm{~kg} / \mathrm{cm}^{2 n}$, Proc. Am. Acad. Arts Sci., 76, 1 (1945).

9. C. E. Weir and G. J. Piermarini, "Lattice Parameters and Lattice Energies of HighPressure Polymorphs of Some Alkali Halides", J. Res. NBS A. Phys. Chem., Vol. 68A, No. 1, 105 (1964).

10. 7. A. R. Cooper, Jr., and L. E. Eaton, "Compaction Behavior of Several Ceramic Powders", J. Am. Ceram. Soc., 45 [3], 97-101, (1962).

11. M. Takahashi, S. Suzuki, and T. Kobayashi, "Study of Powder Compression Equations by the Form of Laplace Integral", J. Soc. Powder Technol. Japan, 19, 567 (1982).

12. M. Takahashi, S. Suzuki, "Numerical Analysis of Tapping Behavior of Ceramic Powders", Am. Ceram. Soc. Bull., 65, 1587-90 (1986). 
13. J. A. Eastman, Y. X. Liao, A. Narayanasam, and R. W. Siegel, "Processing and Properties of Nanophase Oxides," Mat. Res. Symp. Proc., 155, 255-66 (1989).

14. R. Dagani, "Nanostructured Materials Promise to Advance Range of Technologies," C\&EN (Washington), November 23, 18-24 (1992).

15. J. E. Bonevich and L. D. Marks, "The Sintering Behavior of Ultrafine Alumina Particles," J. Mater. Res., 7, 1489-1500 (1992).

16. J. A. Thornton and J. Chin, "Structure and Heat Treatment Characteristics of SputterDeposited Alumina," Am. Ceram. Soc. Bull., 56, 504-12 (1977).

17. M. R. Gallas and G. J. Piermarini, "The Bulk Modulus and Young's Modulus of Nanocrystalline $\gamma$-Alumina," J. Am. Ceram. Soc., 77, $2917-20$ (1994).

18. T. C. Chou, D. Adamson, J. Mardinly, and T.G. Nieh, "Microstructural Evolution and Properties of Nanocrystalline Alumina Made by Reactive Sputtering Deposition," Thin Solid Films, 205, 131-39 (1991).

19. A. Pechenik, G. J. Piermarini, and S. C. Danforth, "Low Temperature Densification of Silicon Nitride Nanoglasses, " Nanostructured Materials, 2, 479 (1993).

20. R. G. Munro, S. Block, G. J. Piermarini and F. A. Mauer, "Diamond Anvil Cell Technology for P, T Studies of Ceramics: $\mathrm{ZrO}_{2}\left(8 \mathrm{~mol} \% \mathrm{Y}_{2} \mathrm{O}_{3}\right)$ "; pp. $783-92$ in Materials Science Research, Vol. 17, Emergent Process Methods for High Technology Ceramics. Edited by R. F. Davis, H. Palmour III, and R. L. Porter. Plenum, New York, 1984.

21. See JCPDS cards $29-63$ for $\gamma-\mathrm{Al}_{2} \mathrm{O}_{3}$ and $16-394$ for $\delta-\mathrm{Al}_{2} \mathrm{O}_{3}$.

22. D. A. Young, Phase Diagrams of the Elements (University of California Press, Berkeley, CA, 1991) pp. 113-117.

23. R. L. Mills, D. H. Liebenberg, and J. C. Bronson, "Melting Properties and Ultrasonic Velocity of Nitrogen to $20 \mathrm{kbar}$, " J. Chem. Phys., 63, 4026-31 (1975).

24. W. L. Vos and J. A. Schouten, "Improved Phase Diagram of Nitrogen up to 85 kbar," J. Chem. Phys., 91, 6302-05 (1989).

25. M. Kumagai and G. L. Messing, "Controlled Transformation and Sintering of a Boehmite Sol-Gel by $\alpha$-Alumina Seeding", J. Amer. Ceram. Soc. 68, 500-505 (1985).

26. G. L. Messing and M. Kumagai, "Low-Temperature Sintering of Seeded Sol-Gel Derived, $\mathrm{ZrO}_{2}$-Toughened $\mathrm{Al}_{2} \mathrm{O}_{3}$ Composites", J. Amer. Ceram. Soc. 72, 40-44 (1989). 
27. T-S Yeh and M. D. Sacks, "Low-Temperature Sintering of Aluminum Oxide", J. Amer. Ceram. Soc. 71, $841-44$ (1988).

28. F. W. Dynys and J. W. Halloran, "Alpha Alumina Formation in Alum-Derived $\gamma$ Alumina" J. Am. Ceram. Soc., 65, 442-448 (1982). 